\title{
Party or Policy? Testing the Elaboration Likelihood Model in the context of voting
}

\author{
Andre.Boyte
}

December 2020 


\section{Contents}

List of Figures

List of Tables iv

$\begin{array}{lll}1 & \text { Introduction } & 1\end{array}$

1.1 Political ideology $\ldots \ldots \ldots \ldots \ldots$. . . . . . . . . . . . . 2

1.2 The Rational Choice Model . . . . . . . . . . . . . . . . . . . 3

1.3 Party affiliation $\ldots \ldots \ldots \ldots \ldots \ldots \ldots \ldots$

1.4 Self-Categorisation theory $\ldots \ldots \ldots \ldots \ldots$

1.5 The Elaboration Likelihood Model . . . . . . . . . . . . . . . . . 9

$1.6 \quad$ Knowledge of subject matter/political sophistication . . . . . . . 12

1.7 The Elaboration Likelihood Model and voting . . . . . . . . . . 13

1.8 The present study $\ldots \ldots \ldots \ldots \ldots \ldots$

1.9 Electoral systems of the United States and New Zealand . . . . . 19

\begin{tabular}{lll}
\hline 2 & Method & 20
\end{tabular}

2.1 Participants . . . . . . . . . . . . . . . . . . 20

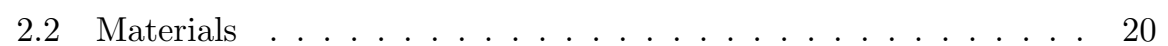

$2.2 .1 \quad$ Experimental trials $\ldots \ldots \ldots \ldots \ldots$

2.2 .2 Other Measures . . . . . . . . . . . . . . . . . . . . 24

2.2 .3 Ideological alignment . . . . . . . . . . . . . . . . . 24

2.3 Design . . . . . . . . . . . . . . . . . . . . . . . . . . . 28

2.4 Procedure $\ldots \ldots \ldots \ldots$

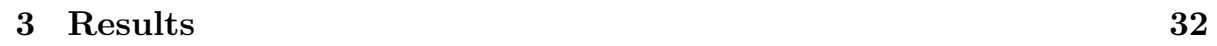

$3.0 .1 \quad$ Data Adjustments . . . . . . . . . . . . . . . . . 32

$3.1 \quad$ Descriptive statistics $\ldots \ldots \ldots \ldots \ldots \ldots$

$3.1 .1 \quad$ Preference for experiment variables . . . . . . . . . . . . 33 
3.1 .2 Voting intentions of participants $\ldots \ldots \ldots \ldots$

$3.1 .3 \quad$ Preference for individual policies . . . . . . . . . . 35

$3.2 \quad$ Main analyses $\ldots \ldots \ldots \ldots \ldots$. . . . . . . . . . . . . . . 41

$3.2 .1 \quad$ Model design . . . . . . . . . . . . . . . . . . . . 41

3.2 .2 Main Effects . . . . . . . . . . . . . . . . 42

$3.2 .3 \quad$ Interactions . . . . . . . . . . . . . . . . . . 43

3.3 Exploratory analyses $\ldots \ldots \ldots \ldots$. . . . . . . . . . . 4 46

3.3.1 $\quad$ Preference for individual policies by political sophistication 46

3.3 .2 Gender of faces . . . . . . . . . . . . . . . 48

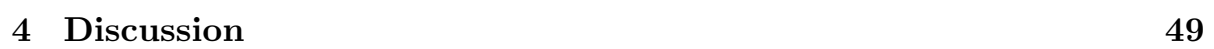

$4.1 \quad$ Ideology as a predictor $\ldots \ldots \ldots \ldots$

4.2 The use of Central Cues . . . . . . . . . . . . . . . . 51

4.3 Party as a predictor $\ldots \ldots \ldots \ldots \ldots \ldots \ldots$

4.4 The use of peripheral cues . . . . . . . . . . . . . . . 60

4.5 Evaluation of the scales $\ldots \ldots \ldots \ldots \ldots$

$4.5 .1 \quad$ Political knowledge . . . . . . . . . . . . . . . . . 63

4.5 .2 Conservative/Liberal scale. . . . . . . . . . . . 65

4.6 Strengths and Conclusions $\ldots \ldots \ldots \ldots$

\begin{tabular}{ll}
\hline A R code & $\mathbf{7 7}$
\end{tabular} 


\section{List of Figures}

$1 \quad$ Examples images of artificially developed faces (Karras et al., 2018] 21

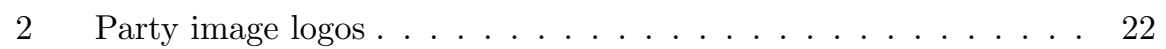

$3 \quad$ Example main trial . . . . . . . . . . . . . . . . . . . . 31

$4 \quad$ Preference for candidates, based on the ideology of their policy and participants' political sophistication . . . . . . . . . . . 44

5 Preference for candidates, based on their party and participants' political sophistication . . . . . . . . . . . . . 45 


\section{List of Tables}

$1 \quad$ Development/Refinement of Political Sophistication Quiz 1 . . . 25

2 Development/Refinement of Political Sophistication Quiz 2 _ . 26

3 Development/Refinement of Political Sophistication Quiz 3 . . . 27

4 Construction of conditions . . . . . . . . . . . . . . . . 30

5 Means and Standard deviations for preference for Parties and

Policies . . . . . . . . . . . . . . . . . 34

6 Preference for Parties and Policies . . . . . . . . . . . . . . . 35

$7 \quad$ Preference for Liberal policies $1 \ldots \ldots \ldots$

$8 \quad$ Preference for Liberal policies 2 $\ldots \ldots \ldots \ldots$

$9 \quad$ Preference for Conservative policies $1 \ldots \ldots \ldots$

$10 \quad$ Preference for Conservative policies $2 \ldots \ldots \ldots$

11 Stepwise model comparisons for main analysis . . . . . . . . . . . 43

12 individual policy differences at levels of political sophistication . 47 


\section{Preface}

Politics has always intrigued me, from learning of peoples' voting decisions, to watching electoral candidates' political strategies, to media representations of political candidates and parties. When I was younger, I witnessed my grandfather curse the name of Robert Muldoon if anything in his life had gone awry (including if he had stubbed his toe), even twenty years after Muldoon served as Prime Minister. I was always intrigued that an average voter like my grandfather could have such a visceral reaction to a politician but as I have grown, I have come to recognise how easy it can be to form strong emotional responses to characters in the theatre of politics.

The focus of this thesis is on voter decisions. Keeping the project on topic has been difficult, as there has been a constant temptation to test the many ways that politics intersects with other facets of society. In truth, there is no endpoint to interesting political research questions that are waiting to be studied, which only increases my fascination with the subject area.

In this project, I test the Elaboration Likelihood Model in a unique voting experiment. To date, the Elaboration Likelihood Model has not been directly tested in an experimental design, and I am happy to be the first to do so. The idea for the experimental design was drawn from that of Cohen (2003), who I cite quite often throughout the thesis. As I point out later, my design veers quite dramatically from the original starting point of Cohen (2003), so I do consider it to be unique. As I mention later, I hope that this design can be adapted and re-used in future studies to quantify how people respond to different political variables.

This study was designed from scratch, and I worked quite independently across the full process (planning, design, ethics, piloting, data collection, data maintenance, and data analysis). For all data processes, I worked exclusively 
through R, as I wanted to use this opportunity to upgrade my skills with coding and data-management. This means that I spent a lot more time on data management than I would have if I had kept to the simple methods (such as Excel, SPSS, Jamovi, etc.). Using only R throughout the entire study was difficult but I was rewarded by being able to use more sophisticated methods of data analysis and data management.

\section{Acknowledgements}

I would like to thank my master's supervisor, Prof. Marc Wilson, for guiding me through this project, and for knowing of the perfect publications to support my research. I am also extremely thankful for my prior research with Dr Todd Jones, who holds such a high standard for experimental design, and who was someone that I could go to for questions about my present study's design. Thanks to Kealagh Robinson and Gloria Fraser, for first introducing me to research in my undergraduate years, your research drive has been inspiring! Thank you to my loving partner, Edward Hardie, for guiding me on this path and supporting me each day. Finally, thank you to the United States' political system, for first engaging me in politics, and to the political systems around the world, for keeping me both engaged, and bewildered, with politics over the past five years. 


\begin{abstract}
In this study, I experimentally tested if the Elaboration Likelihood Model applies to a voting context. Participants rated their likelihood to vote for hypothetical candidates where the candidates' associated policy and party affiliation were both manipulated. Participants also completed a quiz as a measure of their political sophistication. As expected, those who demonstrated high political sophistication used policy information more often when rating candidates. Contrary to expectations, there was no evidence that low politically sophisticated individuals used party cues more often to guide their ratings of candidates. The findings provide partial support for the Elaboration Likelihood Model, and future adaptations to the experimental design are discussed.
\end{abstract}

\title{
1 Introduction
}

Voting can be difficult to predict. Through political polls we can gauge potential winners and losers of elections and through focus groups we may gain insight into why voters prefer one electoral candidate over another. However, information from polls and focus groups go through the filter of participant introspection and is therefore prone to heuristics and biases (Pronin, 2009). Furthermore, there are notable recent instances where information from polls and focus groups dramatically sway from the results of their election (see: Brexit and the 2016 US Presidential election results). Former New Zealand Prime Minister famously stated "Bugger the pollsters" following his surprisingly slim election victory in 1993, as he was led to believe that the margins would be much larger. It is also common for politicians with low favorability to undervalue the polls. A politician may disparage the validity of polls when those polls do not sway in the candidate's favour, as seen in the current cases of New Zealand National Party leader Judith Collins (in 2020) and United States President 
Donald Trump (in 2016 and 2020). In one of those cases, the candidate was correct, and Donald Trump was able to overcome the negative polls to an electoral victory in 2016. In the other two cases, the polls were a better indicator for an election result, as both Judith Collins and Donald Trump did not enjoy victories in 2020. It has not yet been determined how useful the subjective opinions in polls truly are, and how much they equate to actual voting behaviour in an election.

There is a plethora of research into voter choice dating back to the early 1900s (see Jost \& Sidanius, 2004), and modelling voters' minds remains a crucial project for political scientists today. In the following section, I will define and describe several of the key variables that can be influential for voters as they evaluate electoral candidates. As I introduce each of the variables, I will also provide empirical evidence that shows how the variables interact with voter choice and will explain theoretical models that highlight these factors in the voting context.

\subsection{Political ideology}

The first construct of note is political ideology, both of the individual voter and of the electoral candidate, and how the ideology of voter and candidate align (Baysu \& Swyngedouw, 2020 Hennessy et al., 2015. Holm \& Robinson, 1978). Political ideology can be described as a belief system or broad set of values that are shared by groups of people (Feldman, 2013 Feldman, 2003). Political Ideology has been popularly conceptualised as a uni-dimensional model that encompasses both social and economic attitudes that groups of people hold (Converse, 2006 Feldman, 2003 Heywood, 2017). On one side of the traditional continuum is the liberal/left-wing/progressive ideology, that emphasizes community accountability, social and monetary equality, and social justice. The other 
side of the spectrum depicts a conservative/right-wing ideology, which portrays individual accountability, traditional values, social order, and a hierarchical social system (Feldman, 2003, Heywood, 2017) 1

Voters selecting candidates based on shared political ideology makes theoretical sense; if a candidate is more likely to implement policies that are ideologically consistent with that of the voter, then the voter should be more willing to place their vote with that candidate. Empirically, self-report data shows political ideology as a strong predictor for the candidate that voters prefer (Baysu \& Swyngedouw, 2020 Holm \& Robinson, 1978). One way that political ideology has been measured in experiments is by measuring participants' preference for a conservative or liberal leaning policy, bill, or political statements of a candidate (Barber \& Pope, 2019, Cohen, 2003, Malka \& Lelkes, 2010 Verkuyten \& Maliepaard, 2013). Several studies have identified that self-identified liberals or conservatives are more likely to prefer policies, bills, or statements that are ideologically aligned to their own political leaning, and will oppose those that are not (Barber \& Pope, 2019 Chmielewski, 2012, Cohen, 2003, Lelkes, 2021. Malka \& Lelkes, 2010 Verkuyten \& Maliepaard, 2013) $\mathrm{L}^{2}$

\subsection{The Rational Choice Model}

An early process model that had been used to explain how political ideology relates to voter choice is the Rational Choice decision-making model (Downs, 1957). In the context of electoral voting, proponents for "pure" Rational Choice models argued that individuals sensibly and meticulously assess positives and negative outcomes for each candidate, if they were elected (Bartels, 1996; Downs, 1957: Simon, 1990). If voters acted on a purely rational basis, they should only

\footnotetext{
${ }^{1}$ In this thesis, I will discuss Political Ideology as measured on a unidimensional scale, with Left-Wing ideology to one side and Right-Wing ideology on the other. I do note that there is a vast literature suggesting the unidimensional scale may oversimplify the construct (see Kalmoe, 2020).

${ }^{2}$ For a summary on the history of ideology and voting, (see Jost, 2006 )
} 
attend to information that promotes their own self-interest, such as by voting for candidates based on their proposed policies, experience, or voting record, among other possible factors (Downs, 1957). According to the Rational Choice Model, the voter makes a calculated weighting for each candidate by assessing the candidates' skills, experiences, and proposed policies, upon which the voter then selects the candidate that is most likely to forward that voter's interests (Downs, 1957).

Researchers have critiqued the Rational Choice Model for its predictive short-comings in voting (Bartels, 1996 Citrin \& Green, 1990 Kinder \& Kiewiet, 1979. Sears \& Funk, 1991; Tversky \& Thaler, 1990). Firstly, there is a discrepancy in what cues subject-experts and subject-novices use (Bartels, 1996), and that people are limited by their own capacity of knowledge regarding choices and, as such, are unable to make well-informed decisions. In one study, participants also lacked rational consistency between trials for their option preferences in a decision-making task (Tversky \& Thaler, 1990). It is not clear if people even vote entirely out of self-interest. Some respondents have previously reported that voting decisions were based on collective aspects such as the national economy, over individual aspects. (Citrin \& Green, 1990 Kinder \& Kiewiet, 1979 Sears \& Funk, 1991).

The "Paradox of Not Voting" also challenges the "pure" theories of Rational Choice (Feddersen, 2004). When people are deciding whether to vote, the costs of voting, such as registering, waiting in line, and researching the various candidates, should outweigh the gains of voting. In this case, the gains of voting is the perceived likelihood that an individual vote will change the outcome of an election (see Aldrich, 1993 Blais, 2000 Feddersen, 2004). As people know that one vote single vote does not usually swing the results of an election from one winner to another, then the gains of voting should be considered small (Blais, 
2000 .

In many cases, the Rational Choice Model has been adjusted to the Bounded Rational Model (Chong, 2013 Conlisk, 1996 Rubinstein, 1998; Simon, 1990), where people make rational decisions, based on available information. Other adjustments to Rational Choice Models have included social behaviours in the decision-making process (Satz \& Ferejohn, 1994). In a Rational Choice Model that promotes social factors, societal norms may persuade people to vote, as the act of voting is considered a pro-social behaviour (Satz \& Ferejohn, 1994), so individuals who place more emphasis on pro-social behaviours would incorporate these social factors in their evaluations for whether to vote or not (Satz \& Ferejohn, 1994). A mix between Rational Choice and social models may explain why voters prefer policies that will help the community over the individual (see, for example: Kinder \& Kiewiet, 1979, Satz \& Ferejohn, 1994 Sears \& Funk, 1991).

\subsection{Party affiliation}

Another predictor that influences voter decisions is a political candidate's party affiliation (Huddy, 2001: Huddy et al., 2013). In theory, the party of the candidate represents a coalition of various factors, ranging from the party's political ideology or values to the party's overall experience or policy agenda. As party membership shifts, by navigating a changing voting bloc, so too does their ideology, values, and policy agenda (see Harmel \& Janda, 1994). If the ideology of the voter matches the ideology of the party, there is a higher likelihood that the individual will vote for that party (Sibley \& Wilson, 2007). Over and above these party-related factors, the act of simply identifying with a party, alone, predicts how a person will vote (Bartels, 2002, Chmielewski, 2012, Cohen, 2003. Malka \& Lelkes, 2010). 
A person's political affiliation has been shown to affect their preference for policies, dependant on their affiliated party's stance on the policy (Barber \& Pope, 2019 Cohen, 2003. Malka \& Lelkes, 2010 Verkuyten \& Maliepaard, 2013). Cohen (2003) showed participants a healthcare bill that was considered either ideologically liberal, as it expanded healthcare and increased taxation to pay for funding of the bill, or ideologically conservative, as the bill cuts costs to healthcare services and therefore reduced individual taxation. Along with the healthcare bill, participants were also informed that either the Republican or Democratic party endorsed the bill. Cohen (2003) found that participants were more likely to favour a bill that was ideologically congruent with their preferred party's alignment (i.e., a Republican participant preferring the conservative bill over the liberal bill), but that manipulating which party endorsed the bill changed participants' preference for that bill. Republican voters preferred liberal bills that were endorsed by the Republican party over the liberal bill with no endorsement attached. Likewise, Democratic voters preferred conservative bills that were endorsed by the Democrat party, compared to the conservative bill with no information about endorsements attached. If the opposing party endorsed a bill, partisan participants preferred the bill the least, regardless of whether the bill was ideologically consistent with their self-identified party affiliation.

Verkuyten and Maliepaard (2013) extended upon the work of Cohen (2003) by using a similar design but, instead of using political bills, participants were asked if they endorse statements made by politicians. Hypothetical statements were manipulated to be from either a member of the participant's self-identified party or from their opposition party and were either about multicultural assimilation or affirmative action. Verkuyten and Maliepaard (2013) showed that participants were more likely to endorse the statements when the statements were said by a 
member of their in-group party, as opposed to when said by a member of the out-group party. Consistent with results of Cohen (2003) and Verkuyten and Maliepaard (2013), Malka and Lelkes (2010) also experimentally showed that partisan voters' support for farm subsidy policy was partially driven by whether their aligned party supported the proposal or not.

It should be noted that in the above cases, party endorsements did not solely predict votes, as there was already an underlying baseline preference for the policies themselves (Cohen, 2003 Malka \& Lelkes, 2010). For Cohen (2003), participants showed a baseline preference for policies that match their own ideological alignment (conservative or liberal). For Malka and Lelkes (2010), preference for policies was driven by whether the Rebublican or Democratic parties opposed the bill, but this effect was mediated by the participant's underlying beliefs about the policy. This means that both party endorsements and policy information are relevant when determining voter choice.

\subsection{Self-Categorisation theory}

The act of self-categorisation to any group identity could produce an increased collective identity that the person feels towards the group (Hogg et al., 1995 . Terry \& Hogg, 1996). In a political context, identifying with the party could help drive the voters' decisions, over and above other factors such as ideology. The use of party identification in voting decision-making could be considered through the lens of Self-categorisation Theory (Turner \& Reynolds, 2011). For Self-categorisation Theory, the individual establishes a link with a social group, and from that link, the individual makes more positive attributions to both members of the identified group, and to the group itself (Abrams \& Hogg, 1990 Turner \& Reynolds, 2011). Identification with a group can lead to in-group bias, by ignoring flaws of the in-group while criticising out-group errors more 
harshly (Turner \& Reynolds, 2011).

Self-categorisation theory was initially created to explain attributions towards any group and was not specific for politics, but the group dynamics of political parties gives reason for the theory to be applied here. In politics, partisan people have shown a preference for members of, or bills and policies endorsed by, their preferred party (Cohen, 2003 Malka \& Lelkes, 2010 Verkuyten \& Maliepaard, 2013). Furthermore, priming participants of their social in-group or out-group can affect behavioural decisions (Transue, 2007). For example. priming Caucasian participants with their national identity produced support for increased funding for minority communities, but highlighting participants' white identity hindered support for the funding (Transue, 2007) ${ }^{3}$

If we were to categorise voters' preference for a candidate's policy or bill as them using a Rational Choice approach, and preference based on the party of a candidate or bill as them using a Self-categorisation approach, then both the Rational Choice Model and Self-categorisation Theory do not solely predict voting behaviour (Barber \& Pope, 2019. Citrin \& Green, 1990 Cohen, 2003 Kinder \& Kiewiet, 1979, Malka \& Lelkes, 2010, Sears \& Funk, 1991; Transue, 2007; Verkuyten \& Maliepaard, 2013). There may also be individual differences in how much participants use party or policy in determining who to vote for. While participants do seem to have a baseline preference for policies or candidates that match the ideology of their own, there still seems to be an effect whereby individuals rely on the party of the policy or candidate to make their decisions (Barber \& Pope, 2019 Cohen, 2003 Malka \& Lelkes, 2010 Verkuyten \& Maliepaard, 2013).

\footnotetext{
${ }^{3}$ For a review on Self-Categorisation Theory, and its roots and distinctions from Social-Identity Theory, see Abrams and Hogg (1990).
} 


\subsection{The Elaboration Likelihood Model}

The Elaboration Likelihood Model attempts to explain voting decisions by incorporating the participant's knowledge or sophistication with a particular topic as an explanation for why they may rely on different factors for decision-making (Cacioppo \& Petty, 1980, 1989, Cacioppo et al., 1984, Cacioppo et al., 1986 . Petty \& Cacioppo, 1979, 1986). In the Elaboration Likelihood Model, there are two routes to persuasion: a central route and a peripheral route (Petty \& Cacioppo, 1986). To be persuaded through the central route, a person critically engages with the main argument (known as central cues) while ignoring the irrelevant cues (Petty \& Cacioppo, 1986). For example, a person who chooses to purchase a computer due to the specifications offered about the computer would be making use of the central route (i.e., using information of the RAM, hard-drive space, processor, etc.). Use of the central route could be closely aligned with expectations of the 'pure' Rational Choice Model, where individuals closely scrutinize relevant information to make an informed choice (Petty \& Cacioppo, 1986).

To use the peripheral route, on the other hand, is to engage with the more superfluous factors, known as peripheral cues (Petty \& Cacioppo, 1986). Peripheral cues are any factors that are not relevant to the central argument. A person using the peripheral route may be swayed by marketing factors such as the image on a product box, the charisma of the product's salesman, or a celebrity endorsement for a product. Use of the peripheral route is when any individual makes a choice by acting on factors or cues that are not informative about the functions of the product (Petty \& Cacioppo, 1986). Use of the peripheral route, in the context of party affiliation in voting, may be more closely related to the theories of social identity, as opposed to the theories of rational choice. 
Whether a person relies on peripheral or central cues is dependent on whether they are both willing and able to engage with the central argument (Petty \& Cacioppo, 1986). An assumption of the Elaboration Likelihood Model is that those that are more likely to elaborate on the central argument are those who carefully assess the issue-relevant information. Those who are both motivated and capable to carefully engage in issue-relevant thought will have a higher 'likelihood to elaborate' on central issues. Those who are not motivated and/or able to engage with the central argument fall back on initial schemas or biases to guide their decisions. If a person is motivated and able to engage with central information, the preconceived schema can be challenged, and the central message may instead be judged (Petty \& Cacioppo, 1986).

There are several manipulations which can bolster a person's ability to engage with the central message, which subsequently leads to a greater likelihood of elaboration. For the following examples, messages were manipulated to be of either a weak or strong argumentative quality. Firstly, introducing a distraction condition differentially affected participants' favourability for both argument qualities (Petty et al., 1976). When no distraction was present, favourability for the strong argument was greater than that of the weak argument. When a distraction was introduced, favourability for the weak and strong arguments did not differ (Petty \& Cacioppo, 1986). Repetition of arguments also resulted in participants showing differential preferences for strong and weak arguments. Simply repeating the same weak or strong argument to participants three times decreased favourability for the weaker argument, and increased favourability for the stronger argument (Cacioppo \& Petty, 1980, 1989).

Petty and Cacioppo (1986) also identified that participants' motivation to engage with the central message was important in the Elaboration Likelihood Model. The authors manipulated participants' personal relevance to a decision, 
which resulted in a differentiation in the scrutiny of the arguments by participants (Petty \& Cacioppo, 1979). Telling participants that a proposed policy could be implemented either within their own university or at a university in a distant city would produce an interacting effect of favourability for arguments, with decreased favorability for weak arguments and increased favorability for strong arguments (Leippe \& Elkin, 1987; Petty \& Cacioppo, 1979). The same effect occurred when participants were told they had either sole responsibility or distributed responsibility for a decision (Petty et al., 1980). The sole responsibility condition resulted in greater scrutiny for the arguments compared to distributed responsibility conditions. Taken together, the above evidence shows that people need both the ability and the motivation to be able to properly scrutinize arguments (Petty \& Cacioppo, 1986).

Measures of individual differences may act as a proxy for a person's motivation and ability to elaborate with a given subject. One noted individual difference is a person's need-for-cognition, which is how inclined a person may be to apply high cognitive effort towards decisions (Cacioppo et al., 1984; Cacioppo et al., 1986 Haugtvedt \& Petty, 1992 Haugtvedt et al., 1988). In political settings, a person's need for cognition predicts their interest in politics; those higher in need for cognition were more likely to show an interest in politics compared to those who are low in need for cognition (Bizer et al., 2000). Furthermore, when partisan individuals were evaluating negative (but factually correct) information about their preferred and dis-preferred party, those with low need for cognition were more likely to dismiss negative information about their party and endorse negative information about the opposing party, compared to people with a high need for cognition (Arceneaux \& Vander Wielen, 2013). 


\subsection{Knowledge of subject matter/political sophistication}

From an individual-differences perspective, measuring a person's overall motivation or ability to engage with the central argument is difficult, as people can vary in their motivation and ability from subject-to-subject. However, if a person holds more information for, or has a vested interest in, a subject then they may be more likely to engage with central arguments compared to those who are not well-versed in that particular subject matter (Wood \& Kallgren, 1988 . Wood et al., 1985). Previous studies that have tested the Elaboration Likelihood Model using participant's knowledge for the subject matter have found encouraging results (Cacioppo \& Petty, 1980 Fiske et al., 1983 Srull, 1983 Wood et al., 1985). Participants who could recall more information about a product were more likely to be persuaded by high-quality arguments, and those that recalled little about the subject were persuaded by low-quality arguments (Wood et al., 1985). Similarly, when presenting participants with false information, resistance was stronger for those who had more exposure to the issue (Cacioppo \& Petty, 1980). Fiske et al. (1983) gave participants a narrative that included information about the country Mauritius and manipulated whether Mauritius was introduced as either a communist or democratic nation. Those with less political knowledge were more likely to rate Mauritius based on the communist or democratic identifier, while high political knowledge participants based their ratings off information from the narrative (Fiske et al., 1983).

In political psychology, a person's knowledge of the subject matter has usually been quantified through some measure of political sophistication. One way to measure political sophistication is through a quiz that asks about current events for the participants' political environment. For example, the Political Knowledge Scale developed by Carpini and Keeter (1996) showed participants the names of current office-holders and asked the participants to identify the 
position of the given name, such as Q: Dan Quayle - A: Vice President, or Q: William Rehnquist - A: Chief Justice of the Supreme Court. The Political Knowledge Scale would also ask questions about their current international-political environment, such as Q: Who is Mikhail Gorbachev, or Q: Who is Nelson Mandela (Carpini \& Keeter, 1996). Further, the Political Knowledge Scale had participants place the Democratic and Republic party on a scale representing how much those parties would agree or disagree with certain policies, such as cutting services, supporting African Americans, or increasing defense spending (Carpini \& Keeter, 1996). Other scales follow a similar format to Carpini and Keeter (1996); participants need to either recall information about individuals or parties in their current political climat 4 or to place people and parties on a spectrum for the entity's liberal or conservative leanings on certain issues $5^{5}$

\subsection{The Elaboration Likelihood Model and voting}

Applying the Elaboration Likelihood Model to a voting context, peripheral cues likely include an electoral candidate's party affiliation, the candidate's charisma, or the candidate's attractiveness. Central cues include the policies that a candidate proposes, the candidate's expertise, or the candidate's previous accomplishments in politics, which is typically drawn from the candidate's voting record or from previous statements. Whether a factor acts as a central or peripheral cue does need to be defined however, and I will make the following argument to show my reasoning for placing certain political factors into either cue category.

Consider a political candidate who is branded as a 'socialist.' Person A may respond negatively to the candidate, by relating the candidate to a stereotypical

\footnotetext{
${ }^{4}$ Other examples of information recall scales include the News Recall Scale (Price \& Zaller, 1993 ) and the Political Information Scales (Iyengar, 1986 J. R. Zaller, 1986).

־Other examples of ideological placement scales include the Political Awareness Scale (J. R. Zaller, 1992), the Information Holding Scale (Luskin, 1987), and the Issue Awareness Scale (Patterson \& McClure, 1976).
} 
socialist, such as Che Guevara, Mao Zedon, or Joseph Stalin and, thus, would be using a peripheral route of persuasion. If person B believes socialism results in increased social security, then they may be more inclined to vote for the candidate. By accessing their prior knowledge of socialist policy, one could argue that Person B is using the central route to inform their decision. In actuality, both Person A and Person B are using the peripheral route for their choices. Person A's decision is informed by comparing the candidates to prototypical socialists who were also dictators, while person B is comparing the socialist to possible positive social policies. Both person A and B have failed to judge the candidate on more concrete variables, such as the candidate's statements or policy proposals. In this context, a person using the proposed policies of a candidate to inform their decision is engaging with the central route, as this is considered the best available information in this study that could be utilized to inform a 'rational' voter ${ }^{6}$ Other cues, such as a candidate's age, gender, or party affiliation, are considered peripheral cues, as these factors rely more on the individual's existing schemas and biases to inform judgments.

There is an important point to be made about whether a cue is categorised as a central or peripheral cue. In the context of voting, many of the peripheral cues could be useful and informative to voters and could reasonably be used to predict how a candidate may govern. For example, research around Identity Politics suggests that voters may be more willing to vote for candidates that represent themselves more, through shared gender, ethnicity, sexual orientation, or age, among other factors (Andersen \& Ditonto, 2020, Plutzer \& Zipp, 1996 Stambough \& O'Regan, 2003). Studies of Identity Politics and voting do

\footnotetext{
${ }^{6}$ Of course, a politician may be lying or over-promising on their campaign goals, and a 'rational voter' may be better at distinguishing a lie from truth, or be better able to determine the likelihood of a campaign promise being enacted. This adds a level of complexity to this study and is outside of the scope of the project. More on the potential of politician's lies or their potential inability to implement proposed policies will be discussed further in the discussion section.
} 
not evaluate whether the voter makes a rational choice, as what is a rational choice can be difficult to quantify. From an Identity-Politics framework, a shared background between voter and candidate should mean that the candidate brings a viewpoint that represents the voter, which could lead to policies being accomplished that benefit the voter. A similar point can be made regarding the party of the candidate as a reason to vote for them. In the voter's mind, the party of the candidate may be the best information that the voter has available to help determine how the candidate would govern. In the context of the present study, however, while cues such as candidates' party, ethnicity, age, and gender are available to participants, more informative policy cues are also available to the participants. In this study, the party affiliation of a candidate may be considered a central cue when no other information is available, but party affiliation would be considered a peripheral cue when the more informative policy cue is also present.

The Elaboration Likelihood Model was initially formulated to explain attitudinal change across broad areas of social and behavioural psychology, but the model may be useful in explaining electoral politics. In fact, when Petty and Cacioppo (1986) first introduced the Elaboration Likelihood Model, the authors argued that the model can "... explain a variety of effects inherent to social scientists, such as the conditions under which people will vote for candidates based on relatively simple cues such as political party..... rather than their issue positions" (Petty \& Cacioppo, 1986, p.viii).

Chmielewski (2012) applied the Elaboration Likelihood Model to a voting context, by comparing respondents' voting intentions against self-reported factors the respondents identified as having informed their decision. These self-reported factors included the candidates' party alignment, proposed policy, age, gender, and perceived expertise. Chmielewski (2012) also coded participants into low 
and high levels of political engagement, based on responses that included the number of times the participants participated in campaigns, watched or read news media, and how much they believed that voting mattered. Chmielewski (2012) showed that participants who reported lower political engagement used factors such as the candidate's affiliated party, attractiveness, or charisma to inform their decision, while those who demonstrated higher political engagement used policy to inform their choices.

Although Chmielewski (2012) showed that the Elaboration Likelihood Model could be applied to a political context, there is one major limitation of the paper. Chmielewski (2012) analysed their results by conducting correlational analyses for high and low political engaged participants separately, instead of an analysis that incorporates both low and high engagement in one model. This means that the authors were not directly comparing low and high political sophistication measures across each of the factors. A better statistical method would be a Factorial Analysis of Variance or a moderated regression analysis.

A study by Barber and Pope (2019), although not explicity testing the Elaboration Likelihood Model, also used measures of political sophistication as a moderating factor for participants' responses to information. Participants were asked to evaluate a proposal for an increased federal minimum wage in the United States, and the researchers manipulated whether or not Donald Trump endorsed or opposed the proposal 7 The researchers showed that participants demonstrating high political knowledge were more likely to rate the policy on its merits, irrespective of Donald Trump's endorsement or opposition to the policy. Those who demonstrated low political knowledge were more likely to use the Donald Trump cue to rate the policy (Barber \& Pope, 2019).

The earlier mentioned study by Fiske et al. (1983) also demonstrates the

\footnotetext{
${ }^{7}$ The study by Barber and Pope 2019) was conducted in 2017, immediately after Donald Trump's inauguration as president.
} 
principles of the Elaboration Likelihood Model. To recap, the authors showed that participants who demonstrated low political knowledge were more influenced by the communist or democratic label when evaluating the narrative of Mauritius. Participants that demonstrated high political knowledge used information from the narrative to inform their judgements (Fiske et al., 1983).

Some may wonder if a measure for ideology acts as an adequate central cue. Individuals may use the information about ideology as a heuristic for navigating a complex political world. It is also not uncommon for political parties to incorporate their ideology into their party branding, such as with the UK Conservative Party or The Liberal Party of Canada. Again, if people were only using the information of the Conservative or Liberal party names when determining who to vote for, I argue that they are using the peripheral route (as with the example of socialism). The study of Cohen (2003) included a bill that was ideologically conservative or liberal however, this was not stated to participants. The participants that are using information about the bill are focusing more on specific aspects within the ideology (generous spending vs. restricted spending), so use of this specific information aligns more with use of a central cue, as participants are using issue-relevant information.

Petty and Cacioppo (1986) note that someone's likelihood to elaborate lies on a spectrum, where at one end is entire use of peripheral cues, and at the other end is full and meaningful evaluations of central cues. In the case of voting, again, the party of a candidate does have some meaningful uses as a central cue. The party could be indicative of the candidate's ideology, if we were to use our previous knowledge for the party's previous campaign promises, their voting records, or the previous bills they have passed. However, when more informative policy information is available, this would be considered a central cue according to the Elaboration Likelihood Model. The party information would be deemed 
as a peripheral cue, by being less informative as a central cue compared with policy information.

\subsection{The present study}

In the current study, I experimentally tested the Elaboration Likelihood Model in a political context. Participants took part in a voting experiment where they saw several hypothetical candidates vying for political office. Each candidate was presented alongside a main policy that the candidate was campaigning to implement, as well as the party that the candidate was affiliated with. The main policy of the candidate represents the central cue, as the proposed policy of the candidate is the best information a person can use as an indication for how the candidate would govern, if elected. The policies of the candidates were manipulated to be either highly conservative or highly liberal, so while the policies differ between one another, they are used to represent an overall ideology of the candidate. Participants do not know if a candidate is truly conservative or liberal. Candidates' parties represented peripheral cues, as party information does not adequately tell the participant what the politician aims to achieve, when the more informative policy cue is available. The manipulated parties represented two of New Zealand's major parties: The New Zealand National Party, who lean ideologically conservative (Spinoff, 2020), the New Zealand Labour Party, who lean ideologically liberal (Spinoff, 2020), and a third 'Independent' party identification label which represents a baseline measure for a person's preference of conservative and liberal policies, when no party affiliation is present. I have also developed a quiz which is focused on New Zealand political-based general knowledge and current events as a measure for political sophistication.

Consistent with the Elaboration Likelihood Model, I expect that participants 
who score high on the political quiz (arguably reflecting higher political sophistication) will show a greater reliance on policy cues to inform their decision, more often than those with low political knowledge. Participants who demonstrate less political sophistication should rely on party cues to inform their decision, more than those with high political knowledge. That is, liberal-leaning participants should show a stronger preference for candidates with liberal policies, over candidates with conservative policies, when their political engagement is high, compared to other liberal participants with low engagement. Low politically engaged liberal participants, however, should have a greater preference for candidates presented alongside the New Zealand Labour Party, over National Party candidates, compared to those whose political engagement is high. Following from Cohen (2003), liberal participants should prefer candidates who propose liberal policies compared to those who propose conservative policies. From Cohen (2003) again, liberal participants should have an overall preference for candidates of the New Zealand Labour Party, compared to candidates of the New Zealand National Party, due to ideological similarities between the party and the left-leaning participants. The research hypotheses were pre-registered through OSF: https://osf.io/35tac.

\subsection{Electoral systems of the United States and New Zealand}

In this study, the main cited articles for voting behaviour have been from the United States (Barber \& Pope, 2019, Chmielewski, 2012, Cohen, 2003 Fiske et al., 1983. Malka \& Lelkes, 2010. Verkuyten \& Maliepaard, 2013), and the present study will focus on New Zealand politics with a New Zealand sample. New Zealand and the United States differ in their political and electoral systems, which could affect how participants of each country respond to different voting factors. 


\section{Method}

\subsection{Participants}

Participants were 196 students (160 females, 33 males, 3 non-responses) enrolled in a first-year psychology course at Victoria University of Wellington. The mean age of participants was 19.48 years, with a standard deviation of 2.72 years. Data from thirteen participants were removed before analysis due to having more than five missing data-points in either of the main experimental trials or in the political quiz. Participants were invited to complete the experiment through SONA, a participant management software platform, as part of their Introductory to Psychology Research Program (IPRP). IPRP is a program for students enrolled in first-year Psychology courses at Victoria University of Wellington. IPRP is a co-curricular research appreciation opportunity that students are required to engage with either actively, through participation, or passively, by summarising research articles. Participants gave their informed consent before they began the experiment. Ethics approval was obtained for this study through the Victoria University of Wellington Ethics Committee (Ethics Application ID: 28366). Aside from receiving IPRP credits, there were no other incentives associated with participation.

\subsection{Materials}

\subsubsection{Experimental trials}

Face stimuli. Participants saw faces that were artificially developed from a generative adversarial network (Karras et al., 2018). The criteria used to select each of the faces were that: faces needed to look as if they represented a person over the age of 18, faces could not have any shaded eyewear or head gear, faces could not appear as androgenous, the eyes of the generated faces needed to be 
directed towards the camera, the background of the pictures could not include any abnormalities (backgrounds of artificially generated images can morph into unrealistic images), and that the left and right sides of the faces had general symmetry. The face stimuli were selected by the primary researcher. Each of the face images were $28 \mathrm{~cm}$ tall and $52 \mathrm{~cm}$ wide and appeared in the left position of the centre box. Examples of the artificial faces are presented below in Figure 1 .
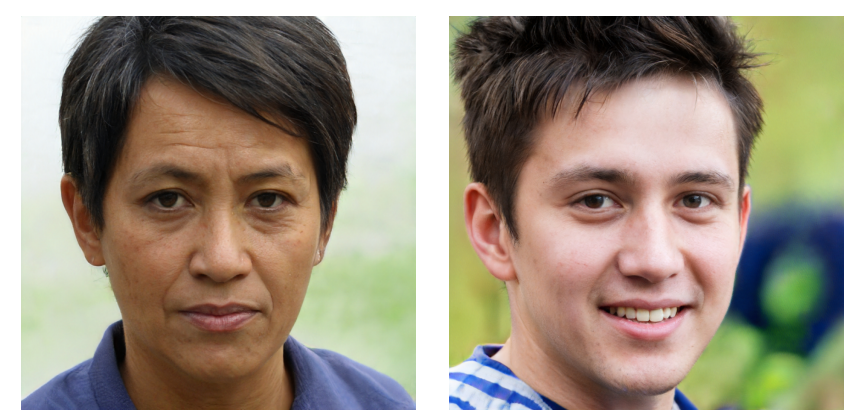

Figure 1. Examples images of artificially developed faces (Karras et al., 2018)

Party stimuli The three party-labels used in this study were the New Zealand Labour party (liberal-leaning), the New Zealand National party (conservative-leaning), and a label for Independent candidates. Note that the Independent logo does not represent an actual party but is used to show that a candidate is not affiliated with any party. The Independent label was used to gauge participants' preference for conservative or liberal policies, when neither of the major party labels were present. The party labels used in this experiment were the current party logos of the National and Labour parties. The label for the Independent condition was a black and white wording for the word 'Independent.' The party labels were $5.5 \mathrm{~cm}$ tall and $11.25 \mathrm{~cm}$ wide and appeared to the upper right of the centre position of the screen. Example imagery of the three logos are shown below in Figure 2 . 


\section{Fiational Labour Independent}

Figure 2. Party image logos

Policy stimuli. Conservative and liberal policy items were drawn from previous attitude scales and adapted to be framed as a policy goal for each hypothetical candidate. These policies were piloted using a different sample (from the same population) to have them rate the items on how liberal or conservative they believed the items to be. The pilot sample also rated the policies on their complexity. Initially, 16 items were selected from the Social Attitudes Statement Scale (Kerlinger, 1984), 17 items were drawn from the Conservatism Scale (Sidanius, 1976a, 1976b), and four from the Public Opinion Inventory (Eysenck, 1995), creating a total of 37 items. For each item that represented a liberal-directed policy, I created my own conservative-direction policy item pair. Liberal pairs were also created for conservative-directed policies, bringing the total number of items to 74 . I created a further 38 items to bring the total amount of pilot items to 112. Eighty-two of the items were mirrored, so that there was a liberal and conservative version of the similar item. The remaining 30 policies did not include a mirrored item of an opposing ideology. All items were framed as policies that the candidate wants to achieve (i.e. "Wants to ease restrictions for acquiring firearms" or "wants to further restrict firearm registration processes"). All policies began with"Wants to" to remain consistent.

Following the pilot study, I decided to include only pairs of policies that mirrored one another in the main study. This meant that the pilot items that did not include a mirrored item were either removed from the study, or a new mirror policy was created as a pair for that item. Forty-eight final items were used in the main study. The 48 items were mirrored so that there was a conservative 
and liberal version of each item (24 pairs). The final 48 policies used in this study will be discussed further in the Results section (section 3.1.3). The pilot study helped to determine which policies were easy to understand, and which were ideologically clear to the sample population. I chose to pilot these items so that the ideologies of the policies were not determined by my own assumptions. Of the final 48 items, 36 were drawn from the pilot study. These items were the most ideologically clear, and easy to understand. The remaining 12 policies were created by me, after piloting, to create mirror items for the existing policies.

Political sophistication. Following previous recommendations around measuring political sophistication, I chose to measure political sophistication through a multiple-choice quiz (Robinson et al., 2013). The quiz included items about New Zealand political current events, as well as items about New Zealand's electoral system. The initial quiz included 20 items. Each item had four possible responses that participants could select as an answer. An example item is "When was the last New Zealand General Election?" with possible answers of “A. 2015, B. 2016, C. 2017, D. 2018." A second example question, that may have captured current events in politics was "Who is the current Minister of Health" with four potential holders of the title as possible answers.

Tables depicting all of the political quiz items and their refinement are shown below in Table 1, Table 2, and Table 3. I performed a discriminative analysis on the items to test if there was discrimination in responses by high and low sophisticated individuals across each of the items (Klecka et al., 1980). The discriminative analysis showed good discrimination between high and low scorers for eighteen of the items, and poor discrimination for items 16 and 20 (see Table 3). Following the Discriminatory Analysis, five further items were dropped (items 1, 3, 4, 8, and 17; see Tables 1 3) due to them showing low inter-item correlation scores (below .30). A Reliability Analysis for the remaining thirteen 
items returned a Cronbach's Alpha of .68, which is lower than the traditional cut-off value of .70 (Cronbach, 1943). The Cronbach's Alpha analysis included the Kuder-Richardson adjustment to account for the response variable being dichotomous (correct vs incorrect), rather than continuous (Cronbach, 1951).

Response set. On each trial, participants responded on the likelihood that they would vote for the presented candidate. Participants responded on a 6-point scale with a prompt stating "What is the likelihood that you would vote for this candidate?" Possible responses on the scale ranged from '1' (Not very likely) to ' 6 ' (Very likely). There were no mid-point options so that participants could only pick a favorable or unfavorable position when rating candidates and could not pick a neutral position.

\subsubsection{Other Measures}

Political engagement. During the study, participants were asked to respond on a slider for how politically engaged they believed that they were. The prompt that accompanied the slider was "Please use your mouse to rate how politically engaged you think you are: "Possible scores on the slider ranged from ' 1 ' (Not very Engaged) to '100' (Very Engaged). When participants placed their score on the slider, they were not aware of the exact number of their placement.

\subsubsection{Ideological alignment}

After the main trials, participants were asked to place several different political parties or people on a spectrum representing their ideological alignment. Participants placed the parties or persons on a scale that varied from 1 (Liberal)

to 6 (Conservative). Before participants were tasked to evaluate the persons and parties, they were given brief definitions of liberalism and conservatism. 


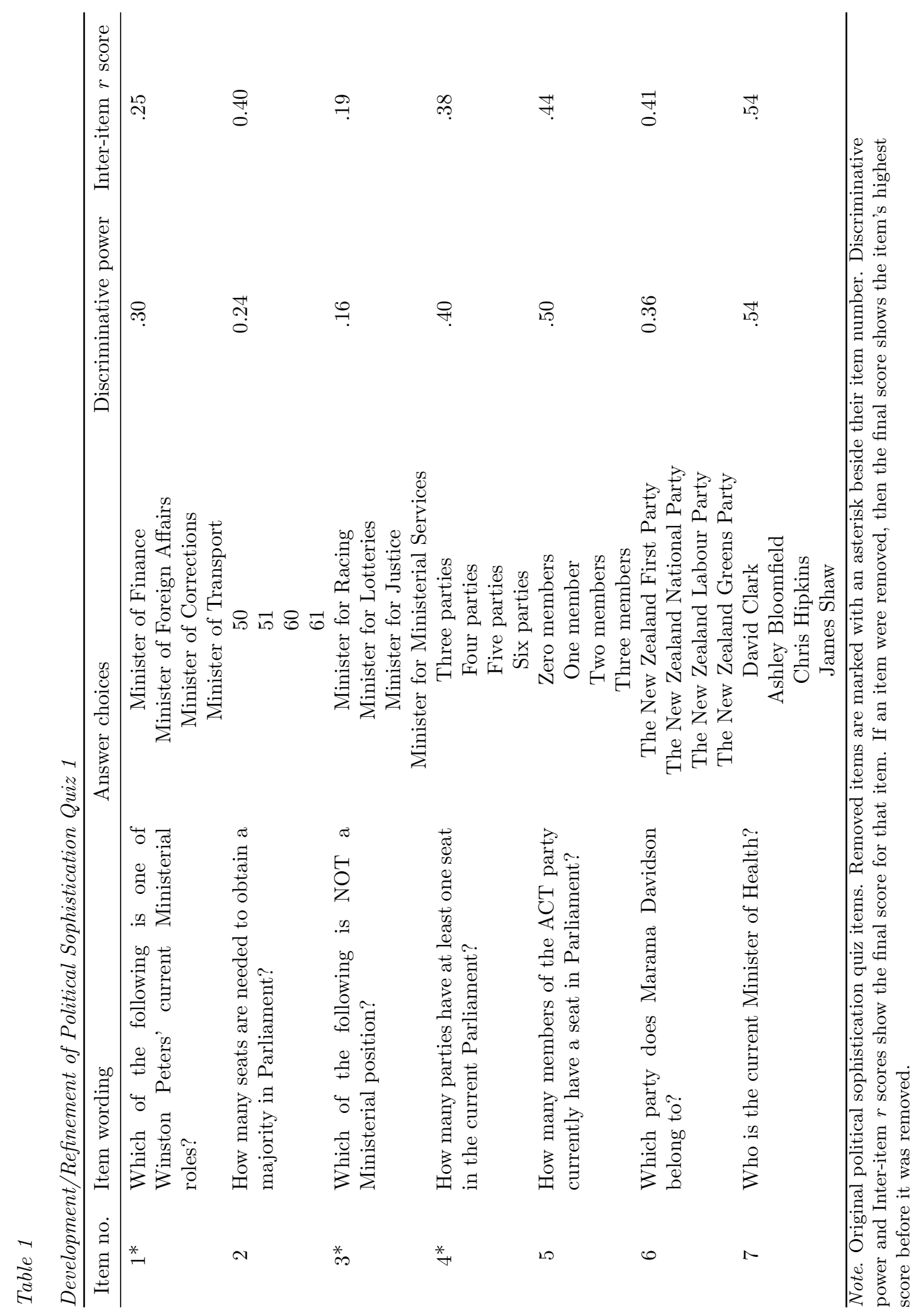




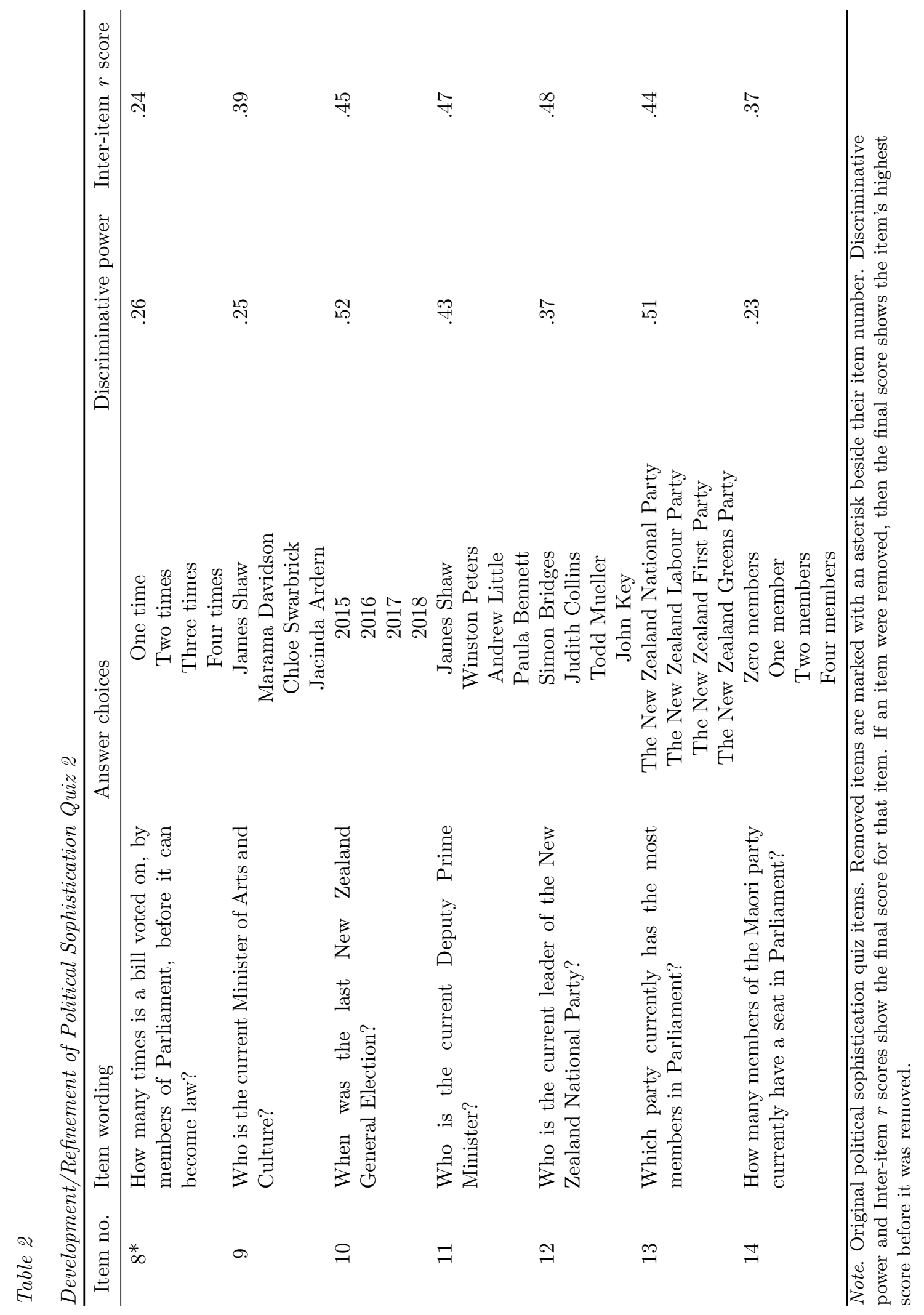




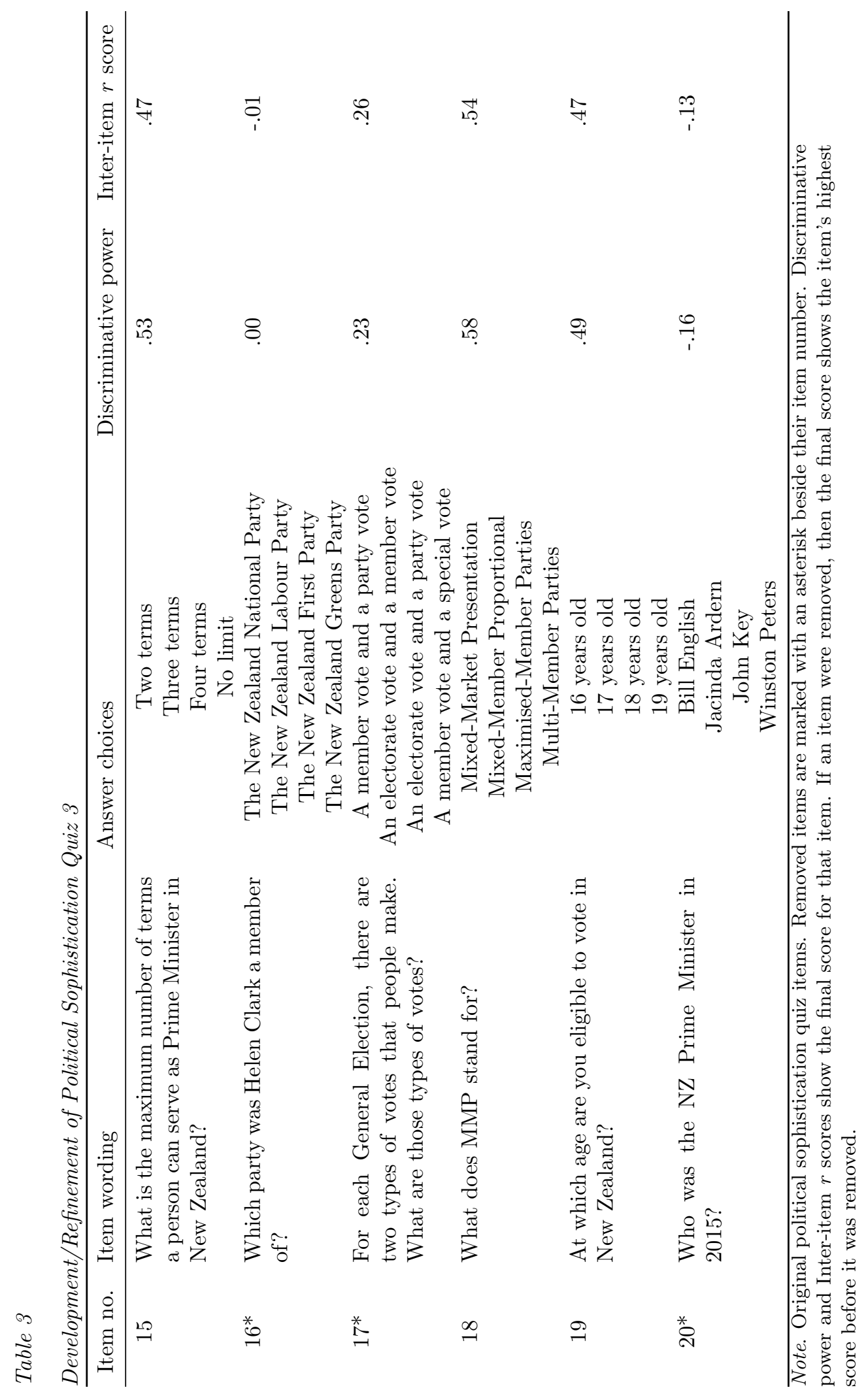


Participants were told that conservative ideals 'relate to individual accountability and traditional values', and that the term liberal 'refers to community accountability and progressive values' (Heywood, 2017). Participants were also given substitute terms for conservatism; traditional and right-wing, and replacement terms for liberalism; progressivism and left-wing. The items that participants were asked to place were (in order) The United States Republican Party, The United States Democratic Party, The New Zealand National Party, The New Zealand Green Party, The New Zealand Labour Party, Donald Trump, and the participant themselves. For analyses involving participants' self-placed ideological alignment, participants who placed the New Zealand Green Party as more conservative than the New Zealand National Party were excluded (13 excluded). This exclusion was because the New Zealand Green Party leans ideologically further left than the New Zealand National Party (Spinoff, 2020). A categorisation of the Green Party as more conservative than the National Party suggests a lack of knowledge about political ideology. This section of the study always occurred after the main experimental trials, as 'teaching' participants about conservatism and liberalism may have contaminated responses on the main trials.

\subsection{Design}

This experiment used a 2(Policy) x 3(Party) x 2(Political Sophistication) $\mathrm{x}$ 8(trials) mixed-measures design. The dependent measure was the participants' self-reported likelihood to vote for the hypothetical candidate presented to them. The three main independent variables were: the ideology of the hypothetical candidates, which is operationalised through the candidates' proposed policies (within-subjects, two levels: Liberal, Conservative), the group influence of the candidate, operationalised by the party label of the hypothetical candidates (within-subjects, three levels: National, Labour, Independent), and the participant's 
political knowledge, operationalised through their performance on the political quiz (between-subjects, two levels: High, Low). The combinations of policy and party created six different within-subject conditions: Liberal and Labour, Liberal and National, Liberal and Independent, Conservative and Labour, Conservative and National, and Conservative and Independent.

There were 48 trials in total for the main section of the experiment ( 8 trials per within-subject condition), and trials were split into two blocks. The blocks were constructed so that each ideologically opposing policy pair appeared in separate blocks to reduce the chance that participants would see two opposing policies within a short amount of time of one another. Before the experiment began, participants were randomly assigned into one of six conditions and, within each condition, were assigned into one of the two block orderings. The blocks were counterbalanced to reduce the probability of an ordering effect. Across all six conditions, each individual policy appeared with the National, Labour, and Independent logos twice. The associated faces for each policy were controlled so that, for each time a face and party appeared with a policy in one condition, that same face and party combination would appear with the ideologically opposing policy in another condition. Once conditions were constructed, the trials were presented to participants in a random order within the blocks. Table 4 shows how the conditions were constructed. 
Table 4

Construction of conditions

\begin{tabular}{ccccc}
\hline \multirow{2}{*}{ Condition } & \multicolumn{2}{c}{ Liberal policy 1} & \multicolumn{2}{c}{ Conservative policy 1} \\
& Face & Party & Face & Party \\
\hline 1 & female \#17 & National & male \#15 & Labour \\
2 & male \#11 & National & female \#22 & Independent \\
3 & male \#15 & Labour & female \#17 & National \\
4 & male \#24 & Labour & female \#9 & Independent \\
5 & female \#22 & Independent & male \#11 & National \\
6 & female \#9 & Independent & male \#24 & Labour \\
\hline
\end{tabular}

Note. In the above table, both Liberal policy 1 and its opposing Conservative policy 1 are presented with each party logo an equal number of times across conditions. For each face and party that Liberal policy 1 appears on, the opposing Conservative policy 1 appears with that same face and party.

\subsection{Procedure}

The experiment was developed using the Psychopy software and administered online through Pavlovia's experiment hosting (see Peirce, 2007). Participation was voluntary and participants' informed consent was gained before they could begin the study. Participants completed the experiment in their own time, from their own computers. Participants took approximately thirty minutes to complete the experiment and received half an IPRP credit for their time. Participants were told that there was no requirement to complete each section of the experiment, and that they could skip trials for any reason. If participants made it to the end of the entire experiment, they received their credit towards the research requirement no matter how many trials they had skipped. The experiment was available to participants six weeks before the 2020 New Zealand 
General Election, and data collection took less than two weeks.

The main section of the experiment showed participants the faces of hypothetical candidates, along with the candidates' main policy (liberal/conservative) and party association (Labour/National/Independent). The face, policy, and party appeared concurrently, for each of the trials 8 Five seconds after the stimuli were presented, participants were then presented with the response scale, for which they could use their mouse or keys to respond. Once the scale was presented to participants, they had seven seconds to respond. In total, participants saw the stimuli for a maximum of 12 seconds, before the trial terminated and moved on to the following trial with a new arrangement of stimuli. An example of the trial layout is presented in figure 3 .

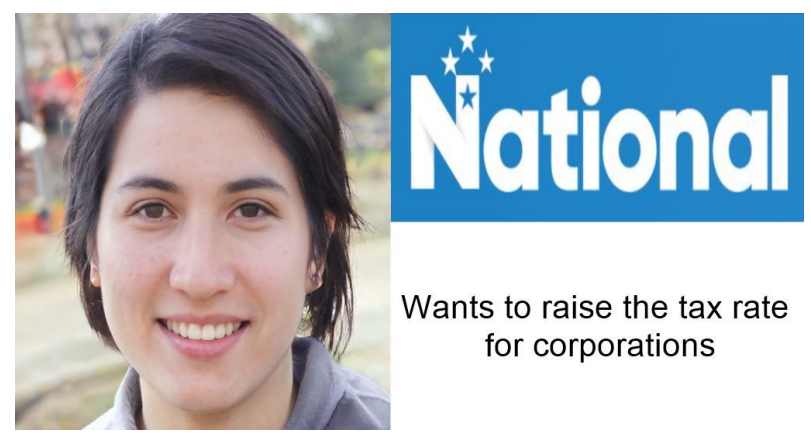

Figure 3. Example main trial

After completing the main section of the experiment, participants responded on a series of measures that have been outlined in the method sections. These measures were the self-report measure for participants' political engagement, their ideological alignment, their political sophistication, some demographic questionnaires, a scale for participants to introspect on what they based their decision on, and a section for participants to provide feedback about the experiment.

\footnotetext{
${ }^{8}$ Information for face stimuli is found on 2.2.1 information for policy stimuli is found on 2.2.1 information for party stimuli is located on 2.2.1 and information for the policy stimuli is located on 2.2 .1
} 
Finally, participants were debriefed about the research hypothesis and were offered the opportunity to receive the results of the study.

\section{$3 \quad$ Results}

Data organisation, maintenance, and analysis was completed entirely through $\mathrm{R}$ and R-studio (R Core Team, 2021), and the R code is shown in appendix A

\subsubsection{Data Adjustments}

The proportion of correct answers on the political quiz was calculated to obtain the measure of political sophistication. The political sophistication measure was then adjusted with a median split, so that participants with the lower half of scores were categorised as demonstrating low political sophistication, and participants with the upper half of scores were categorised as having high political sophistication. In planning this study, I was unsure whether to split participants' political sophistication by median split, or as a tertile split with participants in the middle tertile removed. Using a tertile split, and removing the middle tertile, would give larger difference between high and low political sophistication levels, and may have removed some of the 'noise' caused by the middle tertile. By using the median split, I am using all the participant's scores, and will be maximising my sample. I don't believe I would be conducting good research if I were taking from a broad sample and removing a large chunk of this sample from the analysis. In the end, I conducted the main analysis with political sophistication categorised by the median split.

The response variable for candidate rating was originally constructed so that participants rated their likelihood to vote for each candidate on a continuous measure (from 1 - Not very likely to 6 - Very likely). As participants' responses were on a continuous measure, it was possible to have partial scores. This made 
the distribution of scores for the response variable multi-modal, with the modes at each full integer, so I changed the scale from continuous to interval data, where responses were rounded to the nearest full number.

Initially, a planned analysis was to group participants by their baseline ideological leaning, either Liberal or Conservative, based on how they responded to candidates for the 'Independent' condition. However, there were only nine participants who showed a higher preference for conservative over liberal policies when the party label was 'Independent', so this planned analysis could not reach the necessary power to be tested. Due to the lack of conservative participants, all nine conservative participants were removed from the dataset.

\subsection{Descriptive statistics}

\subsubsection{Preference for experiment variables}

A table of participants' ratings for candidates under different party and policy conditions is presented below in Table 5 Across each party condition, the average preference for liberal policies $(M=4.40, S D=0.63)$ was greater than the preference for conservative policies $(M=2.33, S D=0.63)$. The average preference for Labour party candidates $(M=3.46, S D=1.21)$ was higher than the preference for candidates with the Independent label $(M=3.35, S D=1.23)$, which was, in turn, higher than the preference for candidates presented with the National party $(M=3.29, S D=1.22) !^{9}$

\footnotetext{
${ }^{9}$ Note that the means for party are averaged across different conditions of liberal and conservative policies. There is no 'baseline' rating for peoples' preference of party on its own. Furthermore, simple descriptive statistics may be misleading. Later, Estimated Marginal Means will be used to discuss means for party and policy preference.
} 
Table 5

Means and Standard deviations for preference for Parties and Policies

\begin{tabular}{cccccc}
\hline Party & Policy & $M$ & $S D$ & Min & Max \\
\hline Labour label & Conservative policy & 2.43 & 0.68 & 1.13 & 5.04 \\
Labour label & Liberal policy & 4.49 & 0.60 & 2.48 & 5.81 \\
National label & Conservative policy & 2.25 & 0.67 & 1.05 & 3.92 \\
National label & Liberal policy & 4.33 & 0.66 & 2.48 & 5.81 \\
Independent label & Conservative policy & 2.31 & 0.65 & 1.02 & 4.28 \\
Independent label & Liberal policy & 4.39 & 0.61 & 2.40 & 5.77 \\
\hline All party labels & Conservative policy & 2.33 & 0.67 & 1.02 & 5.04 \\
All party labels & Liberal policy & 4.40 & 0.63 & 2.36 & 5.81 \\
Labour label & All policies & 3.46 & 1.21 & 1.13 & 5.81 \\
National label & All policies & 3.29 & 1.23 & 1.05 & 5.72 \\
Independent label & All policies & 3.35 & 1.22 & 1.02 & 5.77 \\
\hline
\end{tabular}

Note. Descriptive statistics for candidate ratings across different party and policy conditions. For this table, averages were first created for each participant before descriptive statistics were created (i.e., the Min represents the lowest average score of an individual participant, not the lowest possible individual data-point).

\subsubsection{Voting intentions of participants}

Table 6 shows a breakdown of the participant's voting intentions at the time of the experiment. Most participants (53\%) planned to vote for the New Zealand Labour Party, 15\% planned to vote for the New Zealand Green Party and 10\% planned on voting for either or a combination of the two. $15 \%$ of the sample did not know who they would vote for or they would not say, with $7 \%$ left over for other voting intentions. 
Table 6

Preference for Parties and Policies

\begin{tabular}{ccc}
\hline Voting intention & Count & Proportion \\
\hline Labour & 89 & .53 \\
National & 2 & .01 \\
Green & 28 & .17 \\
ACT & 2 & .01 \\
TOP & 1 & .005 \\
Labour or Green & 19 & .11 \\
Labour or ACT & 1 & .005 \\
ACT or Green & 1 & .005 \\
Don't know & 25 & .15 \\
Not telling & 1 & .005 \\
\hline
\end{tabular}

Note. Descriptive statistics for candidate ratings across different party and policy conditions. For this table, averages were first created for each participant before descriptive statistics were created (i.e., the Min represents the lowest average score of an individual participant, not the lowest possible individual data-point).

\subsubsection{Preference for individual policies}

Participants' preference for each policy is presented in Tables 7. 10 . These means are the average preference for candidates when the given policy was presented alongside the candidate, and while the party label was 'Independent.' Included in Tables 7.10 is a measure of the skew for each item. If the skew of an item lies between -0.5 and 0.5 , then responses to that item are considered to follow a normal distribution. Skew scores above 0.5 and below -0.5 are of moderate skew, and scores over 1, below -1 are considered to have large skews. If a score has a negative skew, as indicated by the presence of a negative sign, 
then this shows that more of the responses lie in the right side of the scale, so most participants had very high preferences for items with a negative skew, with little variation in responses. A positive skew is the opposite; most participants had very low preference for items with a positive skew and varied little from this low preference. Of the liberal items, seven had a strong skew, seven had a moderate skew, and the remaining ten items had minimal skew. For conservative items, eight had strong skews, eleven had moderate skews, and the remaining five items showed minimal skews. As would be expected, the items with the strongest skews are the liberal items that were rated most favourably and the conservative items which were rated least favourably. 
Table 7

Preference for Liberal policies 1

\begin{tabular}{|c|c|c|c|c|}
\hline Item code & Item description & $M$ & $S D$ & Skew \\
\hline Lib17 & Wants to make dental-care free & 5.13 & 0.85 & -0.99 \\
\hline Lib15 & $\begin{array}{l}\text { Wants government supported, national healthcare available } \\
\text { to all people }\end{array}$ & 5.12 & 0.97 & -1.10 \\
\hline Lib5 & $\begin{array}{l}\text { Wants corporations to be penalised if they are found to } \\
\text { knowingly cause environmental harm }\end{array}$ & 5.10 & 0.90 & -1.03 \\
\hline Lib14 & $\begin{array}{l}\text { Wants to fund free university for all able and wanting } \\
\text { students }\end{array}$ & 5.08 & 0.87 & -1.03 \\
\hline Lib8 & Want to increase funding to help with vulnerable youth & 5.05 & 0.74 & -1.10 \\
\hline Lib19 & Wants sex education to be taught in school & 4.97 & 1.13 & -1.14 \\
\hline Lib22 & Wants more rehabilitative opportunities for offenders & 4.93 & 1.00 & -0.71 \\
\hline Lib7 & $\begin{array}{l}\text { Wants to reduce the inequality between rich and poor } \\
\text { people }\end{array}$ & 4.89 & 0.95 & -1.10 \\
\hline Lib18 & $\begin{array}{l}\text { Wants to allow access to all forms of contraceptives, } \\
\text { regardless of if the person is under } 16\end{array}$ & 4.88 & 1.15 & -1.14 \\
\hline Lib11 & $\begin{array}{l}\text { Wants to reduce unplanned pregnancies by subsidizing the } \\
\text { costs of contraceptives }\end{array}$ & 4.72 & 1.18 & --0.93 \\
\hline Lib9 & $\begin{array}{l}\text { Wants to increase the minimum wage to equal the living } \\
\text { wage }\end{array}$ & 4.71 & 1.20 & -0.86 \\
\hline Lib16 & $\begin{array}{l}\text { Wants schools to be separated by the income of the parents, } \\
\text { so only children of similar wealth are schooled together }\end{array}$ & 4.64 & 1.14 & -0.55 \\
\hline
\end{tabular}

Note. Average preference for hypothetical candidates with liberal policies when the party label was 'Independent.' Items are ordered from most preferred to least preferred. There are 12 liberal policies presented here. The remaining liberal policies are presented in Table 8 
Table 8

Preference for Liberal policies 2

\begin{tabular}{|c|c|c|c|c|}
\hline Item code & Item description & $M$ & $S D$ & Skew \\
\hline Lib10 & $\begin{array}{l}\text { Wants businesses not to discriminate against certain } \\
\text { customers if the business owner disagrees with the } \\
\text { customer's life choices }\end{array}$ & 4.63 & 1.01 & -0.46 \\
\hline Lib21 & Wants to reduce crime by rehabilitating perpetrators & 4.36 & 1.14 & -0.64 \\
\hline Lib13 & $\begin{array}{l}\text { Wants to fund construction of more schools from } \\
\text { government money }\end{array}$ & 4.22 & 1.10 & -0.10 \\
\hline Lib4 & Wants to raise the tax rate for corporations & 4.16 & 0.98 & -0.03 \\
\hline Lib24 & $\begin{array}{l}\text { Wants to legalise marijuana usage to anyone over the age } \\
\text { of } 18\end{array}$ & 4.08 & 1.36 & -0.57 \\
\hline Lib23 & Wants to allow all prisoners to vote from prison & 4.05 & 1.41 & -0.27 \\
\hline Lib20 & Wants funding for the arts to be protected & 3.89 & 1.21 & -0.42 \\
\hline Lib1 & $\begin{array}{l}\text { Wants those with large fortunes to be taxed over and above } \\
\text { their income tax }\end{array}$ & 3.62 & 1.34 & -0.11 \\
\hline Lib12 & $\begin{array}{l}\text { Wants to increase the amount of money given for the } \\
\text { unemployment benefit }\end{array}$ & 3.53 & 1.07 & -0.14 \\
\hline Lib3 & $\begin{array}{l}\text { Wants the government to heavily regulate business and } \\
\text { trade }\end{array}$ & 3.37 & 0.99 & -0.15 \\
\hline Lib6 & $\begin{array}{l}\text { Wants every person who is not working to receive an } \\
\text { unemployment benefit, with no exceptions }\end{array}$ & 3.18 & 1.32 & 0.09 \\
\hline Lib2 & Wants to reduce funding to the military & 3.08 & 1.21 & -0.32 \\
\hline
\end{tabular}

Note. Average preference for hypothetical candidates with liberal policies when the party label was 'Independent.' Items are ordered from most preferred to least preferred. There are 12 liberal policies presented here. The remaining liberal policies are presented in Table 7 
Table 9

Preference for Conservative policies 1

\begin{tabular}{|c|c|c|c|c|}
\hline Item code & Item description & $M$ & $S D$ & Skew \\
\hline Con3 & $\begin{array}{l}\text { Wants the government not to interfere with business and } \\
\text { trade }\end{array}$ & 2.97 & 0.93 & 0.46 \\
\hline Con21 & Wants to reduce crime by creating harsher punishments & 2.95 & 1.48 & 0.53 \\
\hline Con22 & Wants longer prison sentences for offenders & 2.91 & 1.33 & 0.48 \\
\hline Con6 & $\begin{array}{l}\text { Wants to move people off the unemployment benefit } \\
\text { because there are too many that abuse the system }\end{array}$ & 2.79 & 1.20 & 0.41 \\
\hline Con7 & $\begin{array}{l}\text { Wants those who made their own wealth to be able to hold } \\
\text { on to that wealth and not pay extra in taxes }\end{array}$ & 2.75 & 1.29 & 0.58 \\
\hline Con23 & $\begin{array}{l}\text { Wants to stop those in prison from voting, until after they } \\
\text { serve their sentence }\end{array}$ & 2.75 & 1.42 & 0.57 \\
\hline Con15 & $\begin{array}{l}\text { Wants healthcare to be handled by insurance companies, } \\
\text { as they believe government can't organise such large-scale } \\
\text { management }\end{array}$ & 2.69 & 1.07 & 0.42 \\
\hline Con2 & Wants to increase funding for the military & 2.64 & 1.17 & 0.39 \\
\hline Con 4 & Wants to lower tax rates on corporations & 2.57 & 1.24 & 0.63 \\
\hline Con12 & $\begin{array}{l}\text { Wants to reduce the amount of money given for the } \\
\text { unemployment benefit }\end{array}$ & 2.53 & 1.22 & 0.63 \\
\hline Con1 & $\begin{array}{l}\text { Wants to protect the wealth of those with large fortunes } \\
\text { from paying extra in taxes }\end{array}$ & 2.46 & 1.20 & 0.83 \\
\hline Con13 & Wants to allow for more private schools & 2.44 & 0.90 & 0.56 \\
\hline
\end{tabular}

Note. Average preference for hypothetical candidates with conservative policies when the party label was 'Independent.' Items are ordered from most preferred to least preferred. There are 12 conservative policies presented here. The remaining policies are presented in Table 10 
Table 10

Preference for Conservative policies 2

\begin{tabular}{|c|c|c|c|c|}
\hline Item code & Item description & $M$ & $S D$ & Skew \\
\hline Con11 & $\begin{array}{l}\text { Wants to reduce unplanned pregnancies by teaching } \\
\text { abstinence }\end{array}$ & 2.20 & 1.28 & 0.68 \\
\hline Con24 & Wants to keep marijuana classed as an illegal substance & 2.20 & 1.24 & 1.17 \\
\hline Con20 & Wants less funding for the arts & 2.16 & 0.90 & 0.70 \\
\hline Con5 & $\begin{array}{l}\text { Wants to ease environmental regulations for businesses to } \\
\text { make it easier for business to achieve profits }\end{array}$ & 2.03 & 1.17 & 0.92 \\
\hline Con9 & $\begin{array}{l}\text { Wants to help business owners by reducing the minimum } \\
\text { wage }\end{array}$ & 2.01 & 1.21 & 1.56 \\
\hline Con17 & Wants dental care to be privatised & 1.96 & 0.95 & 0.77 \\
\hline Con18 & $\begin{array}{l}\text { Wants to restrict access to contraceptives for those under } \\
16\end{array}$ & 1.91 & 1.15 & 1.01 \\
\hline Con10 & $\begin{array}{l}\text { Wants businesses to be able to refuse the right of service to } \\
\text { those that disagree with the business' values }\end{array}$ & 1.88 & 0.96 & 1.42 \\
\hline Con16 & $\begin{array}{l}\text { Wants schools to be separated by the income of the parents, } \\
\text { so only children of similar wealth are schooled together }\end{array}$ & 1.85 & 0.97 & 1.49 \\
\hline Con14 & $\begin{array}{l}\text { Wants to remove the student allowance so that students } \\
\text { pay for their own university fees up front or through a loan }\end{array}$ & 1.76 & 1.07 & 2.08 \\
\hline Con8 & $\begin{array}{l}\text { Wants to allow parents to physically discipline their } \\
\text { children }\end{array}$ & 1.59 & 0.83 & 1.39 \\
\hline Con19 & $\begin{array}{l}\text { Wants sex education to only be taunt by the child's } \\
\text { parent/guardian }\end{array}$ & 1.42 & 0.56 & 1.94 \\
\hline
\end{tabular}

Note. Average preference for hypothetical candidates with conservative policies when the party label was 'Independent.' Items are ordered from most preferred to least preferred. There are 12 conservative policies presented here. The remaining policies are presented in Table 9 


\subsection{Main analyses}

The main goal of this study was to test if the Elaboration Likelihood Model could be applied to a political context. According to the Elaboration Likelihood Model, people that are more knowledgeable in a particular subject area are more likely to engage with central cues over peripheral cues when making their decision. Political knowledge was operationalised through the participants proportion of correct scores on the multiple-choice quiz. The central cue was operationalised as how much a person engages with the policies of the hypothetical candidates. The peripheral cue was operationalised as how much a person engages with the party label of the hypothetical candidates.

\subsubsection{Model design}

I tested the hypothesis using a Linear Mixed-Effect Model. The fixed effects were political sophistication (2 levels: Low and High), party label (3 levels: The New Zealand National party, the New Zealand Labour party, \& an Independent logo), and the ideology of the policy (2 levels: conservative \& liberal). Subject ID was added to the model as a random effect to account for the repeated measures in the experiment. The eight trials for each condition were included in the model as a nested variable; as preferences for each of the policies are expected to vary, both at the ideological level, and at the individual policy-level, the effect of the individual policies needs to be nested within the overall ideology to effectively account for the variation. The participants' likelihood to vote for the hypothetical candidate was used as the outcome variable.

The final model was developed using step-wise model comparisons, and information of this process is shown in Table 11. Six possible models were compared against one another. The null model included only the response variable, while accounting for the repeated measures component of the design. 
Model 1 added the overall political ideology of policies as a fixed effect. Model 2 incorporated the nested effects for each individual policy within the overall ideology of that policy. Model 3 added political party as a fixed effect. Model 4 added participants' average scores on the political quiz as a fixed effect. Model 5 included the political sophistication measure as a moderating variable. Interactive effects among all fixed effects were tested for each of the models. Each of the models were compared against one another using the Aikake Information Criteria (AIC Sakamoto et al., 1986). AIC compares competing models to summarise which model fits the data best, without over-fitting the data. A lower AIC means that adding the selected variable was a good choice for the model. If an added variable results in a higher AIC, or a minimal change in AIC (less than 2 points lower), then the variable is not a meaningful addition in explaining the data (Sakamoto et al., 1986). As shown in Table 11, Model 1 is a better fit than the null model, so it is good to include the overall ideology of policies as a fixed effect $(A I C=27306$, compared to an $A I C$ of 31784$)$. Model 2 has a better goodness-of-fit than Model 1 statistic $(A I C=25686)$, so nesting the effects of the individual policies inside their respective ideology is a useful addition. Model 3 has a better fit than Model $2(A I C=25658)$, so the fixed effect of party is a meaningful addition to the model. Model 4 is better than Model $3(A I C=25518$, so political sophistication is a useful predictor variable for explaining the data. Model 5 has the best overall fit $(A I C=25513)$, so the political sophistication variable serves adequately as a moderating variable in the model.

\subsubsection{Main Effects}

In the final model, the ideology of the policy was a significant predictor of responses $(B=1.83, S E=0.17, t(5405)=10.78, p<.001)$. There was also a 
Table 11

Stepwise model comparisons for main analysis

\begin{tabular}{ccc}
\hline Model & Added Predictor & AIC \\
\hline Null model & Subject ID as a random effect & 31784 \\
Model1 & Ideology of the policies as a fixed effect & 27306 \\
Model2 & Nested effect of individual policies & 25686 \\
Model3 & Party as a fixed effect & 25658 \\
Model4 & Pol Soph as a fixed effect & 25518 \\
Model5 & Pol Soph as a moderating variable & 25513 \\
\hline
\end{tabular}

main effect for the political sophistication of participants $(B=-0.42, S E=$ $0.07, t(1138)=-5.76, p<.001)$. As expected, there was a main effect for party $(B=-0.11, S E=0.05, t(8264)=-2.11, p=.035)$, as participants preferred Labour candidates over National candidates. Each of these variables are qualified by the later interaction, so marginal means will not be shown for the main effects. There were no other significant difference in responses for party labels, from Independent to Labour $(B=0.05, S E=0.05, t(8264)=1.05, p=$ $.295)$, nor from Independent to National $(B=-0.06, S E=0.06, t(8264)=$ $-1.10, p=.288) .4$.

\subsubsection{Interactions}

Policy-Political Sophistication As expected, there was a significant interaction between political sophistication and the ideology of the presented policy $(B=$ $0.65, S E=0.09, t(8264)=7.27, p<.001)$. Multiple contrasts with Bonferroni adjustment were used to test for interaction effects between policy type and political sophistication. Participants with high political sophistication scores showed a significant difference in their preference for liberal policy candidates $(M=4.54, S E=0.12)$ over conservative policy candidates $(M=2.09, S E=$ $0.12 ; B=-2.31, S E=.04, p<.001)$. Low politically sophisticated participants also rated liberal policy candidates as higher than $(M=4.31, S E=0.12)$ conservative policy candidates $(M=2.46, S E=0.12 ; B=-1.91, S E=.04, p<$ 
.001). This means that high politically sophisticated participants rated liberal policies higher, and conservative policies lower, compared to those who demonstrated low sophistication. As expected, this finding suggests that highly sophisticated participants used the central cue of policy more often when evaluating candidates, compared to those who demonstrated low political sophistication. A depiction of this interaction is shown below, in Figure 4

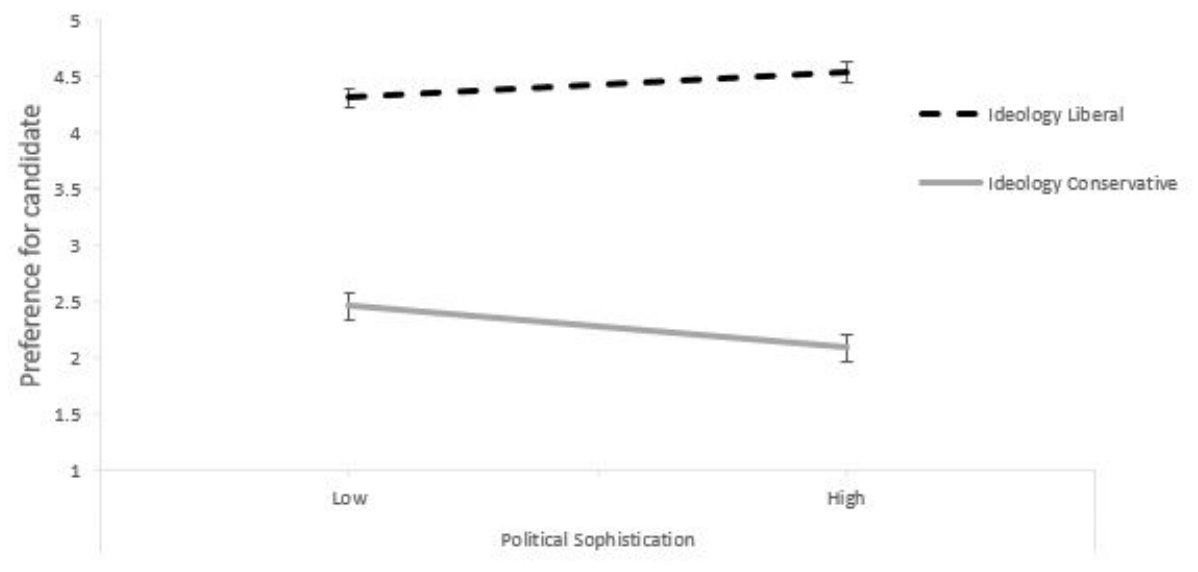

Figure 4. Preference for candidates, based on the ideology of their policy and participants' political sophistication

Party-Political Sophistication There was also an interaction between political sophistication and the party label of candidates for the National and Labour parties $(B=-.18, S E=0.09, t(8264)=-2.06, p=.040$, but not between Independent and National, nor between Independent and Labour (both $p^{\prime} s>$ .05). Participants with high sophistication showed a significantly higher preference for Labour candidates $(M=3.45, S E=0.09)$ over National candidates $(M=$ $3.20, S E=0.09 ; B=0.25, S E=.0 .05, p<.001)$. Similarly, participants of 
low sophistication preferred Labour candidates $(M=3.45, S E=0.09)$ over National candidates $(M=3.32, S E=0.09 ; B=0.12, S E=0.06, p<.001)$. This meant that high sophisticated participants and low politically sophisticated participants did not differ in their preference for Labour party candidates, but instead, high sophistication participants preferred National candidates less than those who demonstrate low sophisticated individuals. This finding was contrary to expectations, as it shows that highly sophisticated participants were more likely to use the peripheral cue of party when evaluating candidates than those who are lower in political sophistication. A figure depicting this interaction is shown in Figure 5. No further possible interactions were significant (all $\left.p^{\prime} s>.05\right)$.

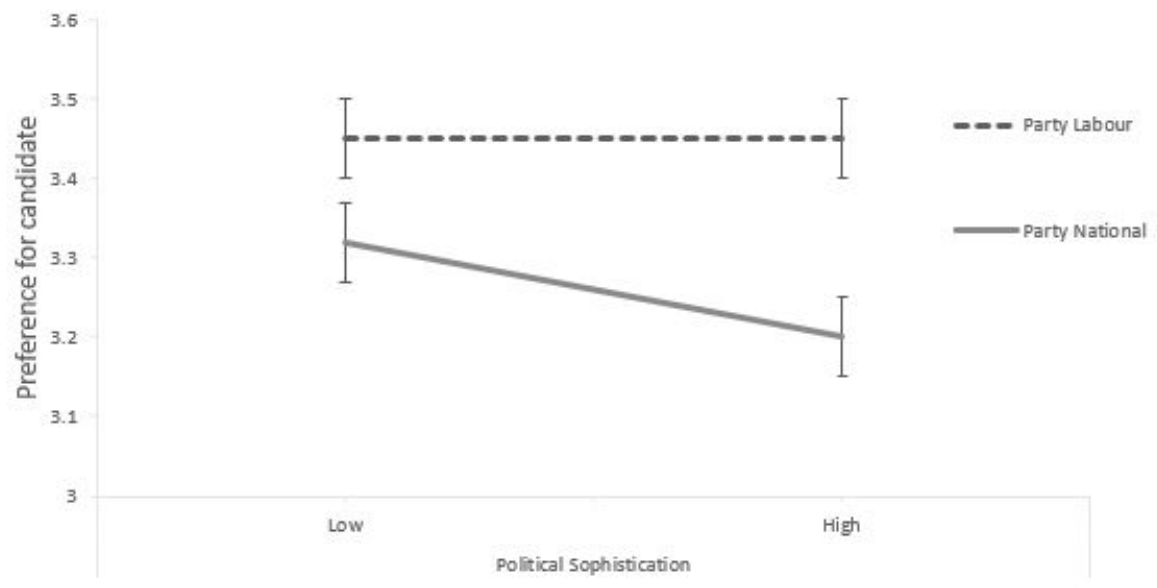

Figure 5. Preference for candidates, based on their party and participants' political sophistication 


\subsection{Exploratory analyses}

\subsubsection{Preference for individual policies by political sophistication}

I tested to see which of the individual policies differed in their preference by those with low and high political sophistication. For this analysis, I used an individual Linear Regression Model for each of the 48 policies to test if there were differences in preference between low and high sophistication for each of the individual policies. Normally a cut-off for statistical significance is set at the $5 \%$ level, however, repeated tests increase the probability of obtaining a false positive result. To overcome this issue, I applied a Bonferroni adjustment to each test; instead of the ordinary cutoff of .05 , analyses were considered statistically significant if the p-value falls below .001 10 For each analysis, variance due to changes in the party label were held constant. In total, eight of the individual conservative policies had statistically significant differences in favorability ratings between low and high political sophistication participants. Those who demonstrated high political sophistication were more likely to rate candidates with these conservative policies as less favorable compared to those who demonstrated low political knowledge across all of the items. Alternatively, two of the liberal policies showed statistically significant differences in scores for high vs. low sophistication groups. For all of these liberal policies, highly sophisticated participants rated candidates presented alongside them as more favorable compared to those who showed low political sophistication. For a list of these statistically significant policies, and their estimated marginal means for those with low and high political sophistication, see Table 12

\footnotetext{
${ }^{10}$ The new cutoff of .001 was calculated by taking the initial cutoff (.05), and dividing by the number of tests (48). The new cutoff was .00104, which was rounded to .001 .
} 


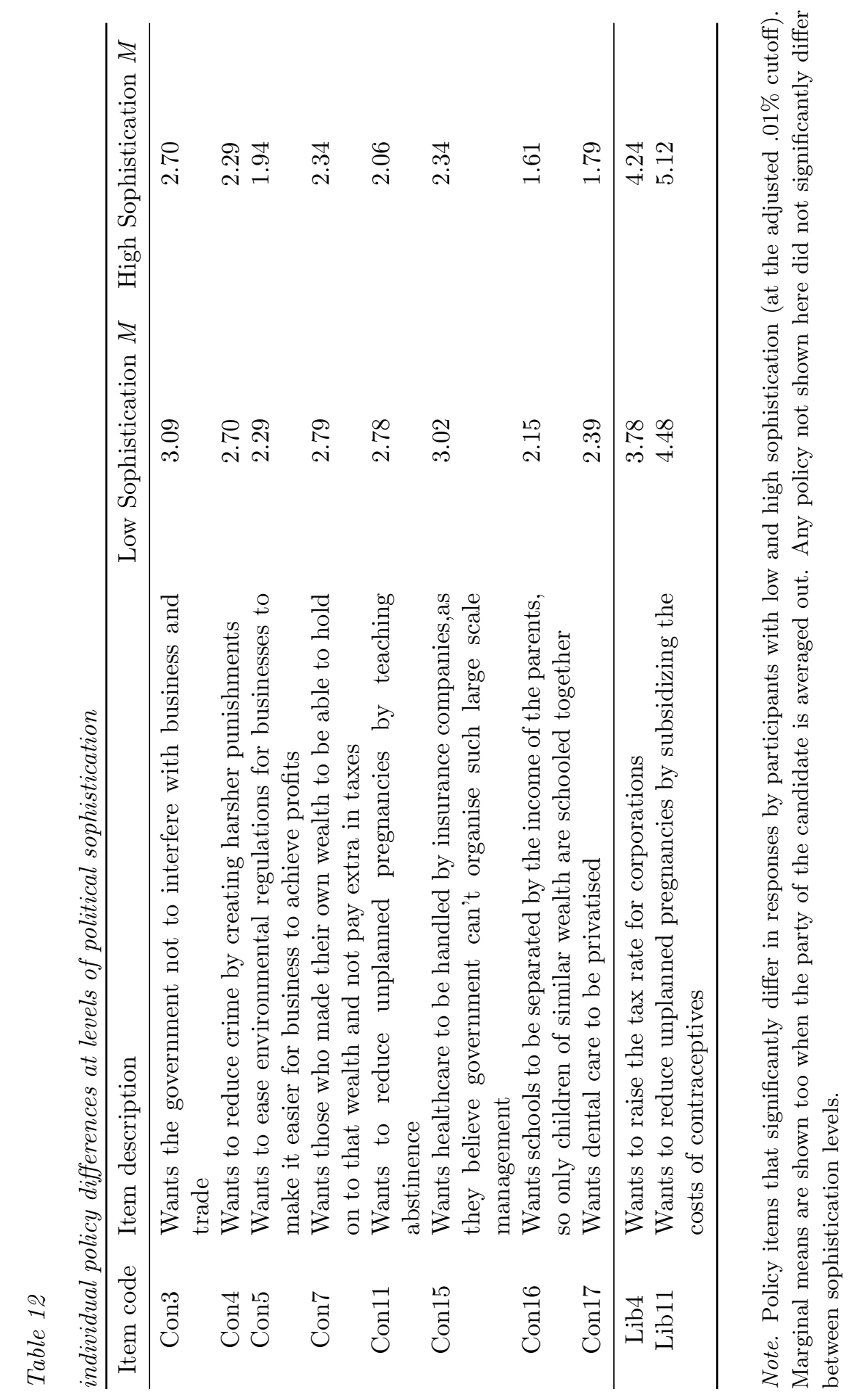




\subsubsection{Gender of faces}

I tested if there were any effect of the gender of the hypothetical candidates in how participants responded with their likelihood to vote for each candidate. I first regressed the perceived genders of the candidates' faces onto the response of participants, to which I found no significant differences $(B=-0.02, S E=$ $0.04, t(8177)=-0.66, p=.509) . \mathrm{I}$ then included a possible interaction between political sophistication and the gender of candidates' faces, to which there were also no significant effects (all $p^{\prime} s>.05$ ) 


\section{Discussion}

In this thesis, I aimed to test the Elaboration Likelihood Model in a voting context. Participants rated their preference for hypothetical candidates while the candidates' face, party and policies were manipulated. In accordance with the Elaboration Likelihood Model, participants that are more informed about politics should rely less on peripheral cues (party) and rely more on central cues (policy) when they rate their preference for each candidate, compared to those who are less engaged in politics (Petty \& Cacioppo, 1986).

\subsection{Ideology as a predictor}

In the present study, the policy of the hypothetical candidates significantly predicted candidate ratings. When grouped together, the policies represented either a conservative or liberal ideology. Candidates that were presented alongside liberal policies were more likely to be rated favourably compared to candidates presented with conservative policies. This was as expected, and is consistent with much of the previous research (Barber \& Pope, 2019, Chmielewski, 2012, Cohen, 2003; Malka \& Lelkes, 2010). Even in studies where party acts as a significant predictor, the ideological alignment between the participant and candidate or policy was still a significant predictor for preference ratings by participants (Barber \& Pope, 2019. Chmielewski, 2012 Cohen, 2003 Malka \& Lelkes, 2010). Participants in this study were more likely to prefer the liberal policies over conservative policies, which may reflect the relative liberalness of either the Wellington sample, or be a reflection of New Zealand's left-wing leanings at the time of the experiment (ElectionsNZ, 2020).

People are more likely to prefer candidates who both represent their own interests and will implement policies that will benefit the individual. The

participants in this study do not know if the candidates' policies would ever be 
enacted, but they are still swayed by the proposals of the candidates, nonetheless. With the limited amount of information available to participants, they may expect that if a candidate holds a liberal view on one topic, they will likely hold a liberal view on a variety of other subjects. Earlier (page 15), I argued that using the policy of candidates is to be engaging with the central cue because the policy is the best available indicator about the candidates in this study. This is also consistent with the expectation of the Rational Choice Model, that people will weigh the costs and benefits of useful information, and ignore irrelevant information when making decisions (Downs, 1957).

In the present study, many of the participants are likely liberal leaning, based on how they prefer candidates of different ideologies when the candidates were presented alongside the Independent label. It is disappointing that I could not include enough participants who leaned conservative, and it would be interesting to see if conservative participants have a similar preference for the conservative policies that participants in this study showed for liberal policies. Furthermore, including conservative participants would have helped to verify the conservative/liberal scale further.

In future, I would change the population group that I sampled from. Instead of using first-year psychology courses as participants, I would aim to include participants from the general population. One plan was to draw an equal number of conservative and liberal participants from the first-year psychology group, but early indications from a separate study showed that there were few participants who leaned conservative. There are other ways to include participants to get a broader share of conservative participants. One way includes the use of an online experimental program, such as Amazon Mechanical Turk (see Crowston, 2012). By conducting this study in a way that reaches a broader population, particularly from a variety of countries, this research may 
be able to make more meaningful claims against the previous literature.

\subsection{The use of Central Cues}

This study is the first to experimentally show that discrimination of preference for conservative and liberal candidates is larger for people that demonstrate greater sophistication. In this study, the ideology of the policies constitutes greater use of the central cue, so this interaction supports one part of the Elaboration Likelihood Model (Petty \& Cacioppo, 1986).

This finding supports previous studies (e.g. Barber \& Pope, 2019; Chmielewski, 2012 Fiske et al., 1983). For Chmielewski (2012), survey respondents with high political engagement were more likely to report policy as a cue when deciding who to vote for. Barber and Pope $(2019)$ described highly politically sophisticated participants as more likely to endorse policy proposals based on its merits and were better able to ignore the endorsement or opposition to the proposal. Finally, Fiske et al. (1983) showed that low politically sophisticated participants were swayed by the 'democratic' or 'communist' label of countries, compared to those that demonstrated high political sophistication.

Instead of one trial or response by participants, as was the case for both studies by Barber and Pope (2019), Chmielewski (2012), and Fiske et al. (1983), this study used multiple trials to test participants' responses across a variety of policies. This distinction allowed for some of participants' variability in responses to be accounted for. On top of including more trials per participant, this study also used a repeated measures design, as opposed to between subjects designs of the previous studies. The repeated measures design reduces between subject variance across conditions. Furthermore, this study was able to identify which of the individual policies showed greater differentiation of preference by both sophistication groups, while the previous studies only used one central 
policy or issue.

There are several possibilities for the interaction between policy preferences and political sophistication of participants. One possibility is that politically sophisticated people interpret policies differently to those who demonstrate low political sophistication. Politically sophisticated people may be better at interpreting the language of policy proposals, or they could be using their previous experiences (or biases) to inform possible outcomes that could occur, if the given policy were enacted. Take the example candidate proposal of "Wants schools to be separated by the income of the parents, so only children of similar wealth are schooled together." In this study, those who demonstrated low political sophistication rated this item more positively than those who showed high political sophistication. I could posit that someone who demonstrates low political sophistication is acting on an idea of freedom; that the government should not restrict parents to a standard schooling environment, and that parents who can afford a better education for their kids deserve to be able to do just that. Someone with greater political sophistication may believe that the societal benefits of educating everyone will outweigh the individual restrictions to those with wealth. I imagine that someone with greater political sophistication has previously accessed information about the education systems of other systems, and the societal benefits of educating more of the population and used that information to make their own ratings. However, this is all speculation, and a deeper variation to this study would need to be made to test possibilities like this.

A second reason for the central cue-political sophistication interaction relates to the possibility of demand-characteristics (Orne, 1996). Demand characteristics are when participants' behaviours change due to them being studies, particularly in an experimental setting (Orne, 1996). Furthermore, if participants become 
aware of the goal of the research then they may shift their behaviours, either implicitly or explicitly, to 'help' the researcher attain that goal (Orne, 1996). As this research tested the dynamic relationships between political sophistication and other variables, participants' awareness of the research goal, along with their own level of sophistication, may have introduced a specific confound to the experiment. If participants were aware of the goal of the study, they may have changed their responses to match what they believed the researcher wanted to find. Participants of low and high political knowledge may have differed in their response, but those with high political knowledge may have been more aware of what answers better constitute the research goal. An individual who is highly knowledgeable in politics may be better able to differentiate between the policies than someone who is not engaged in politics. Therefore, an awareness of the research goal may differentially affect the two groups of political sophistication, as those with a higher knowledge of politics may be better able to apply their awareness of the research intentions to their responses, which would result in the same pattern of data shown in this study.

The potentially confounding effect of demand-characteristics could be reduced by better hiding the intentions of the experiment, perhaps by adding a memory component to the study. Next time, I would ask participants to rate candidates, policies, and parties again, but would tell participants that this is a memory study, and that they need to recall the ratings that they gave each trial. This way, participants should be dis-incentivised from lying, and should choose the more valid option when evaluating candidates, as the valid option should be more likely to be remembered later in time.

The experimental design was well-balanced, which would have helped to reduce noise between participants. However, the study may also lack external validity. Much of politics in the real-world is complex, and there are more factors 
that people can use to determine who they vote for. Some of these factors could include the candidate's perceived expertise, job experience, or voting history on previous bills. Aside from these factors, some people may be unaware of why they prefer one candidate over another. Nevertheless, it is unlikely that one experimental design can capture the complex nature of electoral voting.

Further variables could be investigated in the future to try and gauge the influence that these factors have on voters. Similar to the designs of Cohen (2003) and Fiske et al. (1983), participants could read more elaborate vignettes about different voting candidates before making their judgements, much like how they would read in a news article or in an election brochure. These brochures could be standardised, while manipulating just one aspect that could affect voting behaviour. Much like how Fiske et al. (1983) manipulated whether Mauritius was introduced as 'communist' or 'democratic,' a narrative from a future study could manipulate the type of job experience that the candidate has, such as 'public school teacher' or 'former CEO.' Candidate's job history is just one of the many factors that could be investigated in future.

Even though high sophisticated individuals rated candidates with liberal policies as more favourable than those with conservative policies, this finding should not be interpreted to mean that a greater political sophistication means that a person is more likely to be liberal. This study was not able to test that specific question. While high politically sophisticated participants appeared more liberal in this sample, all of the participants in this study showed some preference for liberal policies, overall ${ }^{11}$ The earlier mentioned studies regarding political sophistication did not test how one's conservativeness interacted with their use of policy, at high and low levels of political sophistication. Testing this prediction would be a natural next step for this research, provided that an adequate number of conservative participants can be sampled. If this study were

\footnotetext{
${ }^{11}$ As the thirteen participants that leaned conservative were removed before data analysis.
} 
conducted with conservative participants, an opposite effect may occur, where higher political knowledge is associated with a higher preference for conservative policies for the conservative-leaning participants. There is no indication so far of how liberals and conservatives of differing political sophistication respond to liberal and conservative policy, so a future study that samples from both groups would be beneficial to test this prediction.

Some policies did not show any differences in endorsements between those with high and low political knowledge, which could be due to possible floor or ceiling effects of policies. A floor effect refers to an item that consistently had low responses by participants, while a ceiling effect had participants respond with high ratings to the item. Floor and ceiling effects can be determined by the skew of responses for each item. Some of the lack in differences for individual policy ratings between high and low politically sophisticated individuals may have been because the policies were too well preferred (ceiling effect) or not preferred at all (floor effect) by all participants. For example, policies concerning funding for the arts, rehabilitative opportunities for offenders, or the unemployment benefit did not differ in endorsement between high and low politically sophisticated participants. While the conservative and liberal policies were tested with a pilot group, the pilot group were only asked if they could understand the policy, and how conservative or liberal they believed the policy to be. If I were to extend this study, I would classify participants into conservative and liberal ideology and ask them to rate policies based on their preference. Further piloting of the policy stimuli would reduce floor and ceiling effects within the scale and would help create greater variation in scores between participants.

A few notes of caution about the analysis regarding the individual policies. Firstly, while the effect of party was held constant, there may still be variance in responding based on the condition assigned to participants. For some participants, 
one policy was presented with the National party while another participant saw the policy with the Labour party, and another with the Independent party. The influence of the associated party label may have biased responses. As there was not a significant effect for party, I am not sure if the preference for individual policies was affected here, but it would be beneficial to test these policies in a more naturalistic setting.

Secondly, while there was a significant difference between low and high political sophistication for certain policies, the mirrored policy failed to show a significant difference in many cases. This failure to find an opposite effect may be due to an issue in the policy items, which could be fixed with further piloting, as mentioned earlier. Overall, there was a significant difference in preference by participants of low and high sophistication for eight of the conservative policies, and two of the liberal policies. A possibility for the differences between mirrored pairs could be due to the framing of similar questions; the participants in this sample who demonstrated greater political sophistication may be more against the conservative policies than they are supportive of liberal policy.

This research found that those who are more politically sophisticated are more likely to engage with policy cues compared to those who are less politically knowledgeable. The finding may be useful in understanding how the voting population responds to political campaigns. Future research could utilize a similar design, but have participants respond to the rhetoric of political candidates or media figures ${ }^{12}$ Lately, news media have taken a renewed interest in the term 'political dog-whistling' which refers to when politicians or media figures say a statement that appears ordinary but, in effect, sends a specific message to partisan individuals. The term 'political dog-whistling' has been used since the early 2000s when referring to racial messaging from speakers (Bonevac, 2018 .

\footnotetext{
${ }^{12}$ Similar to the stimuli by Verkuyten and Maliepaard (2013), where they tell participants that a statement is said by a leading member of a given political party, without naming the actual politician.
} 
López, 2015). Much like how a literal dog-whistle can only be heard by dogs, a political dog-whistle acts as a coded-message that is only heard by a select audience, while most listeners miss the message.

In the present study, participants' political sophistication interacted with how they engaged with the policy cues. It could be possible that more-informed public are better able to disseminate between preferable and unpreferable policies. Take, for example, the policy of military spending. A political layperson may be interested in increased military spending to enforce the perception of their country becoming a strong nation, while a politically sophisticated person may base their decision on historical military actions of the country and evaluate possible flow-on effects of increased military funding, such as increased military action and disruption of other countries' sovereignty. What is most interesting about political dog-whistles is that two individuals may consume the same media but interpret the same message in different ways. Arguably, political dog-whistles benefit the speaker of the message, as the speaker can spread their ideas while having the luxury to feign ignorance if they are accosted for their message (Bonevac, 2018). Much of the design of the present study can be adapted to investigate the political dog-whistle, by substituting candidate policy proposals for speech excerpts made by hypothetical politicians. Political dog-whistles provide more complex central messages that need to be critically assessed by participants (for a recent experimental design that tests racial dog-whistling with participants, see Wetts \& Willer, 2019).

\subsection{Party as a predictor}

Participants of high and low political knowledge both partially used party cues to rate the politicians, as shown through the overall preference for Labour candidates over National candidates. This result is consistent with the previous 
research of Chmielewski (2012), Cohen (2003), and Malka and Lelkes (2010), although it should be noted that this effect occurred only between the National and Labour candidates, and the effect was not strong enough between both those two parties and the baseline, Independent candidates.

Participants using the party information when evaluating political candidates is an expectation for Self-Categorisation Theory (Turner \& Reynolds, 2011), if we were to expect that the liberal leaning sample does categorise themselves as Labour party members. During the study, I had asked participants who they were planning to vote for, to which a majority reported they intended to vote for either the Labour party or a Labour candidate. However, participants were not asked a direct question of how affiliated they were to the given parties. Asking participants who they intend to vote for may not capture a person's true party affiliation, as someone's intention to vote for a party could be due to other context-dependant factors ${ }^{13}$ In future, I would suggest using more elaborate measures of partisanship and party affiliation.

Though this study's party effect only was only found between the two major parties, and not between the parties and the independent label, Cohen (2003) found a significant difference in preference between baseline measures and both Democratic and Republican party labels (and similar patterns were found for Fiske et al., 1983 Malka \& Lelkes, 2010). The policy proposals used by Cohen (2003) were more complex than the policies used in the present study. The policy proposals that Cohen $(2003)$ created were crafted to seem like a newspaper report and included a variety of components to each policy. Potentially, the complexity of the policy in Cohen's (2003) study reduced participants' reliance on the central policy, and so participants relied on the party cue, in lieu of the

\footnotetext{
${ }^{13}$ Participation for this study was one month before the 2020 New Zealand General Election. 2020 was a strange year for politics in many countries, due to the Covid-19 pandemic. During 2020, the Labour Party soared in popularity, so a participant's intention to vote for the Labour Party may not be due to a stronger party affiliation with that party and could be due to how the party responded to the pandemic.
} 
policy cue. In the context of the Elaboration Likelihood Model, ambiguity of the central cue may lead to greater use of peripheral cues.

The present study used simplified policy cues. In fact, the policy cues were tested with a separate sample to ensure that the policies were easy to understand, as I did not know if the first-year university sample were well-versed with some of the political terms used in the policies. To overcome this discrepancy, another study could present a collection of policies with each of the hypothetical candidates, instead of including only one 'main' policy for each candidate. The policy collections could be manipulated to be highly liberal, highly conservative, or a combination of both to add a level of ambiguity among policy sets. By manipulating the complexity of the policy proposals of each candidate, one could determine if a reliance on peripheral cues occurs as an adaptive process to a complex or ambiguous central cue and can measure where a possible 'tipping point' occurs between complex and simple cues. The more complex policy information of Cohen (2003), Fiske et al. (1983), and Malka and Lelkes (2010) may explain why the previous literature found a difference between their baseline measure and party manipulations while this present study did not.

Much of the previously cited research was drawn from the United States and, as such, there may be distinct differences between American and New Zealand samples. For instance, the political systems between the two countries differ quite dramatically; the Presidential elections of the United States is decided through the Electoral College, which deters voting for candidates that are not associated with one of the two dominating parties (Kimberling, 1992). In the United States, voting for a third-party candidate usually pulls votes away from the major-party candidate who is most ideologically similar to the third-party candidate (Kimberling, 1992). New Zealand operates under the MMP election style, where multiple parties can govern with a coalition agreement. Under 
MMP, voting for a third-party usually does not take votes away from other candidates of a similar ideology, as the ideologically similar parties are likely to form a coalition agreement if the parties' combined seats make up a majority of the seats in parliament (Boston et al., 1996). Due to the varying electoral processes of New Zealand and the United States, participants that are sampled from these countries may differ in their reliance on party-related cues. From a Self-Categorisation theory perspective, the group function of the party label may be more important to a citizen of a two-party system, and may therefore act as a more distracting cue for them. There are possible ways to overcome the differences in electoral systems between New Zealand and the United States. A measure for participant partisanship could be included, and participants from the New Zealand sample could be drawn from the extreme ends of the partisanship spectrum. Even though an electoral system may produce different levels of average partisanship, sourcing participants based on their partisanship may overcome systematic differences between participants of different political systems.

\subsection{The use of peripheral cues}

When comparing the use of party-related cues between those of high and low political knowledge, there was a significant difference in how the groups used party cues to inform their decision. The effect opposed what was hypothesised; those who were more politically sophisticated were more likely to prefer candidates who were presented with the Labour logo, compared to those with Independent or National Party labels,

The present study's results differ from those of Chmielewski (2012). Chmielewski (2012) used a survey design and asked participants several questions regarding who they voted for in the 2004 and 2008 United States Presidential Elections, as 
well as the 2006 Gubernatorial Elections. Survey respondents were also asked questions related to their political engagement. Chmielewski (2012) reported that those that were more politically engaged were more likely to rely on candidates' central cues such as candidates' favorability and image, while those low in engagement relied on their own party preference when rating candidates. As mentioned earlier, Chmielewski (2012) used simple correlations to conduct the analysis, and a more sophisticated analysis should have been conducted to compare the politically engaged groups for each of the above variables.

The findings of this present study partially support the Elaboration Likelihood Model. On one point, the increased use of policy by people who demonstrate high political sophistication supports the argument that greater knowledge of a subject area encourages greater use of central cues. However, the findings from the main analysis did not support any argument that poorer subject knowledge enabled greater use of peripheral cues. In fact, the significant interaction was in the opposite direction to what is expected by the Elaboration Likelihood Model. The discrepancy between the present study's findings and the expectations of the Elaboration Likelihood Model could show that the model is not viable in a political setting.

The interaction whereby higher political sophistication was associated with more use of the party label, rather than less, could indicate that party may be wrongly categorised as a peripheral cue and that group membership could instead be utilised as a central cue. Much of the theoretical reasoning for party being used as a peripheral cue came from an assumption that participants who solely rely on party labels as an indicator for voting would be hurting their own cause, as the policy information is a better indicator for future governance under that candidate.

There are cases in the real-world when a rational voting choice approach 
would be using the party information as opposed to the policy information. Take, for example, if a candidate or party is known to lie about their campaign promises, or if the party has a greater track-record of being able to implement a policy. If a voter does not believe that a candidate would actually implement a given policy, then it may be more beneficial to the voter to fall back on the party that they trust the most in elections. People may prefer one party over another due to the party's experience, their ability to handle a crisis, or their overall ideological approach. While one candidate may be pushing for a policy that is ideologically unpalatable to the participant, the rest of their inferred policies that the extended party would achieve may produce a net-positive for ideological advances in the mind of the voter. The Elaboration Likelihood Model has previously been criticised for its lack of robustness. Although publications by the model authors report findings that consistently support the model (see Petty \& Cacioppo, 1986), other replications have shown that the model cannot endure minor changes to either the central or peripheral cues, or to the subject-sophistication measure (Kitchen et al., 2014). Furthermore, a direct replication of a study by Cacioppo and Petty (1989), but with a younger sample group, failed to show any difference in cue usage between low and highly sophisticated participants (Te'eni-Harari et al., 2007). Also, there is no precise way to define a construct as either a central or peripheral cue, as some constructs' type of cue may be context-dependent (Petty \& Cacioppo, 1986). Petty and Cacioppo (1986) have also stated that central and peripheral cues are not categorically different but rather points on a continuous spectrum. While the classification of having central and peripheral cues on a spectrum is theoretically plausible, it does make the theory unfalsifiable. Overall, this study's findings do not fully support the principles of the Elaboration Likelihood Model.

The findings that participants reliably use policy information more than 
party information when both cues are available is useful for election campaigns and election organisers. Election campaigners may become complacent by believing that people will consistently vote for the same party at each election. In this study, the party information did partially influence preference for candidates however, the liberalness or conservativeness for each policy was a stronger predictor for candidate' preference. Of course, the ideological differences between the liberal and conservative ideologies were quite dramatic, which may mean that more distinct policies are likely to receive a response by participants, and that middle-of-the-road policies may not be preferred by the voter. A future study could adapt the current study to investigate if ideologically moderate policies are preferred by voters over ideologically extreme policies, or vice-versa.

Finally, this study could benefit from having more ideological distinction between parties. The New Zealand Labour Party is considered more liberal than the New Zealand National Party however, outlets have categorised both parties as being relatively centrist on the ideological spectrum (Spinoff, 2020). A future study could include more ideologically opposing parties. For example, the New Zealand Green Party is considered a much more liberal party than the New Zealand Labour Party (Spinoff, 2020).

\subsection{Evaluation of the scales}

\subsubsection{Political knowledge}

The present study operationalised political knowledge through a 20-item multiple-choice quiz that was framed around New Zealand's current and historical political atmosphere. Political knowledge tests have previously been used to estimate political engagement in participants, as many have done before (Iyengar, 1986 Luskin, 1987, Patterson \& McClure, 1976, Price \& Zaller, 1993, J. R. Zaller, 1986, 1992). One issue with these scales is that they are only usable for 
a small amount of time before they become outdated. This issue means that there is no valid scale for political engagement that can be used across studies, which reduces reliability across studies for this measure. The items used in this quiz showed good discrimination scores and relatively good inter-item reliability ratings. The relatively high reliability is encouraging, as this scale was a newly developed quiz. While the Cronbach's alpha for the political quiz did not reach the standard cut-off for acceptable reliability, the score for the scale was close to acceptable, which is encouraging. In future, the scale could benefit from prior testing with a separate sample. The quiz could also be adapted to only include questions that do not change much over time. As of writing, many of the questions of the political sophistication measure are now invalid, due to the changes following New Zealand's General Election of 2020. For example, the questions that asked participants about the allocation of seats in parliament showed strong reliability within the scale. Questions such as these included how many parties were currently in government, or for participants to identify how many seats certain parties held at the time of the quiz. There is a need to create a reliable political sophistication quiz for a New Zealand sample, and then create a measure of political knowledge that can be used across samples of different political systems.

Categorising participants into low and high levels of political sophistication may be a crude measure that does not capture the complex world of politics, as the relationship between party cue usage and political sophistication may not be linear. Instead of a linear relationship, the relationship between the two variables may instead be quadratic. For example, a person with very low political sophistication may have little use for party labels, as they are not engaged with politics enough to know what the parties represent. A person with low engagement may use party information the least. Someone who is 
moderately engaged in politics may make use of party over policy as they may have identified themselves as a member of a party, as with Self-Categorisation Theory (Hogg et al., 1995; Turner \& Reynolds, 2011). Someone who is moderately sophisticated with respect to politics may use the party cues the most to inform their decision. A person with high sophistication may be able to make better use of the policy information, and can put aside their party preference if they see the policy as beneficial or detrimental to their own ideological goals 14

\subsubsection{Conservative/Liberal scale}

In addition to the political sophistication measure, this study also 'created' a Conservative/Liberal policy scale, partially adapted from previous scales (Eysenck, 1995 Kerlinger, 1984 Sidanius, 1976a, 1976b). These policy items were piloted with a separate sample, to determine if the members of the population group both understood the items and could differentiate the items to be conservative or liberal in nature. Piloting was conducted so that my own assumptions that an item would be considered liberal or conservative were verified by the population. Piloting was somewhat successful; several of the items were removed following pilot-testing, as they were considered neither liberal nor conservative by the pilot sample. However, piloting would have been stronger if there were measures of preference that each participant had for the policy being enacted. In the present study, many of the items had high or low mean preferences from participants, with very little variation across participants, which indicates the presence of ceiling or floor effects for some items. Ceiling or floor effects can reduce variability in responses and could have potentially diminished the interaction effect between political sophistication and ideology. The liberal/conservative scale showed very strong measures of reliability, both through the Cronbach's

\footnotetext{
${ }^{14}$ This present study was not able to test this goal, as there was not enough variation in scores for the political sophistication measure to separate participants into three unique groups. Also, a much higher sample size would be needed to test this.
} 
Reliability Analysis and from the results of the Exploratory Factor Analysis, but the presence of floor and ceiling effects could contribute to the reliability being quite so high. It would be good to further test this scale through a survey design, to reduce the possible contamination effects of the experimental design.

Finally, political ideology is a complex construct, and many different facets of interest fall under the umbrella of liberal and conservative ideology, and what is considered a liberal or conservative policy can vary across countries. Furthermore, participants may vary on their conservative or liberal leanings they are across different societal issues. For example, the policies in this study covered issues such as welfare, health, education, crime, and economics, and it is possible that Participants may appear more conservative on one issue and more liberal on another. For example, if people are expected to vary across issues, then much of the variation is unaccounted for by averaging out participants' responses across all liberal or conservative policies. In future, I would include an equal number of policies for each social aspect and would account for the variation across social issues by including the social 'type' of policy (e.g., welfare, health, education, etc.) as a nested variable inside of the overall ideology.

\subsection{Strengths and Conclusions}

This study has made several advances for the literature. Firstly, I developed and tested two new scales under different conditions. Secondly, this study used an experimental design that measured participants over multiple trials, which is uncommon for political research. Thirdly, the findings of this study did not follow the pattern of results for party as studies in the United States had found (e.g. Chmielewski, 2012, Cohen, 2003 Verkuyten \& Maliepaard, 2013) which sets up for a possible research of voter partisanship across countries of different

political systems. Finally, I tested if the Elaboration Likelihood Model could be 
applied to the context of voting, for which I found partial support.

There is still much more that can be researched using the design of this experiment as a starting point. For example, participants' need for cognition could be incorporated into the model, and may explain a person's likelihood to use central cues, over and above their political sophistication (e.g. Cacioppo et al., 1984). Also, the relevance of policies could be manipulated to be either of high personal relevance to participants, or of low personal relevance, with an expectation that as personal relevance increases, so too does their likelihood of using the central cue (Petty \& Cacioppo, 1979). As mentioned above, the complexities of policies could be manipulated to test if use of peripheral cues is an adaptive process, to overcome a complex or ambiguous central cue. The peripheral cue could also be adapted to represent other candidates' cues in the real-world, such as the charisma of candidates. Finally, this research could lead well into an analysis of political discourse, through the avenue of 'political dog-whistles.'

In this study, I aimed to apply the Elaboration Likelihood Model to a political context. This study was the first to do so, both in a New Zealand context, and as an experimental design. I developed a measure of political sophistication in a New Zealand context and created a unique measure of a person's liberal or conservative ideological leanings. The experimental design can be adapted in multiple ways to test various theories or variables that are related to voter choice, and I provided possible alterations for the future studies. This study found partial support for the Elaboration Likelihood Model, and discrepancies between the theory's predictions and the present study findings can be investigated further in future studies. 


\section{References}

Abrams, D. E., \& Hogg, M. A. (1990). Social identity theory: Constructive and critical advances. Springer-Verlag Publishing.

Aldrich, J. H. (1993). Rational choice and turnout. American journal of political science, 246-278.

Andersen, D. J., \& Ditonto, T. (2020). The importance of candidate sex and partisan preference over time: A multiday study of voter decision making. The Journal of Politics, 82(4), 1337-1353.

Arceneaux, K., \& Vander Wielen, R. J. (2013). The effects of need for cognition and need for affect on partisan evaluations. Political Psychology, 34(1), $23-42$.

Barber, M., \& Pope, J. C. (2019). Does party trump ideology? disentangling party and ideology in america. The American Political Science Review, $113(1), 38-54$.

Bartels, L. M. (1996). Uninformed votes: Information effects in presidential elections. American Journal of Political Science, 194-230.

Bartels, L. M. (2002). Beyond the running tally: Partisan bias in political perceptions. Political behavior, 24(2), 117-150.

Baysu, G., \& Swyngedouw, M. (2020). What determines voting behaviors of muslim minorities in europe: Muslim identity or left-right ideology? Political Psychology, 41(5), 837-860.

Bizer, G. Y., Krosnick, J. A., Petty, R. E., Rucker, D. D., \& Wheeler, S. C. (2000). Need for cognition and need to evaluate in the 1998 national election survey pilot study. National election studies report.

Blais, A. (2000). To vote or not to vote?: The merits and limits of rational choice theory. University of Pittsburgh Press. 
Bonevac, D. A. (2018). Association arguments: Dog whistling in the dark. Academic Questions, 31(2), 157-166.

Boston, J., Levine, S., \& Roberts, N. (1996). New Zealand under MMP: A new politics? Auckland University Press.

Cacioppo, J. T., \& Petty, R. E. (1980). Persuasiveness of communications is affected by exposure frequency and message quality: A theoretical and empirical analysis of persisting attitude change. Current issues and research in advertising, 3(1), 97-122.

Cacioppo, J. T., \& Petty, R. E. (1989). Effects of message repetition on argument processing, recall, and persuasion. Basic and Applied Social Psychology, $10(1), 3-12$.

Cacioppo, J. T., Petty, R. E., \& Feng Kao, C. (1984). The efficient assessment of need for cognition. Journal of personality assessment, 48(3), 306-307.

Cacioppo, J. T., Petty, R. E., Kao, C. F., \& Rodriguez, R. (1986). Central and peripheral routes to persuasion: An individual difference perspective. Journal of personality and social psychology, 51(5), 1032.

Carpini, M. X. D., \& Keeter, S. (1996). What americans know about politics and why it matters. Yale University Press.

Chmielewski, T. L. (2012). Applying the elaboration likelihood model to voting. International journal of interdisciplinary social sciences, 6(10).

Chong, D. (2013). Degrees of rationality in politics. The oxford handbook of political psychology.

Citrin, J., \& Green, D. P. (1990). The self-interest motive in american public opinion. Research in micropolitics, 3(1), 1-28.

Cohen, G. L. (2003). Party over policy: The dominating impact of group influence on political beliefs. Journal of personality and social psychology, 85(5), 808. 
Conlisk, J. (1996). Why bounded rationality? Journal of economic literature, $34(2), 669-700$.

Converse, P. E. (2006). The nature of belief systems in mass publics (1964). Critical review, 18(1-3), 1-74.

Cronbach, L. J. (1943). On estimates of test reliability. Journal of Educational Psychology, 34(8), 485.

Cronbach, L. J. (1951). Coefficient alpha and the internal structure of tests. psychometrika, 16(3), 297-334.

Crowston, K. (2012). Amazon mechanical turk: A research tool for organizations and information systems scholars. Shaping the future of ict research. methods and approaches (pp. 210-221). Springer.

Downs, A. (1957). An economic theory of democracy. Harper New York.

ElectionsNZ. (2020). 2020 general election official results. https://elections.nz/ media-and-news/2020/2020-general-election-official-results/

Eysenck, H. j. (1995). In Robinson, John P and Shaver, Phillip R and Wrightsman, Lawrence S (Ed.), Measures of personality and social psychological attitudes: Measures of social psychological attitudes. Academic Press.

Feddersen, T. J. (2004). Rational choice theory and the paradox of not voting. Journal of Economic perspectives, 18(1), 99-112.

Feldman, S. (2013). Political ideology. In L. Huddy, D. O. Sears, \& J. S. Levy (Eds.), The Oxford handbook of political psychology. Oxford University Press.

Feldman, S. (2003). Values, ideology, and the structure of political attitudes. In L. Huddy, D. O. Sears, \& J. S. Levy (Eds.), The Oxford handbook of political psychology. Oxford University Press. 
Fiske, S. T., Kinder, D. R., \& Larter, W. M. (1983). The novice and the expert: Knowledge-based strategies in political cognition. Journal of experimental social psychology, 19(4), 381-400.

Harmel, R., \& Janda, K. (1994). An integrated theory of party goals and party change. Journal of theoretical politics, 6(3), 259-287.

Haugtvedt, C. P., \& Petty, R. E. (1992). Personality and persuasion: Need for cognition moderates the persistence and resistance of attitude changes. Journal of Personality and Social psychology, 63(2), 308.

Haugtvedt, C. P., Petty, R. E., Cacioppo, J. T., \& Steidley, T. (1988). Personality and ad effectiveness: Exploring the utility of need for cognition. $A C R$ North American Advances.

Hennessy, M., Delli Carpini, M. X., Blank, M. B., Winneg, K., \& Jamieson, K. H. (2015). Using psychological theory to predict voting intentions. Journal of Community Psychology, 43(4), 466-483.

Heywood, A. (2017). Political ideologies: An introduction. Macmillan International Higher Education.

Hogg, M. A., Terry, D. J., \& White, K. M. (1995). A tale of two theories: A critical comparison of identity theory with social identity theory. Social psychology quarterly, 255-269.

Holm, J. D., \& Robinson, J. P. (1978). Ideological identification and the american voter. Public Opinion Quarterly, 42(2), 235-246.

Huddy, L. (2001). From social to political identity: A critical examination of social identity theory. Political psychology, 22(1), 127-156.

Huddy, L., Sears, D. O., \& Levy, J. S. (2013). The oxford handbook of political psychology. Oxford University Press. 
Iyengar, S. (1986). In Robinson, John P and Shaver, Phillip R and Wrightsman, Lawrence S (Ed.), Measures of personality and social psychological attitudes: Measures of social psychological attitudes. Academic Press.

Jost, J. T. (2006). The end of the end of ideology. American psychologist, 61(7), 651.

Jost, J. T., \& Sidanius, J. (2004). Political psychology: An introduction. Political psychology: Key readings, 1-17.

Kalmoe, N. P. (2020). Uses and abuses of ideology in political psychology. Political Psychology, 41(4), 771-793.

Karras, T., Laine, S., \& Aila, T. (2018). A style-based generator architecture for generative adversarial networks. CoRR, abs/1812.04948. http://arxiv. org/abs/1812.04948

Kerlinger, F. N. (1984). Liberalism and conservatism: The nature and structure of social attitudes (Vol. 1). Lawrence Erlbaum Assoc Incorporated.

Kimberling, W. C. (1992). The electoral college. National Clearinghouse on Election Administration, Federal Election Commission.

Kinder, D. R., \& Kiewiet, D. R. (1979). Economic discontent and political behavior: The role of personal grievances and collective economic judgments in congressional voting. American Journal of Political Science, 495-527.

Kitchen, P. J., Kerr, G., Schultz, D. E., McColl, R., \& Pals, H. (2014). The elaboration likelihood model: Review, critique and research agenda. European Journal of Marketing.

Klecka, W. R., Iversen, G. R., \& Klecka, W. R. (1980). Discriminant analysis (Vol. 19). Sage.

Leippe, M. R., \& Elkin, R. A. (1987). When motives clash: Issue involvement and response involvement as determinants of persuasion. Journal of Personality and Social psychology, 52(2), 269. 
Lelkes, Y. (2021). Policy over party: Comparing the effects of candidate ideology and party on affective polarization. Political Science Research and Methods, 9(1), 189-196.

López, I. H. (2015). Dog whistle politics: How coded racial appeals have reinvented racism and wrecked the middle class. Oxford University Press.

Luskin, R. C. (1987). Measuring political sophistication. American journal of political science, 856-899.

Malka, A., \& Lelkes, Y. (2010). More than ideology: Conservative-liberal identity and receptivity to political cues. Social Justice Research, 23(2), 156-188.

Orne, M. T. (1996). Demand characteristics. Introducing psychological research. Springer.

Patterson, T. E., \& McClure, R. D. (1976). Television and the less-interested voter: The costs of an informed electorate. The Annals of the American Academy of Political and Social Science, 425(1), 88-97.

Peirce, J. W. (2007). Psychopy - psychophysics software in python. Journal of neuroscience methods, 162(1-2), 8-13.

Petty, R. E., \& Cacioppo, J. T. (1979). Issue involvement can increase or decrease persuasion by enhancing message-relevant cognitive responses. Journal of personality and social psychology, 37(10), 1915.

Petty, R. E., \& Cacioppo, J. T. (1986). The elaboration likelihood model of persuasion. Communication and persuasion. Springer.

Petty, R. E., Harkins, S. G., \& Williams, K. D. (1980). The effects of group diffusion of cognitive effort on attitudes: An information-processing view. Journal of personality and social psychology, 38(1), 81.

Petty, R. E., Wells, G. L., \& Brock, T. C. (1976). Distraction can enhance or reduce yielding to propaganda: Thought disruption versus effort justification. Journal of Personality and social Psychology, 34(5), 874. 
Plutzer, E., \& Zipp, J. F. (1996). Identity politics, partisanship, and voting for women candidates. Public Opinion Quarterly, 60(1), 30-57.

Price, V., \& Zaller, J. (1993). Who gets the news? alternative measures of news reception and their implications for research. Public opinion quarterly, 57(2), 133-164.

Pronin, E. (2009). The introspection illusion. Advances in experimental social psychology, 41, 1-67.

R Core Team. (2021). R: A language and environment for statistical computing. R Foundation for Statistical Computing. Vienna, Austria. http://www. R-project.org/

Robinson, J. P., Shaver, P. R., \& Wrightsman, L. S. (2013). Measures of personality and social psychological attitudes: Measures of social psychological attitudes (Vol. 1). Academic Press.

Rubinstein, A. (1998). Modeling bounded rationality. MIT press.

Sakamoto, Y., Ishiguro, M., \& Kitagawa, G. (1986). Akaike information criterion statistics. Dordrecht, The Netherlands: D. Reidel, 81(10.5555), 26853.

Satz, D., \& Ferejohn, J. (1994). Rational choice and social theory. The Journal of philosophy, 91(2), 71-87.

Sears, D. O., \& Funk, C. L. (1991). The role of self-interest in social and political attitudes. Advances in experimental social psychology, 24, 1-91.

Sibley, C. G., \& Wilson, M. S. (2007). Political attitudes and the ideology of equality: Differentiating support for liberal and conservative political parties in new zealand. New Zealand Journal of Psychology, 36(2), 72.

Sidanius, J. (1976a). Further tests of a swedish scale of conservatism. Stockholm: Department of Psychology, University of Stockholm.

Sidanius, J. (1976b). A swedish scale of conservatism. Stockholm: Department of Psychology, University of Stockholm. 
Simon, H. A. (1990). Bounded rationality. Utility and probability. Springer.

Spinoff, T. (2020). The complete guide to NZ Election 2020. https://policy.nz/

Srull, T. K. (1983). The role of prior knowledge in the acquisition, retention, and use of new information. ACR North American Advances.

Stambough, S. J., \& O'Regan, V. R. (2003). Cue voting: Which women vote for women senate candidates? Politics \&3 Policy, 31(2), 216-231.

Te'eni-Harari, T., Lampert, S. I., \& Lehman-Wilzig, S. (2007). Information processing of advertising among young people: The elaboration likelihood model as applied to youth. Journal of Advertising Research, 47(3), $326-340$.

Terry, D. J., \& Hogg, M. A. (1996). Group norms and the attitude-behavior relationship: A role for group identification. Personality and social psychology bulletin, 22(8), 776-793.

Transue, J. E. (2007). Identity salience, identity acceptance, and racial policy attitudes: American national identity as a uniting force. American Journal of Political Science, 51(1), 78-91.

Turner, J. C., \& Reynolds, K. J. (2011). Self-categorization theory. Handbook of theories in social psychology, 2(1), 399-417.

Tversky, A., \& Thaler, R. H. (1990). Anomalies: Preference reversals. Journal of Economic Perspectives, 4(2), 201-211.

Verkuyten, M., \& Maliepaard, M. (2013). A further test of the "party over policy" effect: Political leadership and ethnic minority policies. Basic and applied social psychology, 35(3), 241-248.

Wetts, R., \& Willer, R. (2019). Who is called by the dog whistle? experimental evidence that racial resentment and political ideology condition responses to racially encoded messages. Socius, 5, 2378023119866268. 
Wood, W., \& Kallgren, C. A. (1988). Communicator attributes and persuasion: Recipients' access to attitude-relevant information in memory. Personality and Social Psychology Bulletin, 14(1), 172-182.

Wood, W., Kallgren, C. A., \& Preisler, R. M. (1985). Access to attitude-relevant information in memory as a determinant of persuasion: The role of message attributes. Journal of Experimental Social Psychology, 21(1), $73-85$.

Zaller, J. R. (1986). Analysis of information items on the 1985 NES pilot study. University of Michigan.

Zaller, J. R. (1992). The nature and origins of mass opinion. Cambridge university press. 


\section{A $\mathbf{R}$ code}

Collection of $\mathrm{R}$ code - denotes a note, values without a at the beginning denotes a function performed

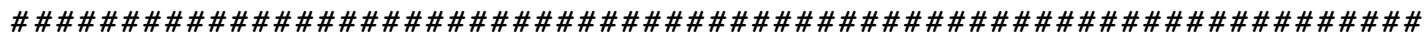
\#\#Part 1 - Compile data frame 


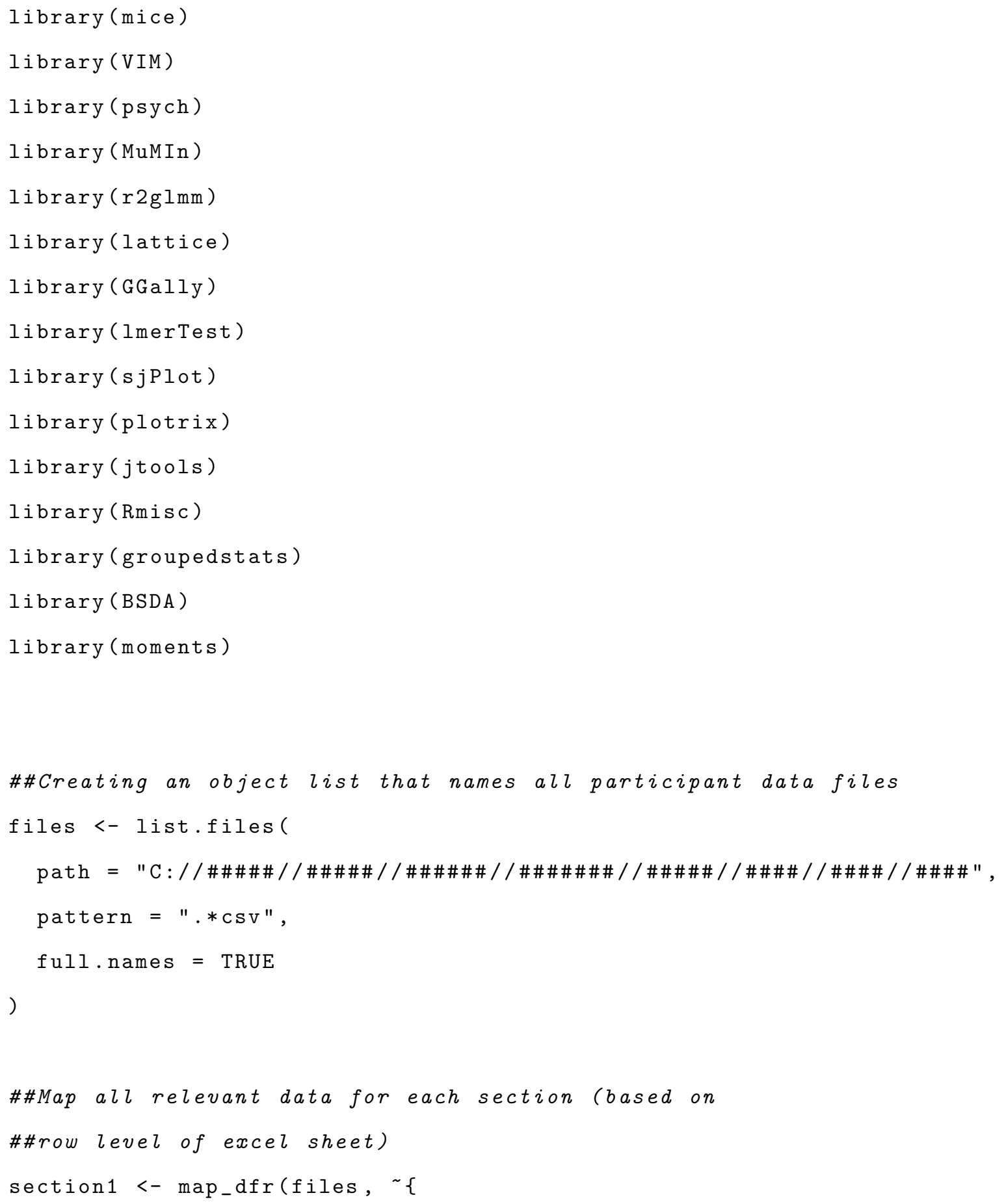




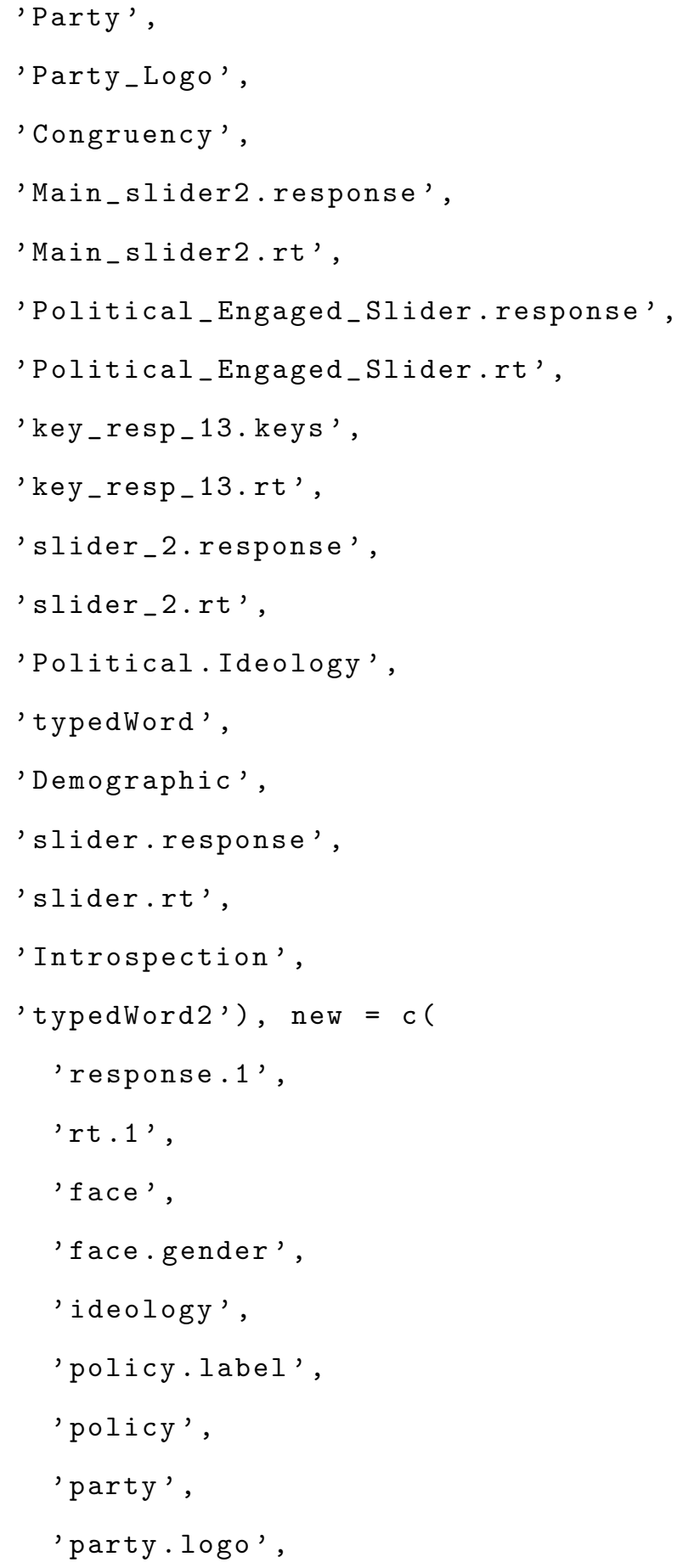




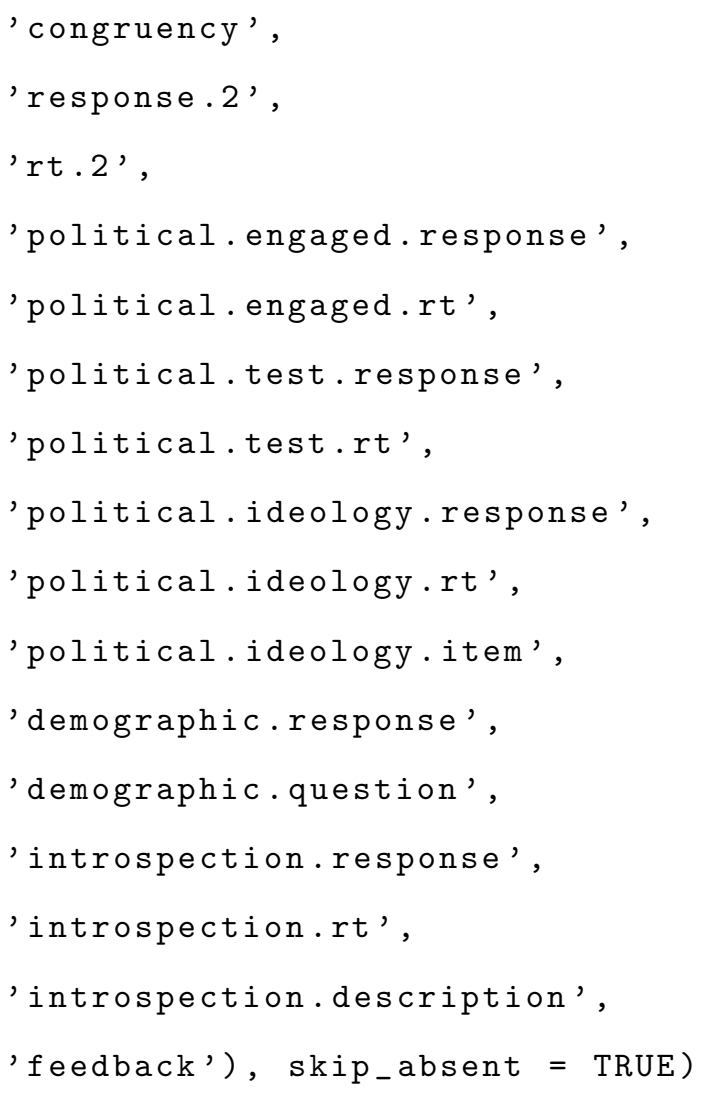




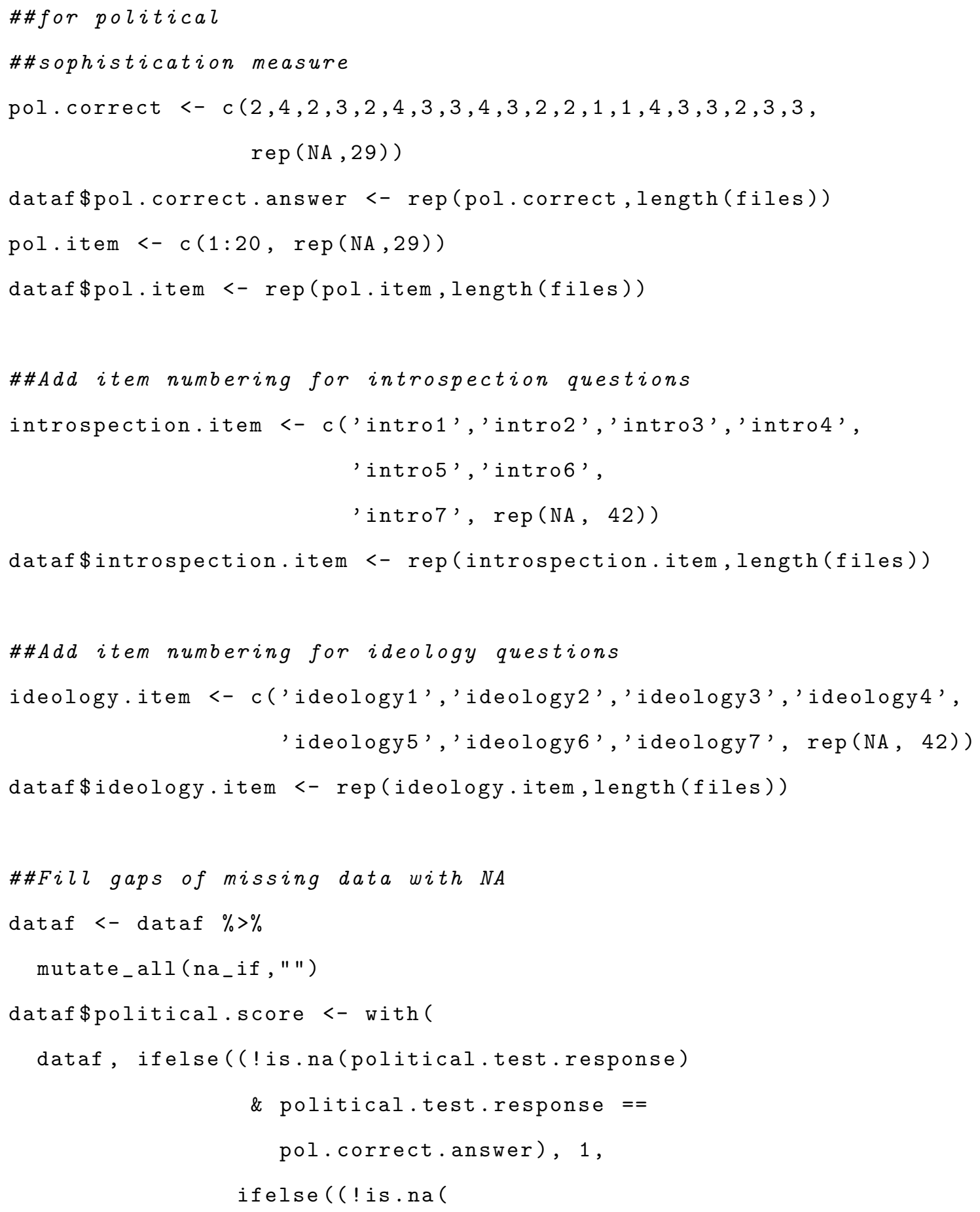




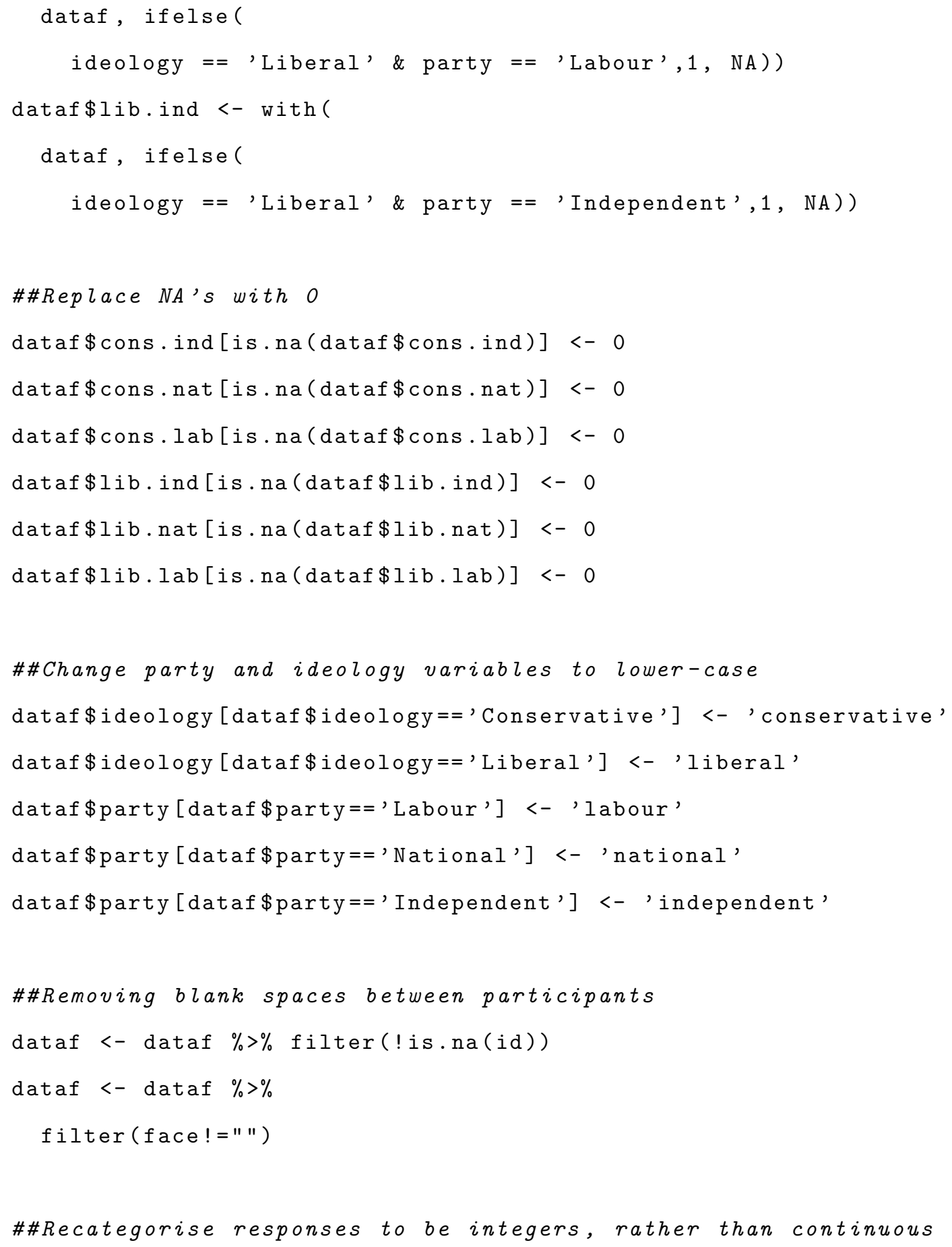




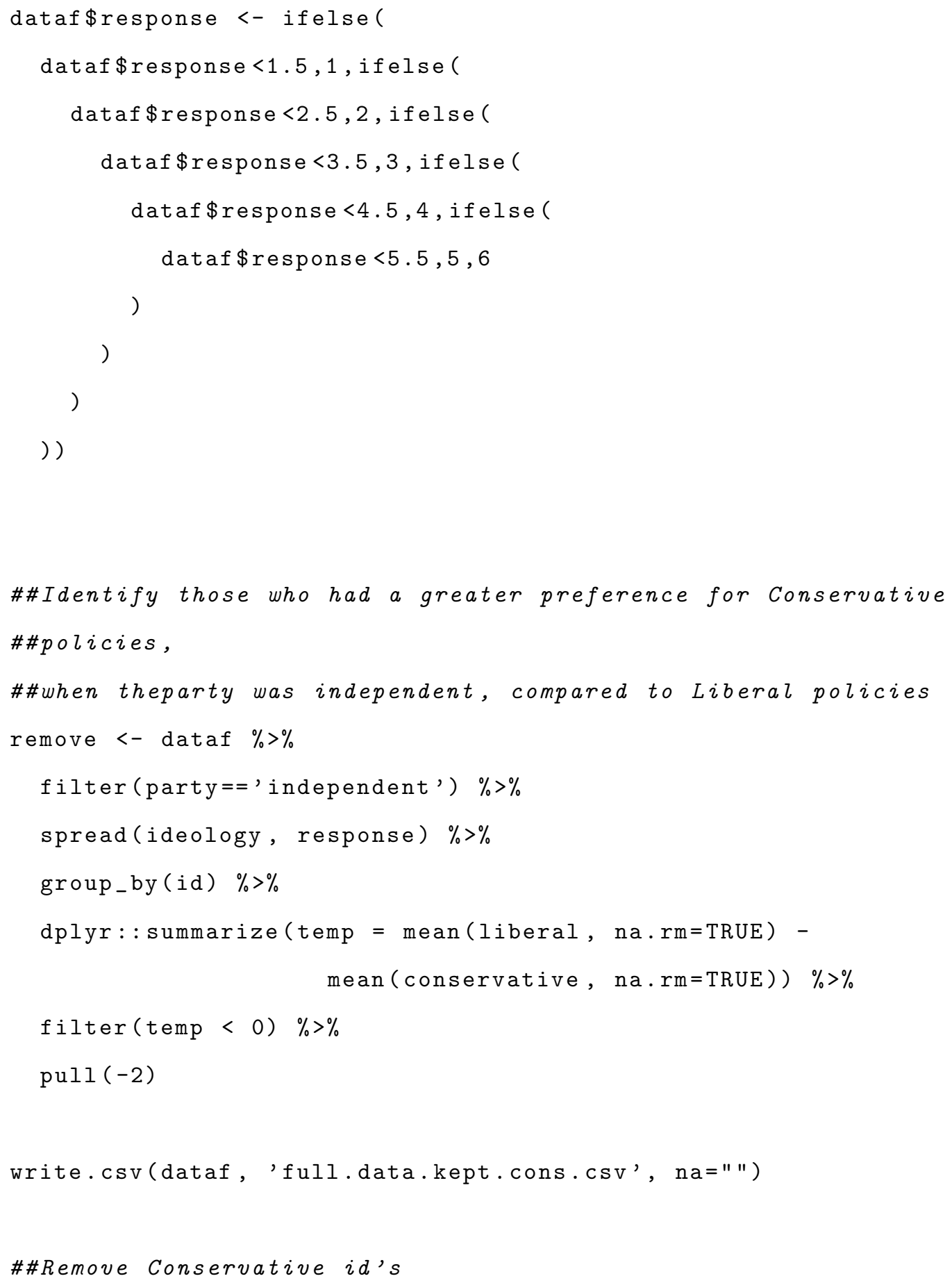


dataf <- subset (dataf, ! id $\%$ in $\%$ remove)

write.csv(dataf, 'full.data.removed.cons.csv', na=" ")

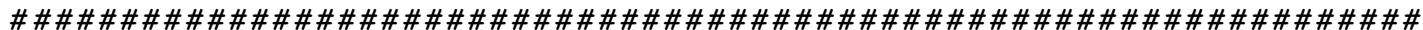

\#\#Part 3 - Missingness

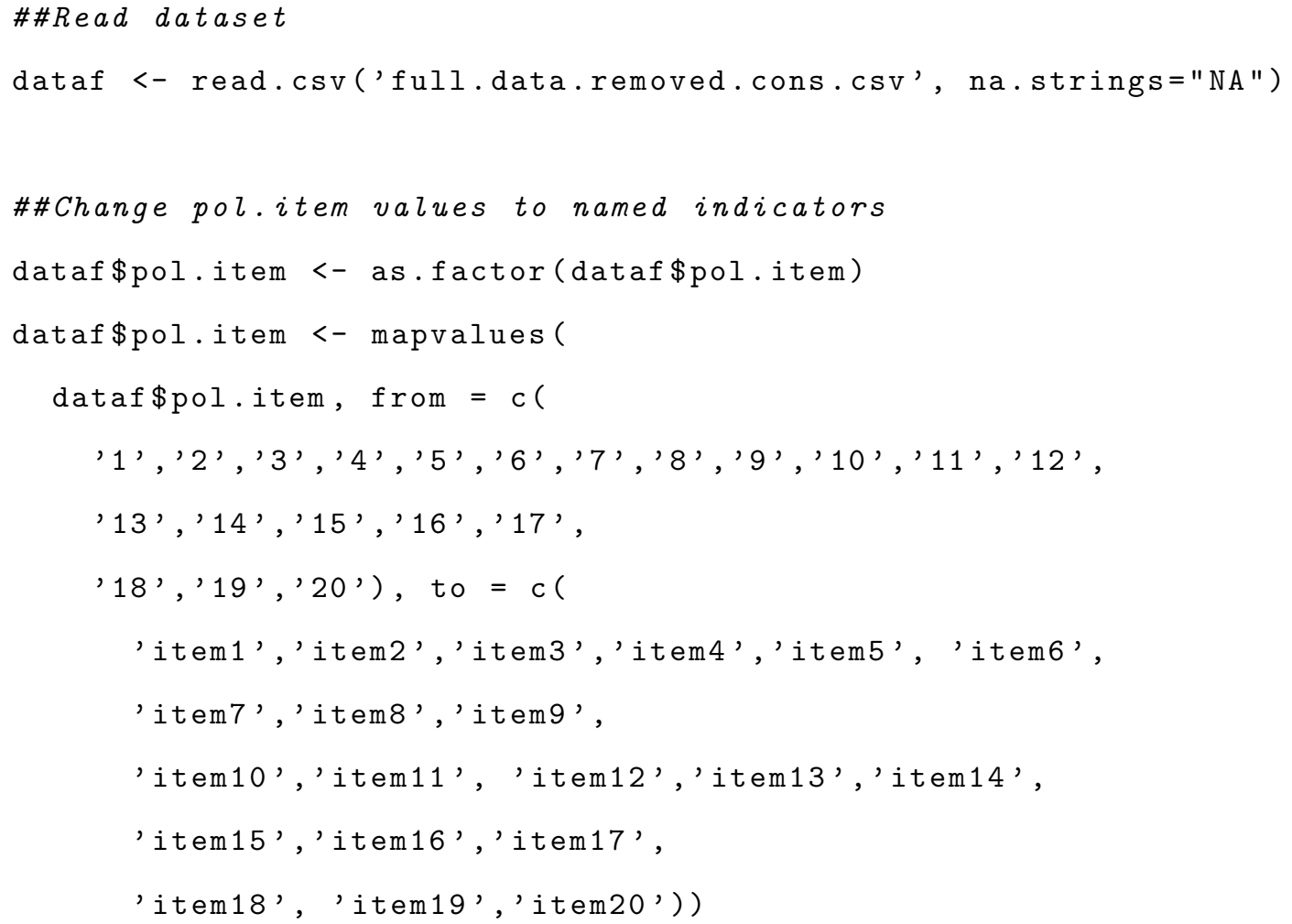




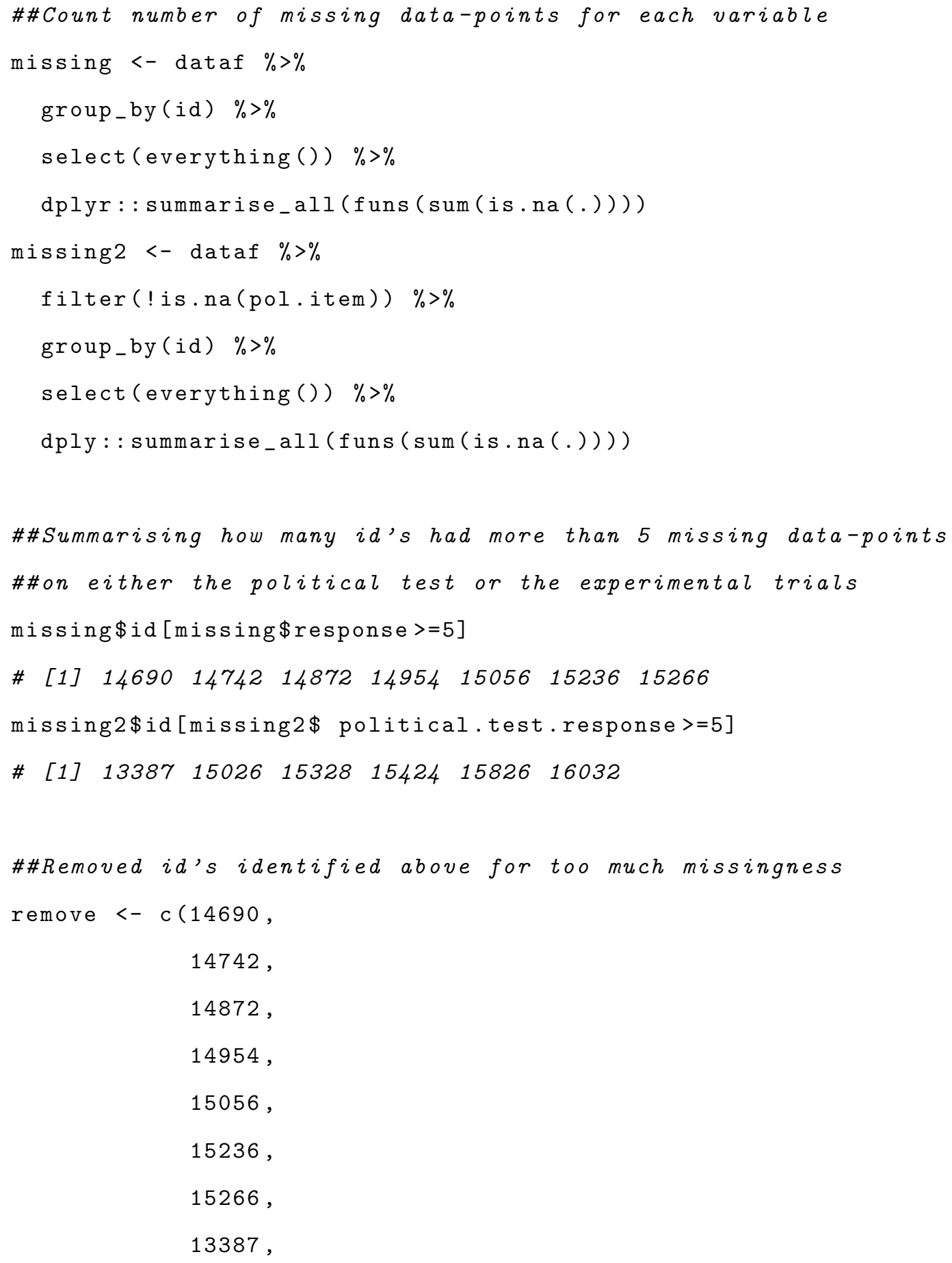




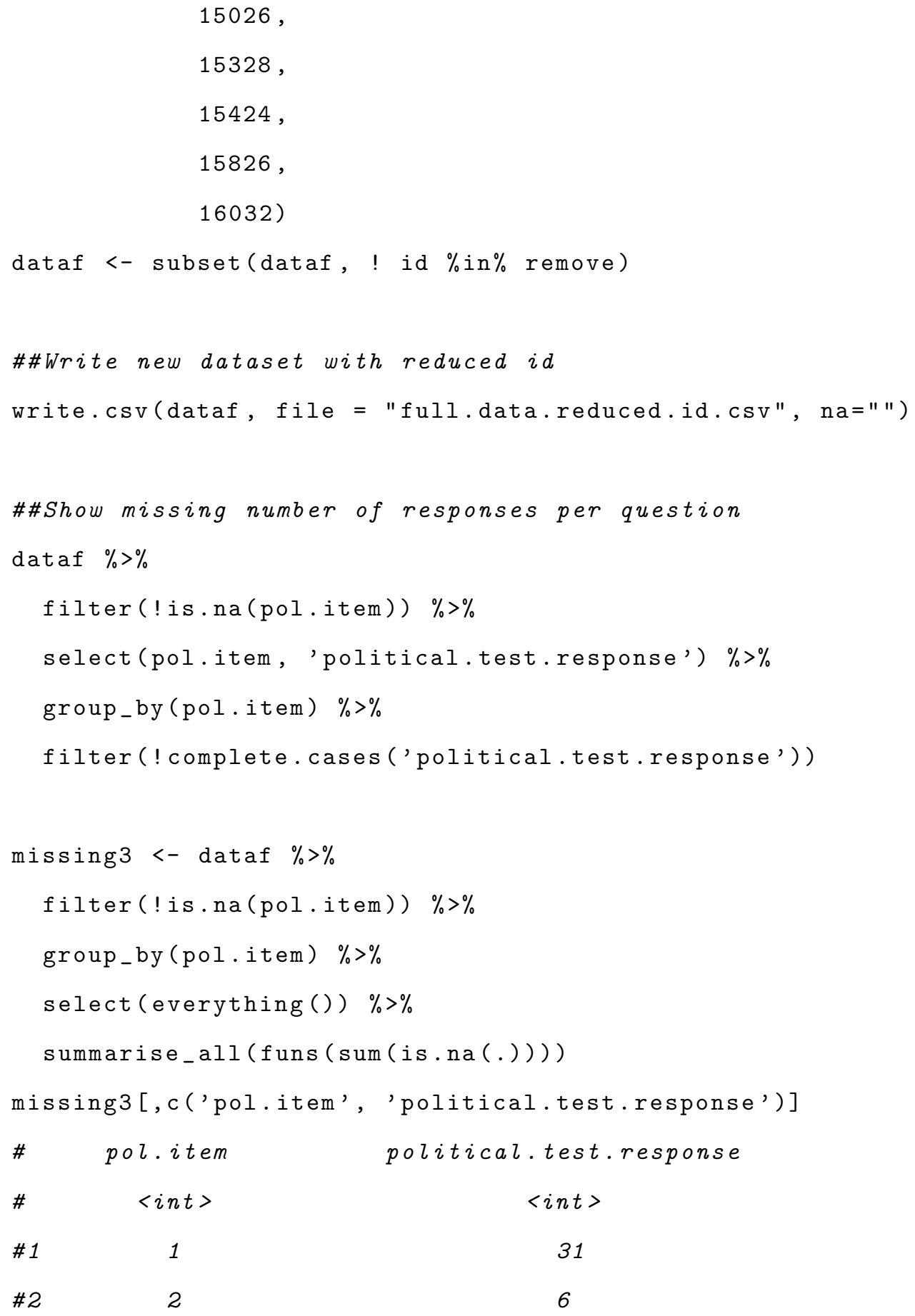




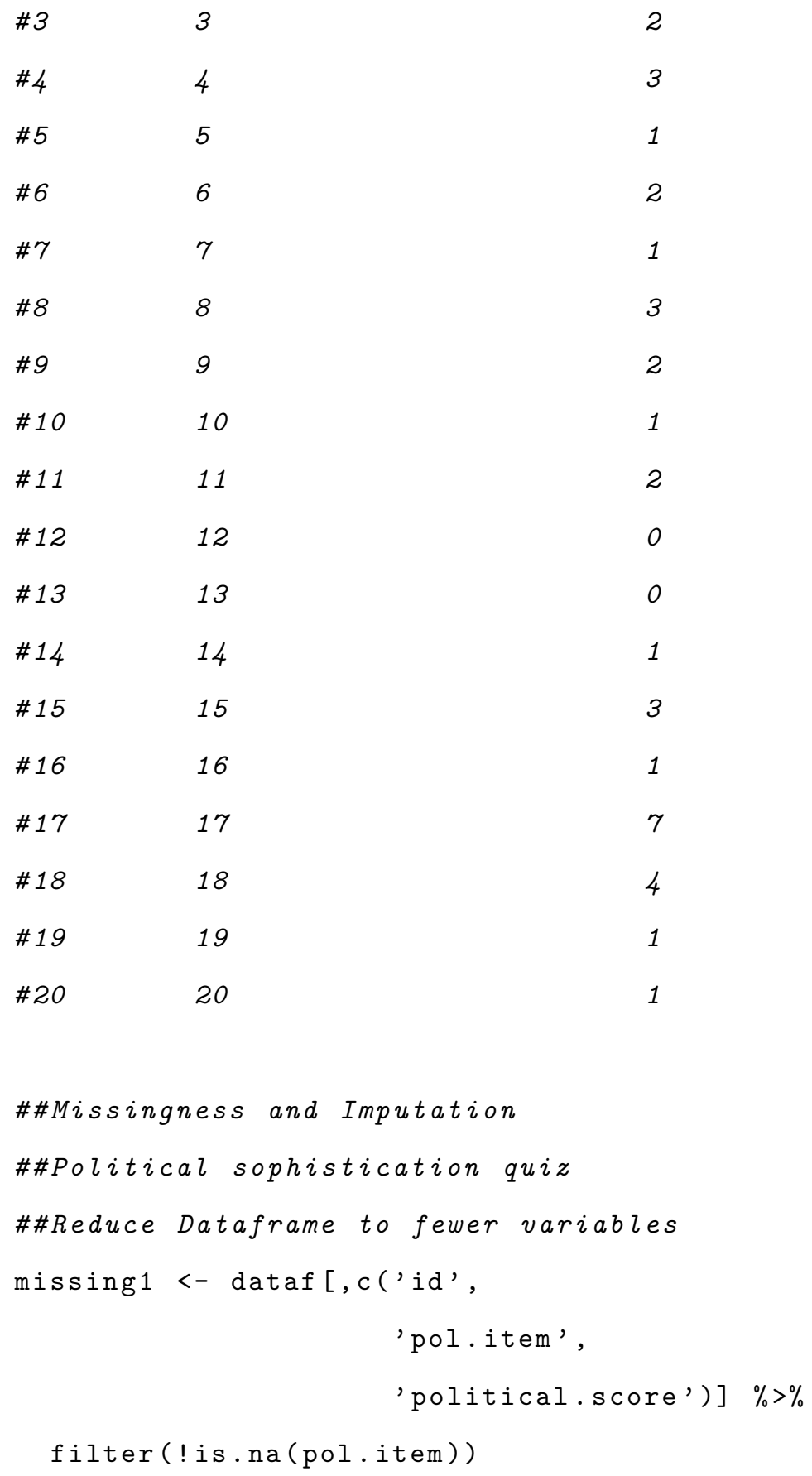




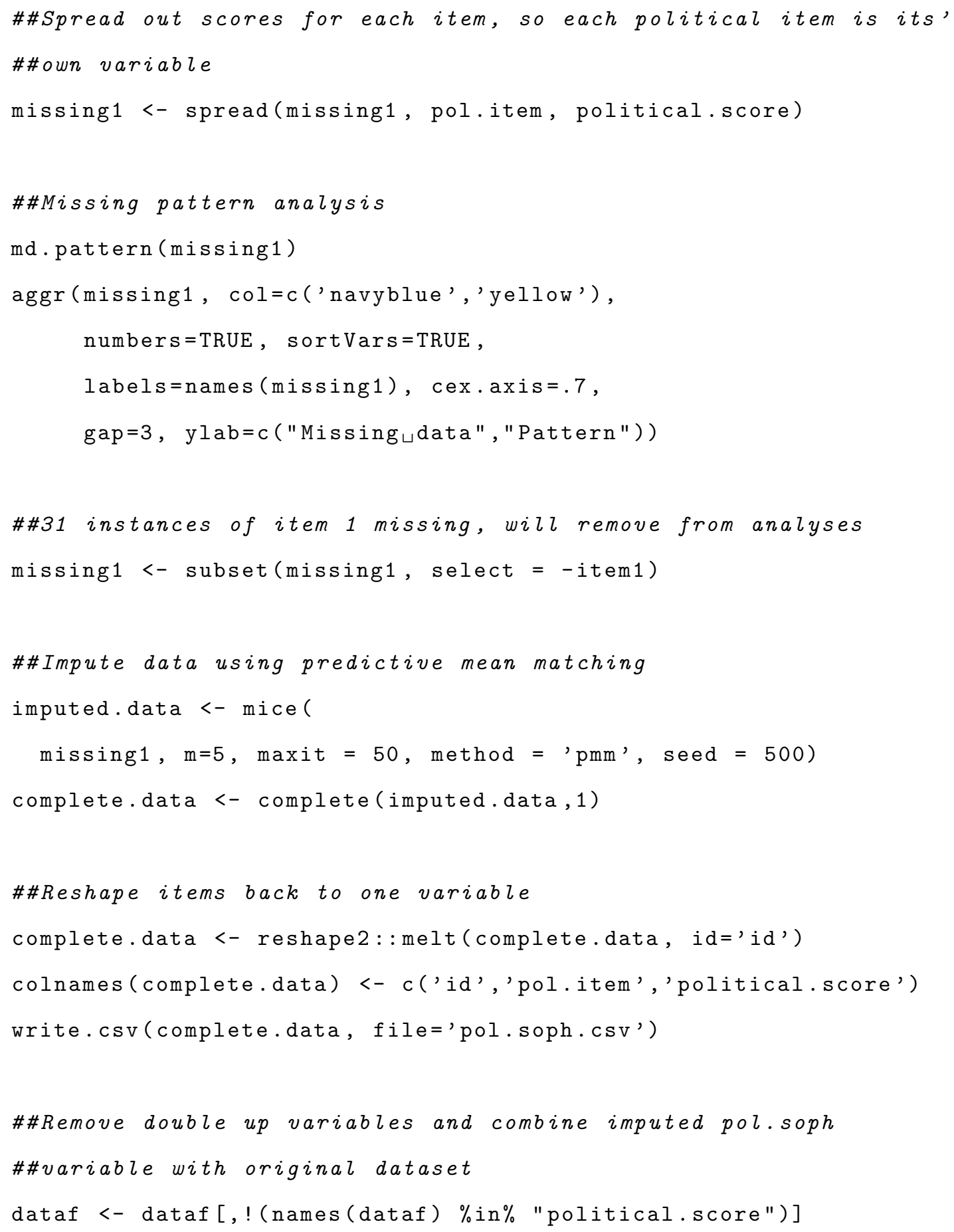




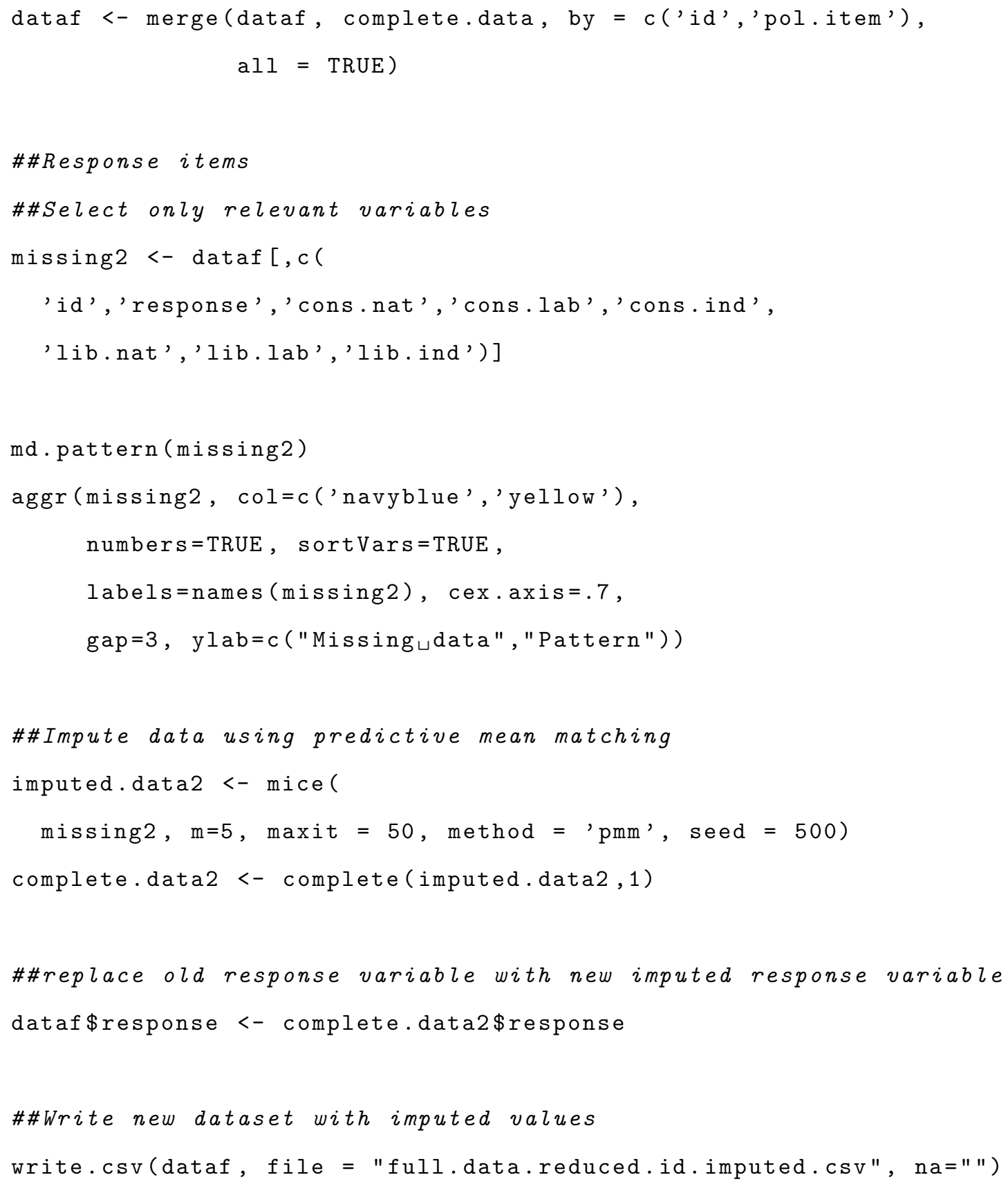




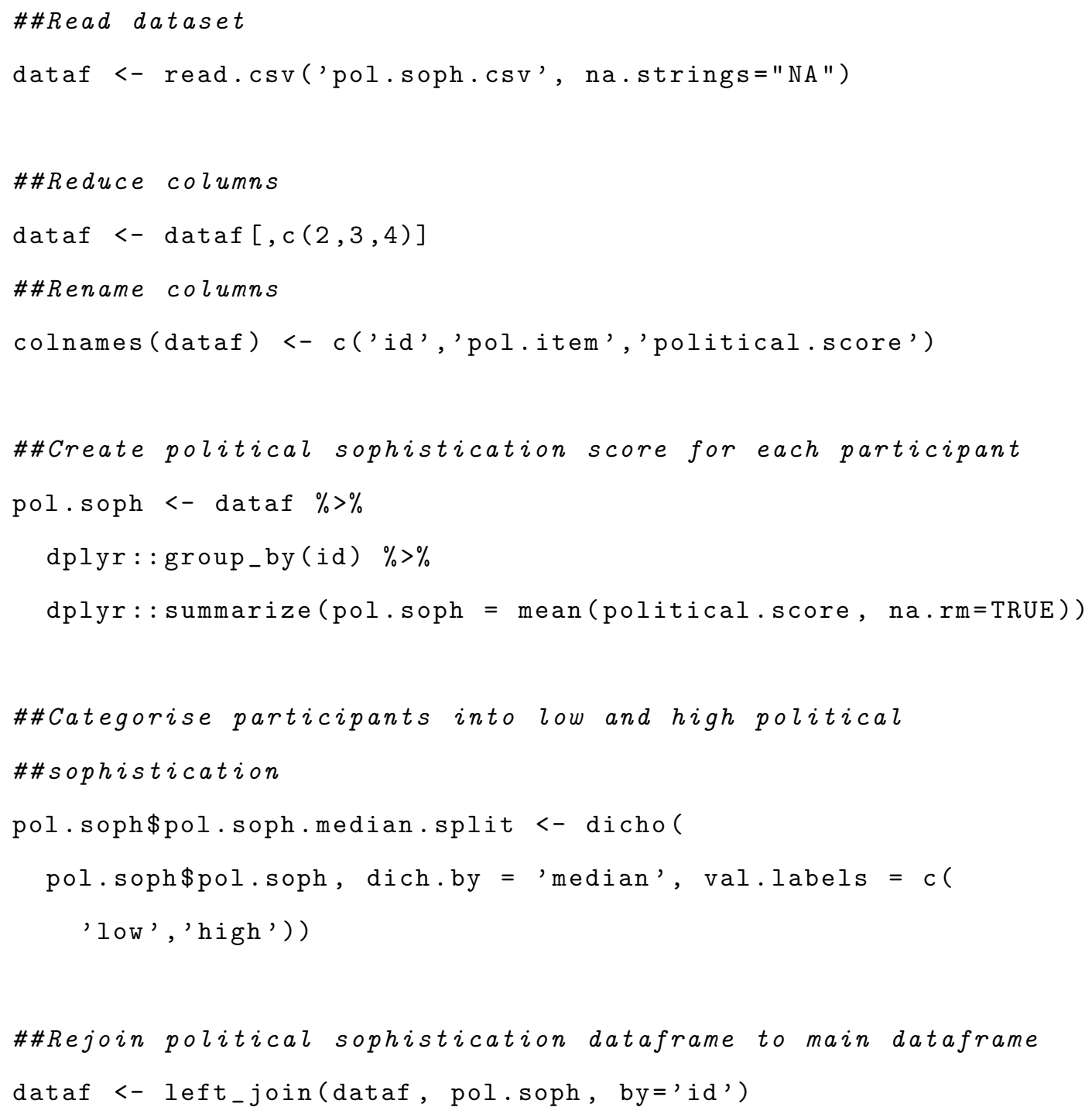




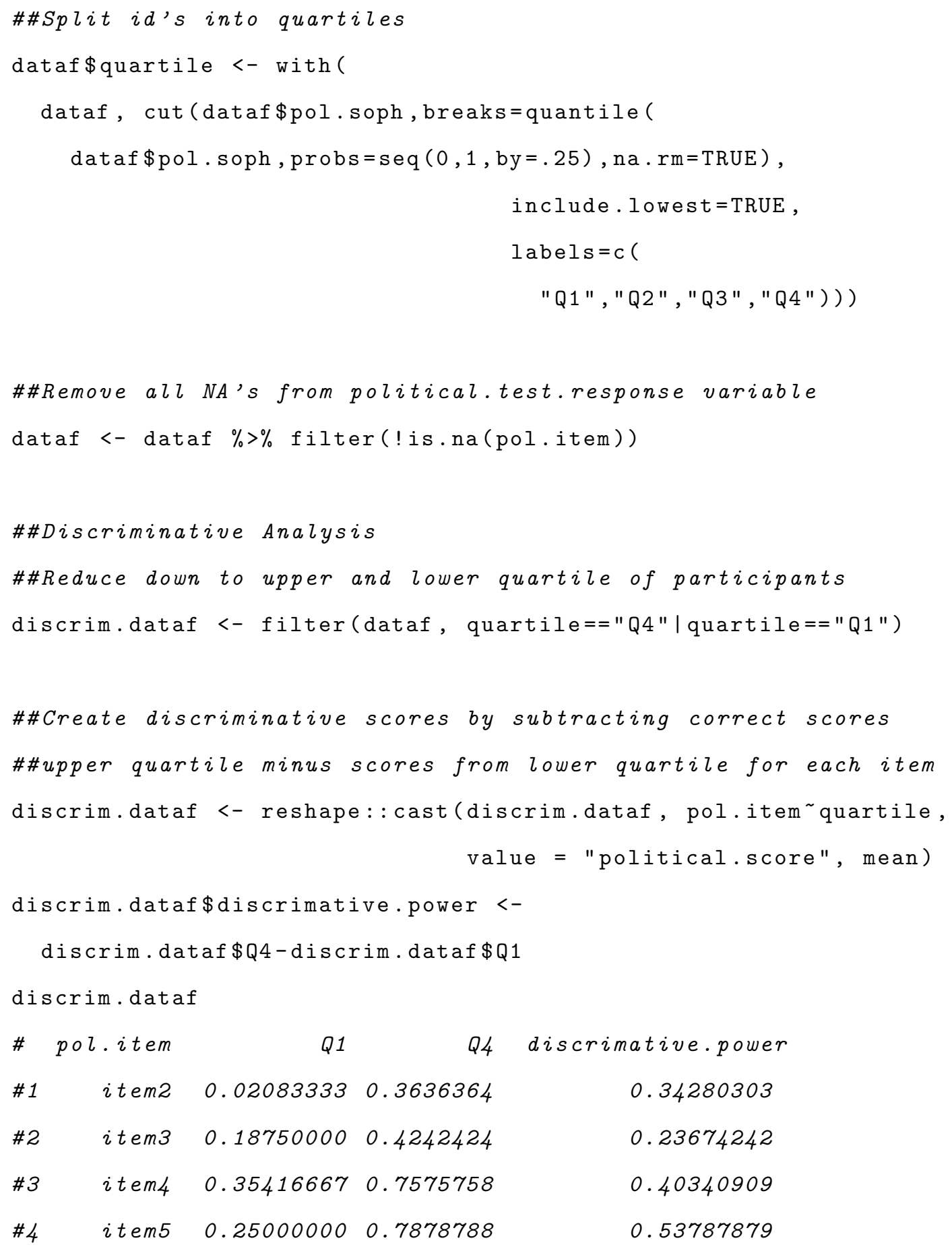




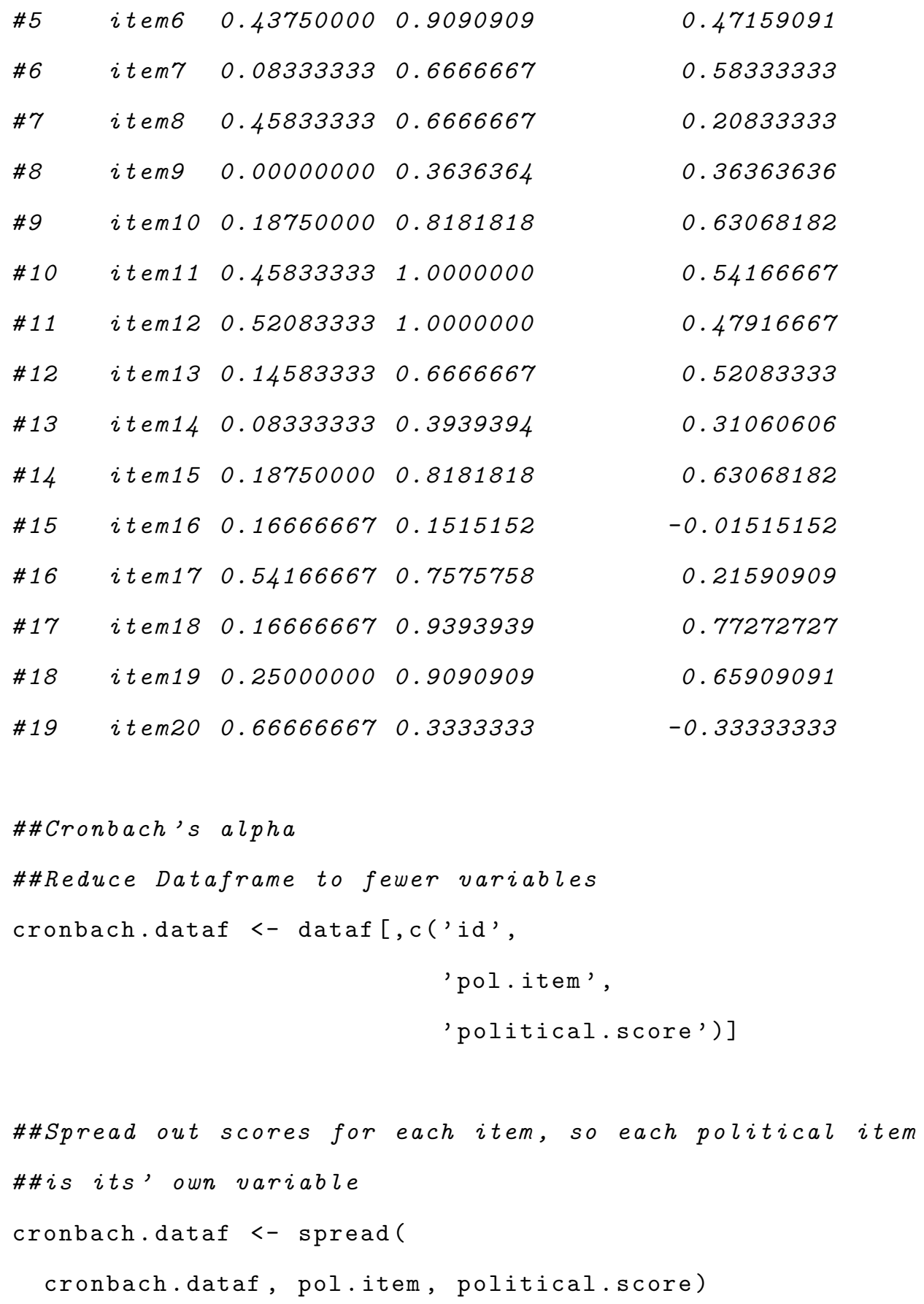




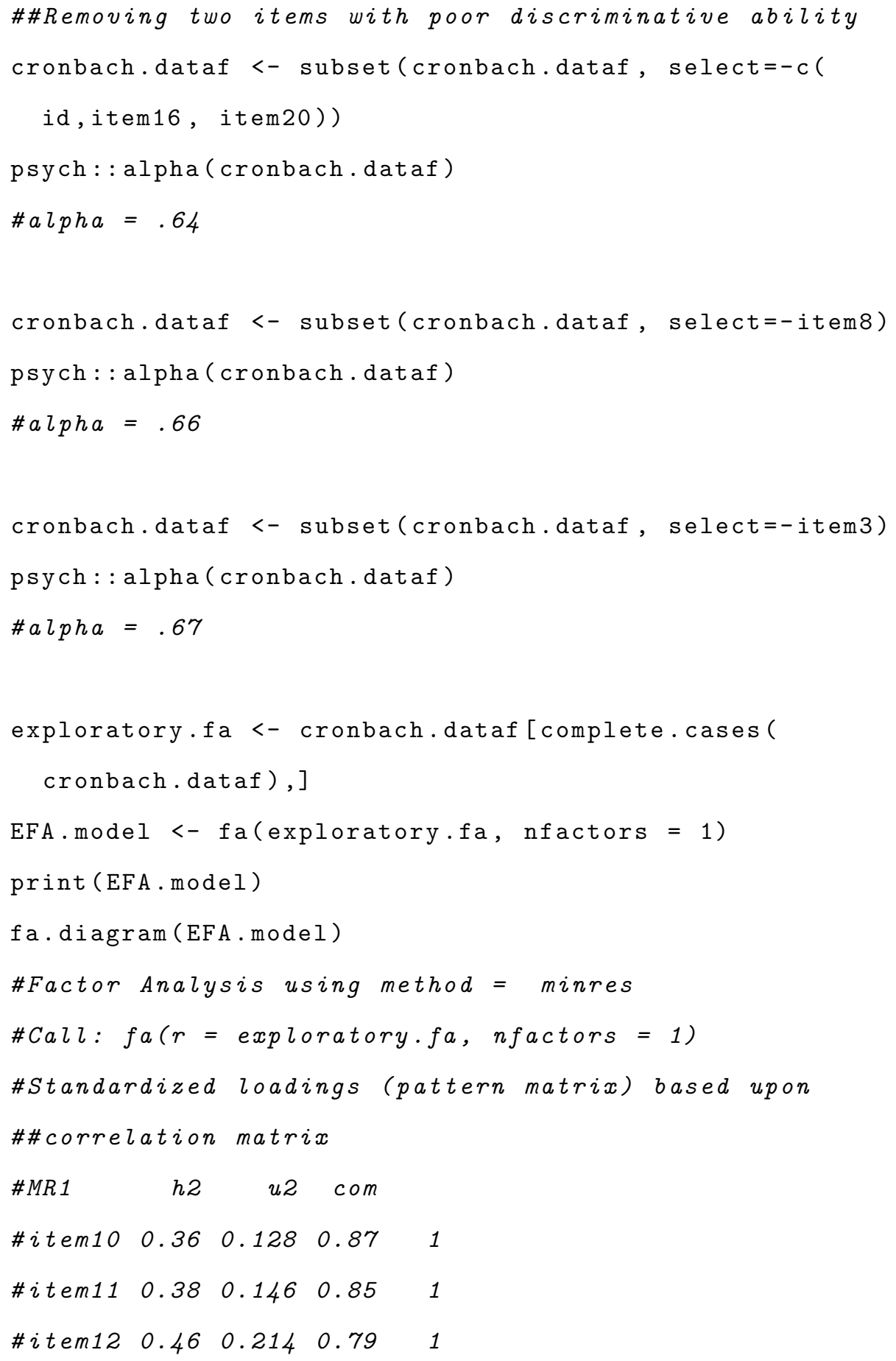




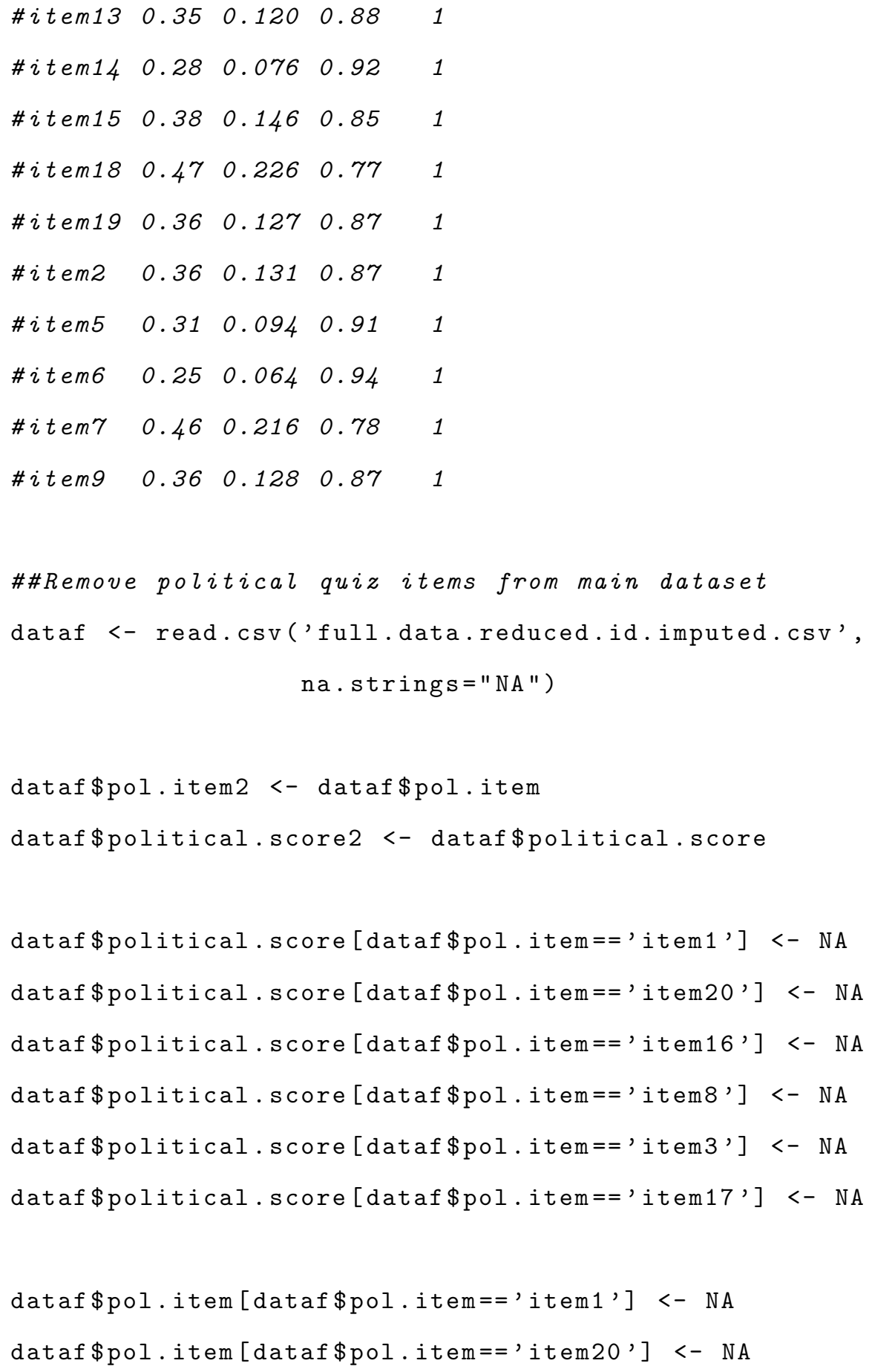




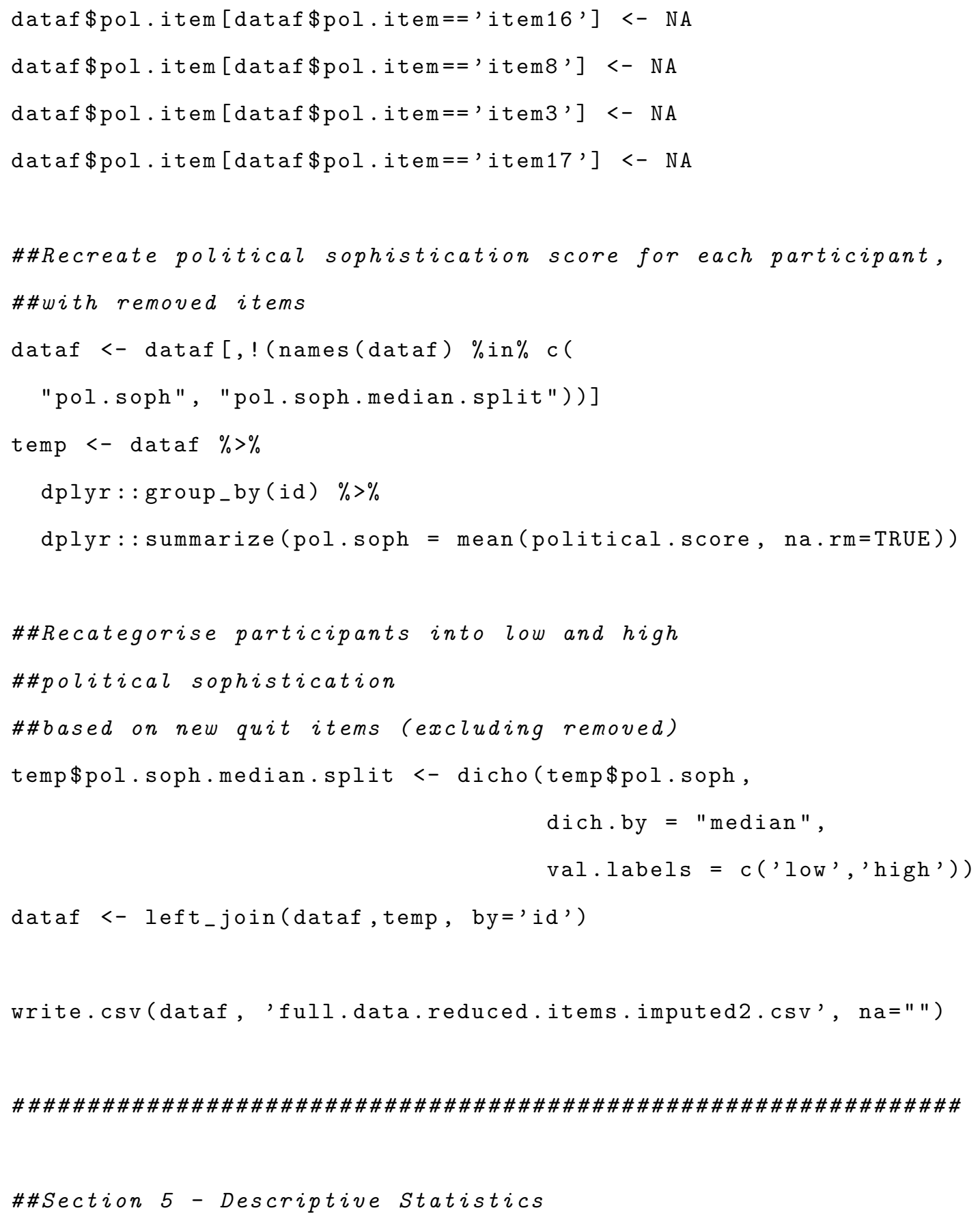




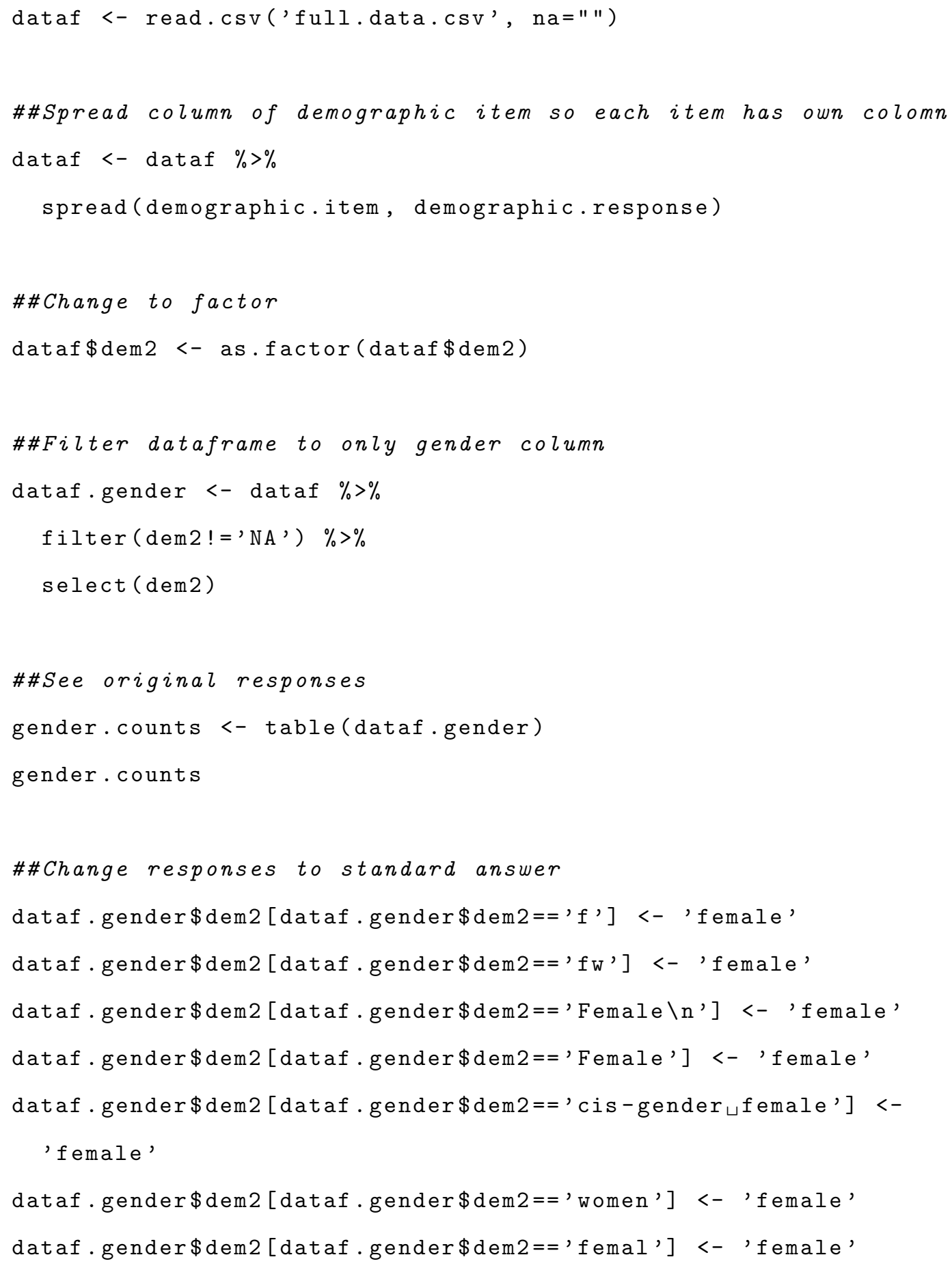




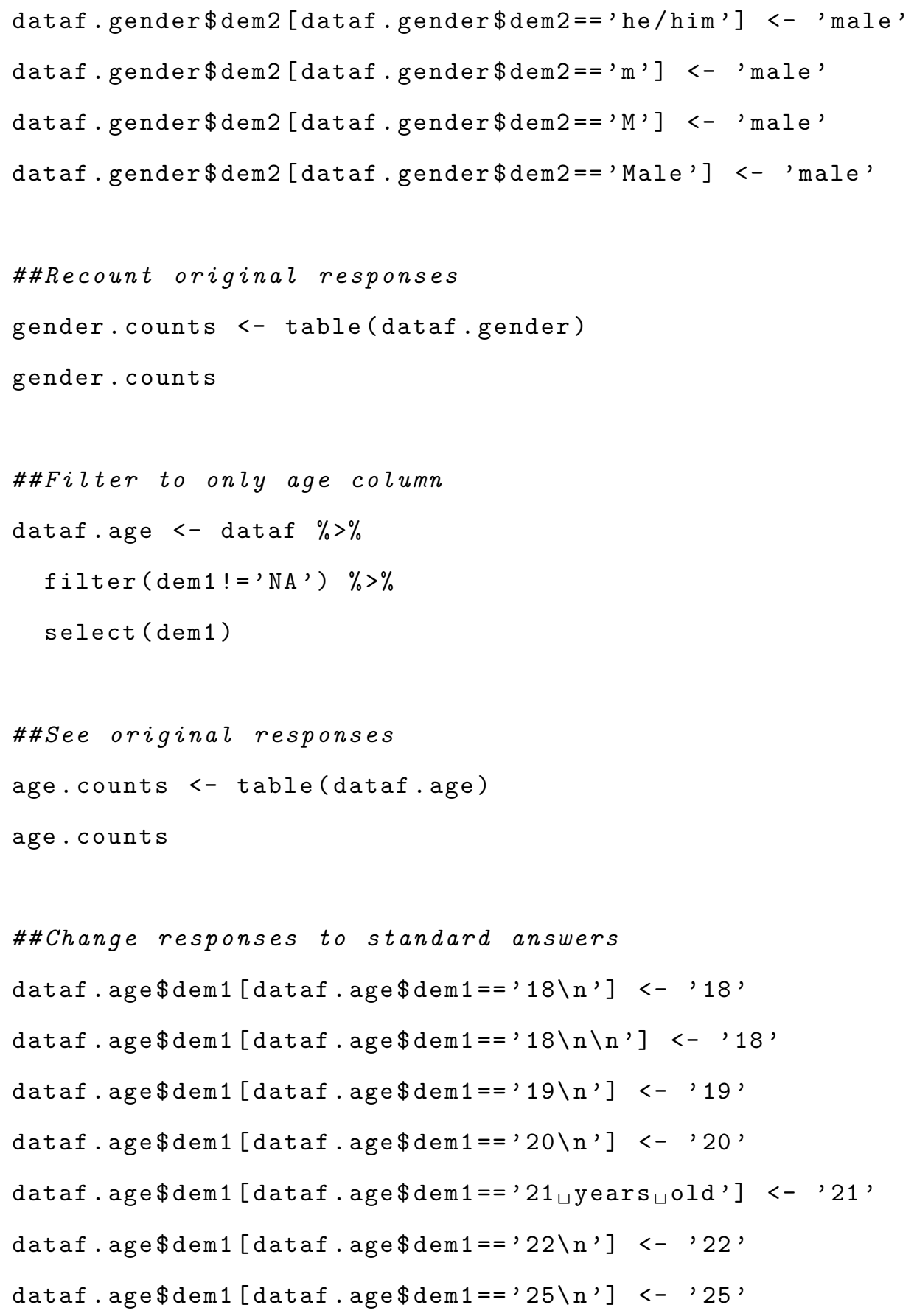




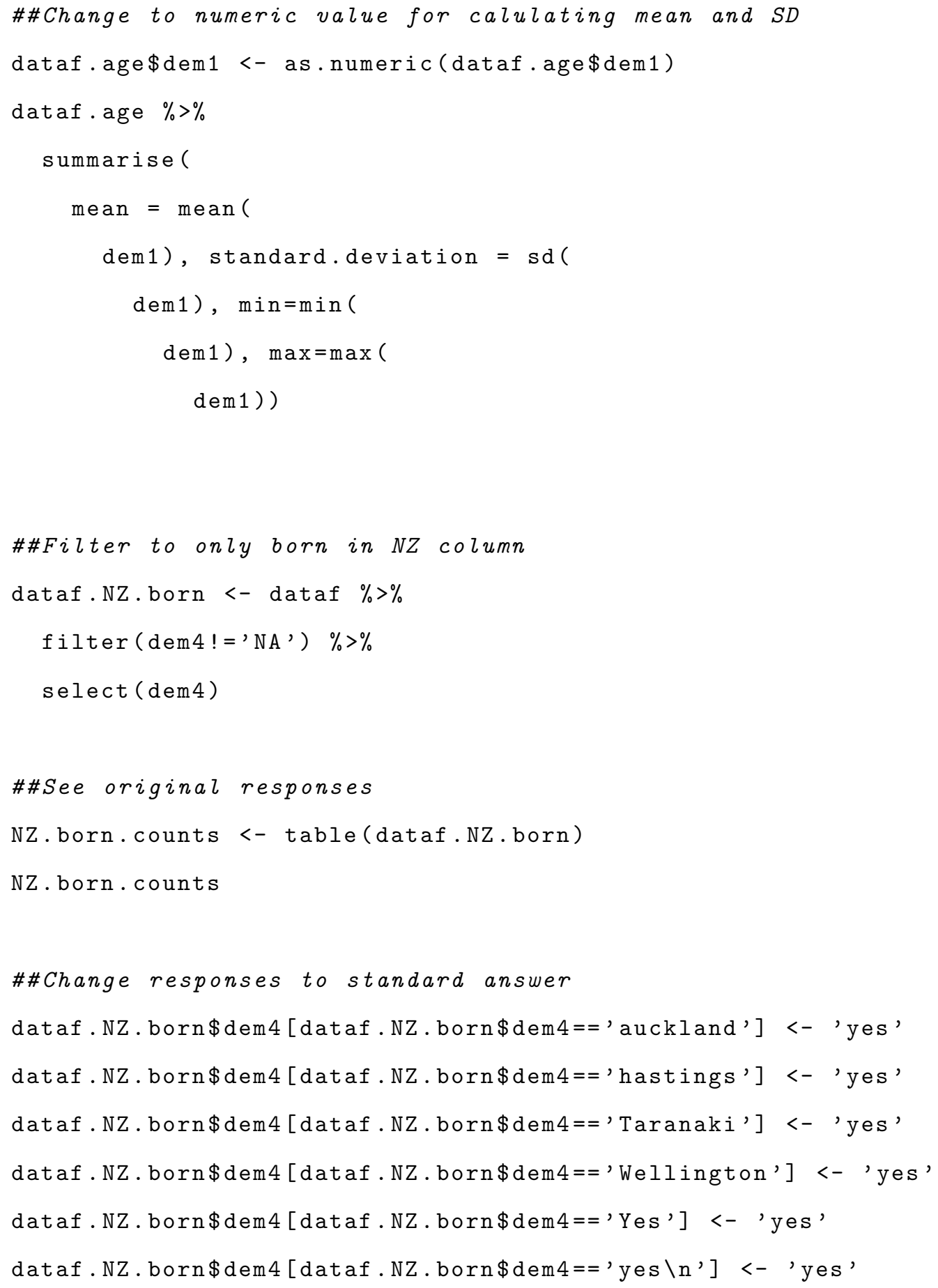




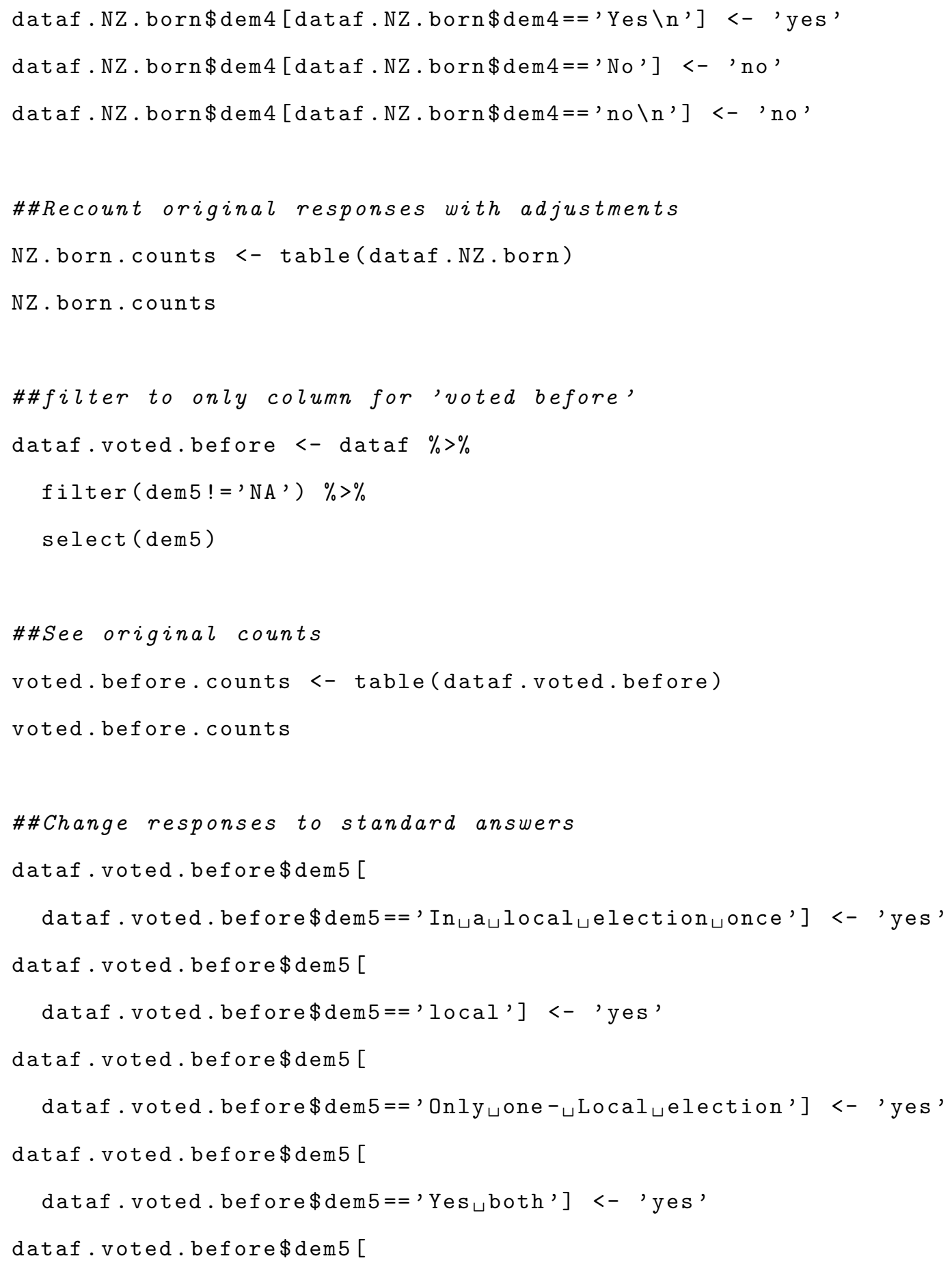




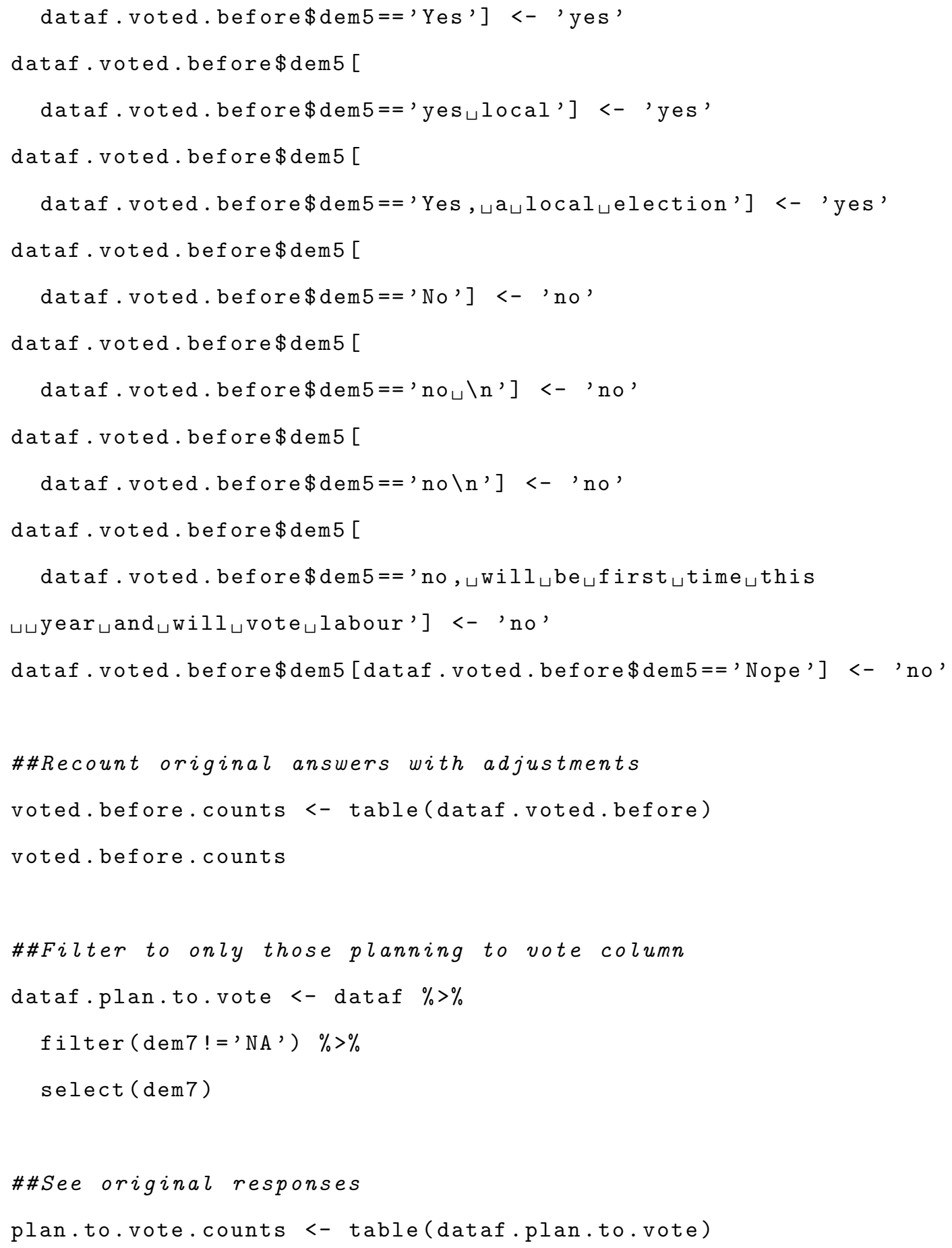




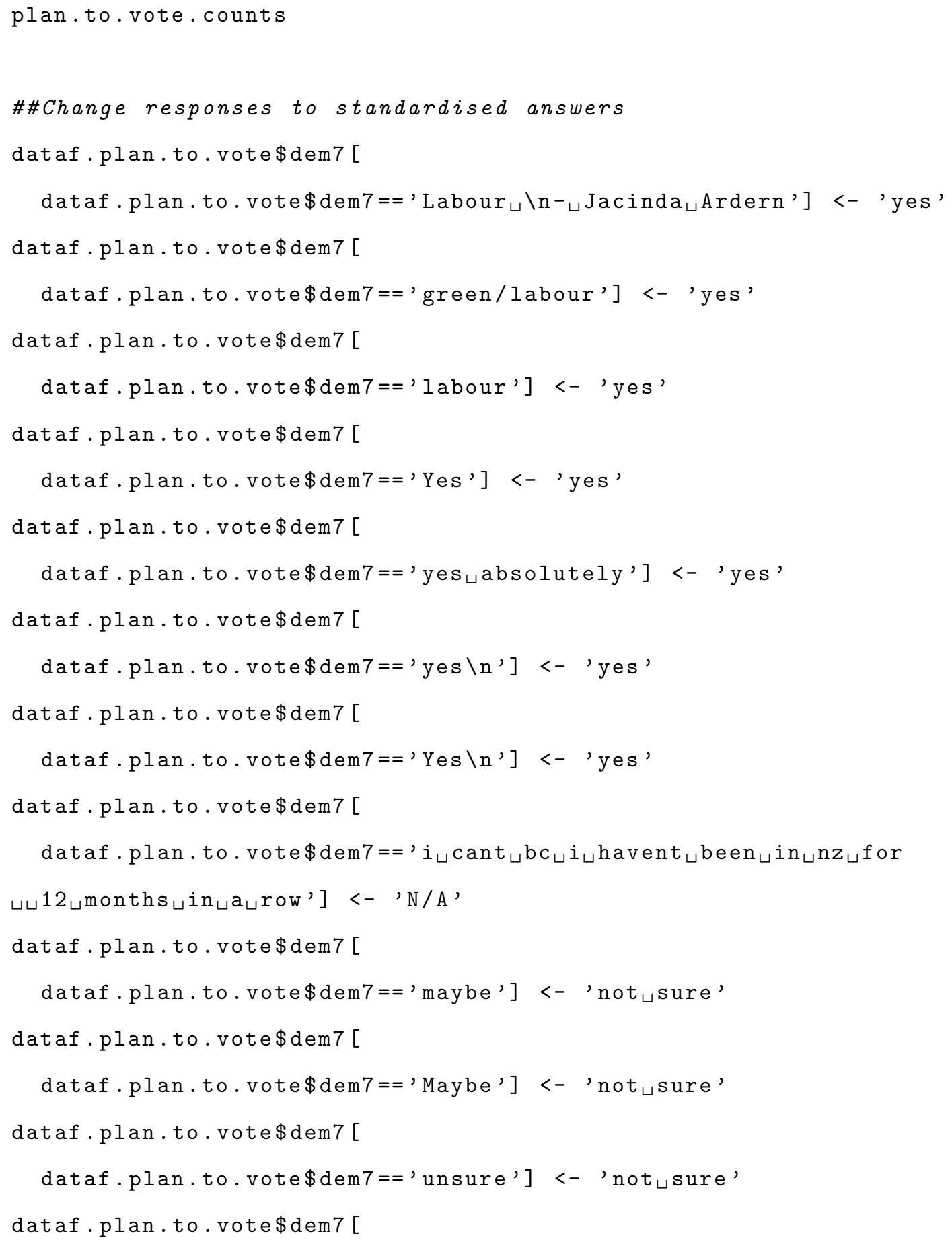




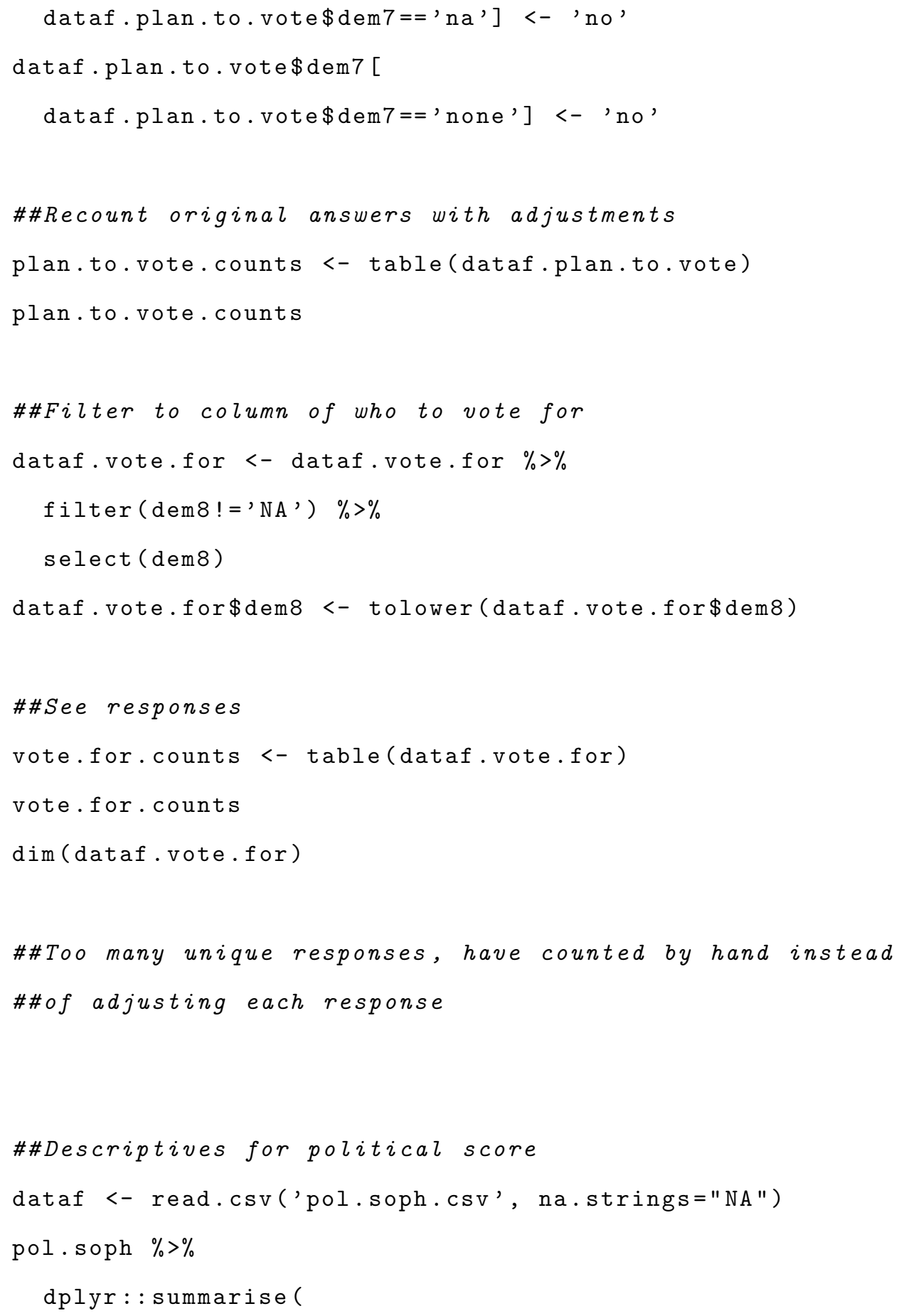




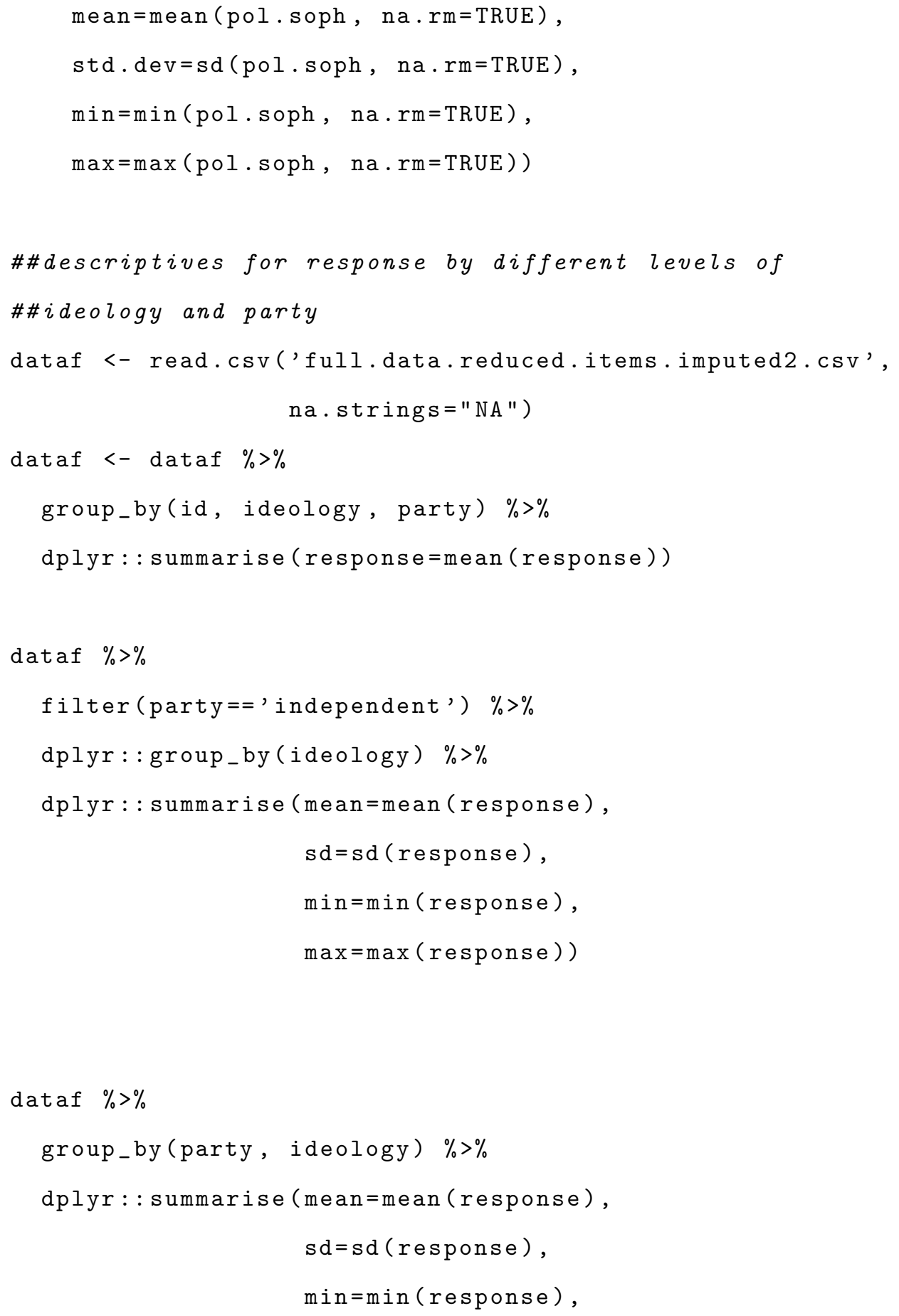


$\max =\max ($ response $))$

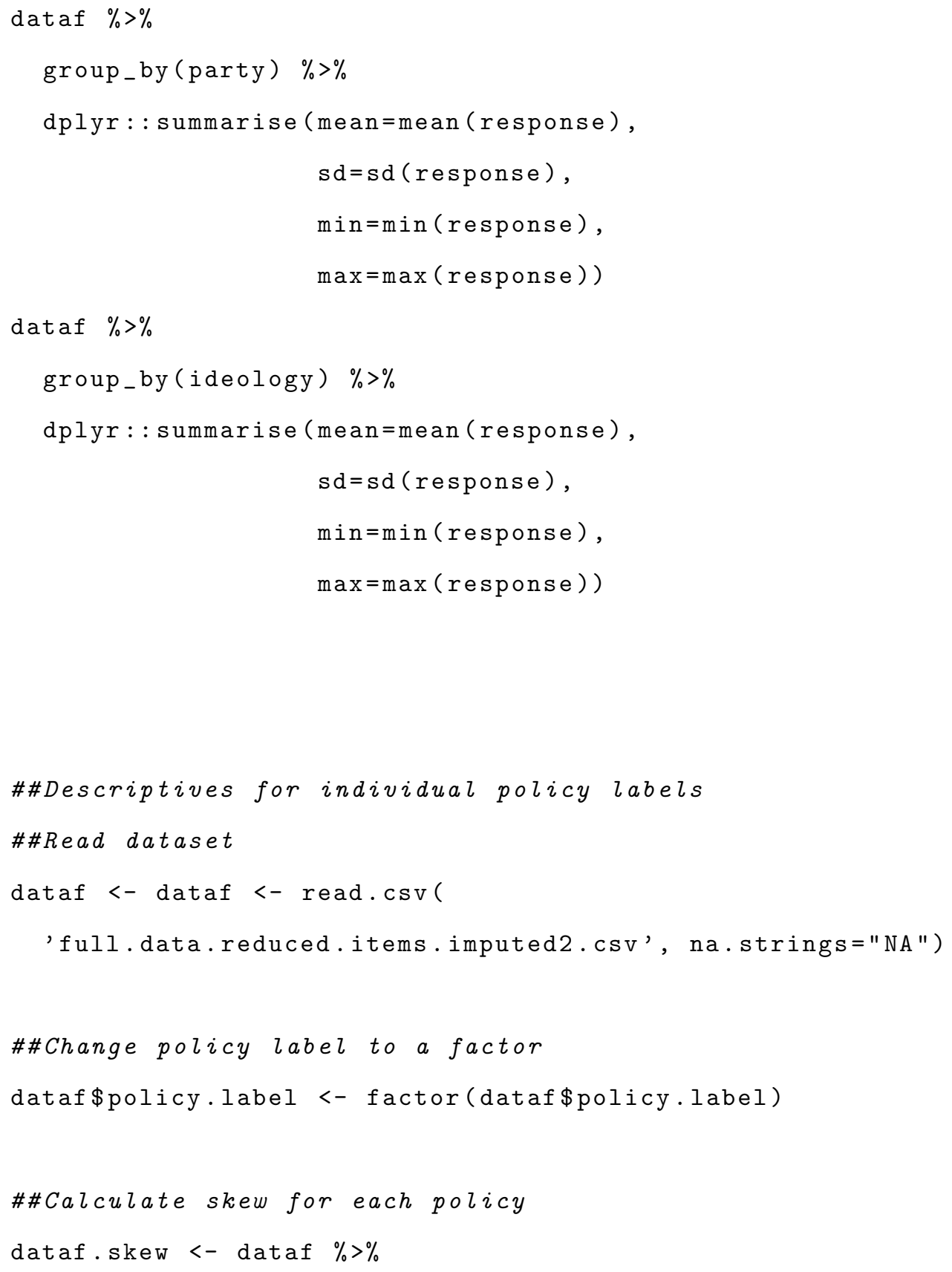




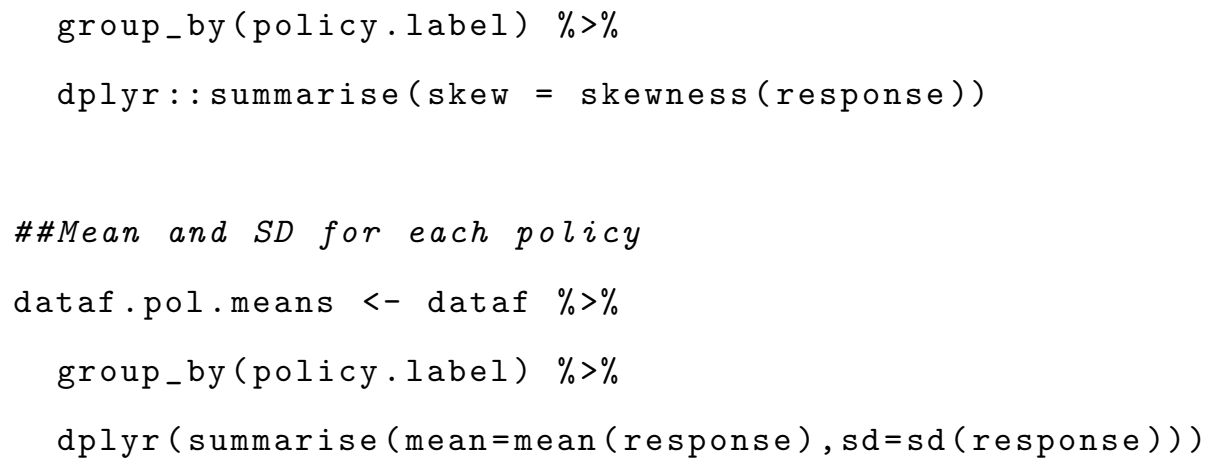




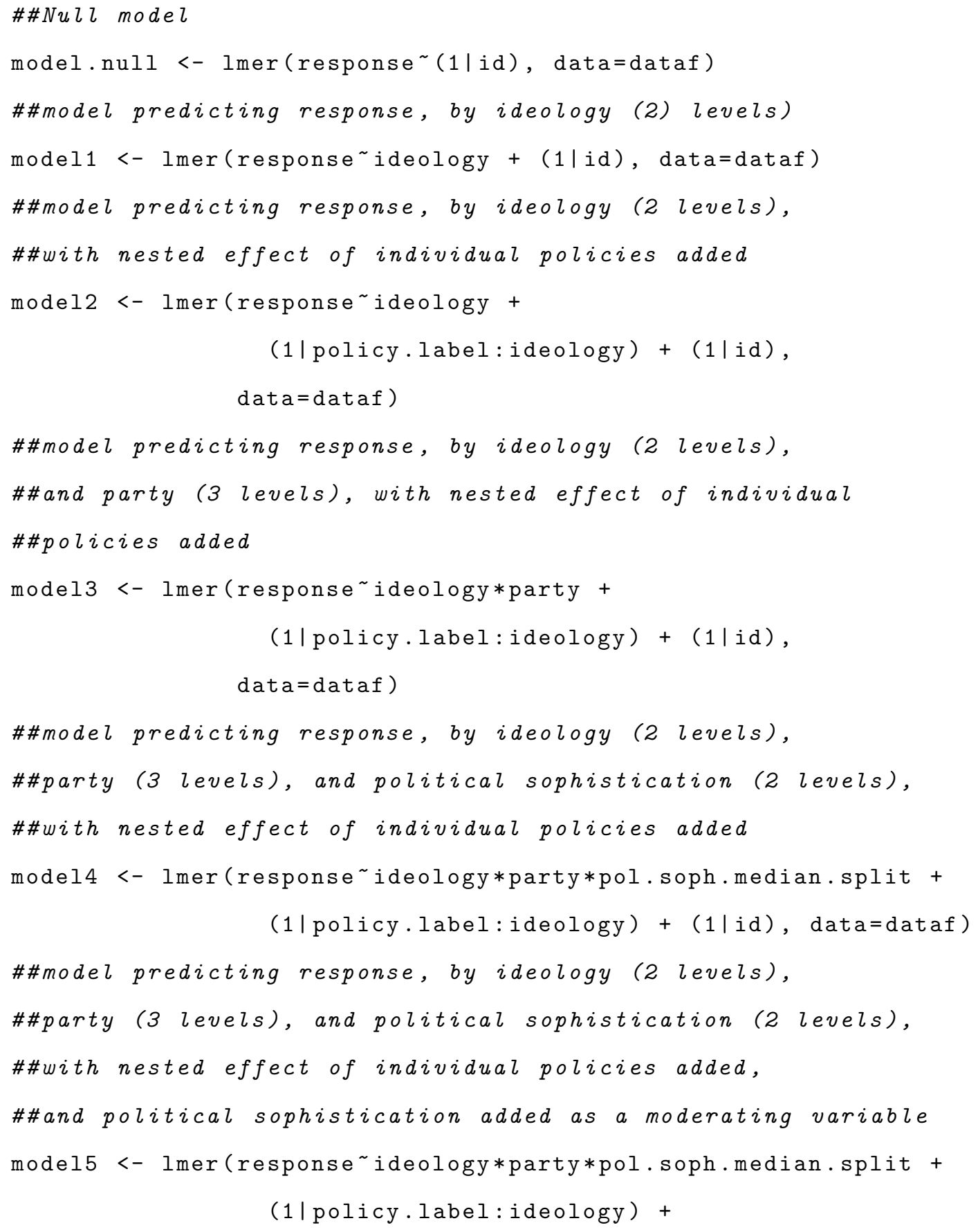




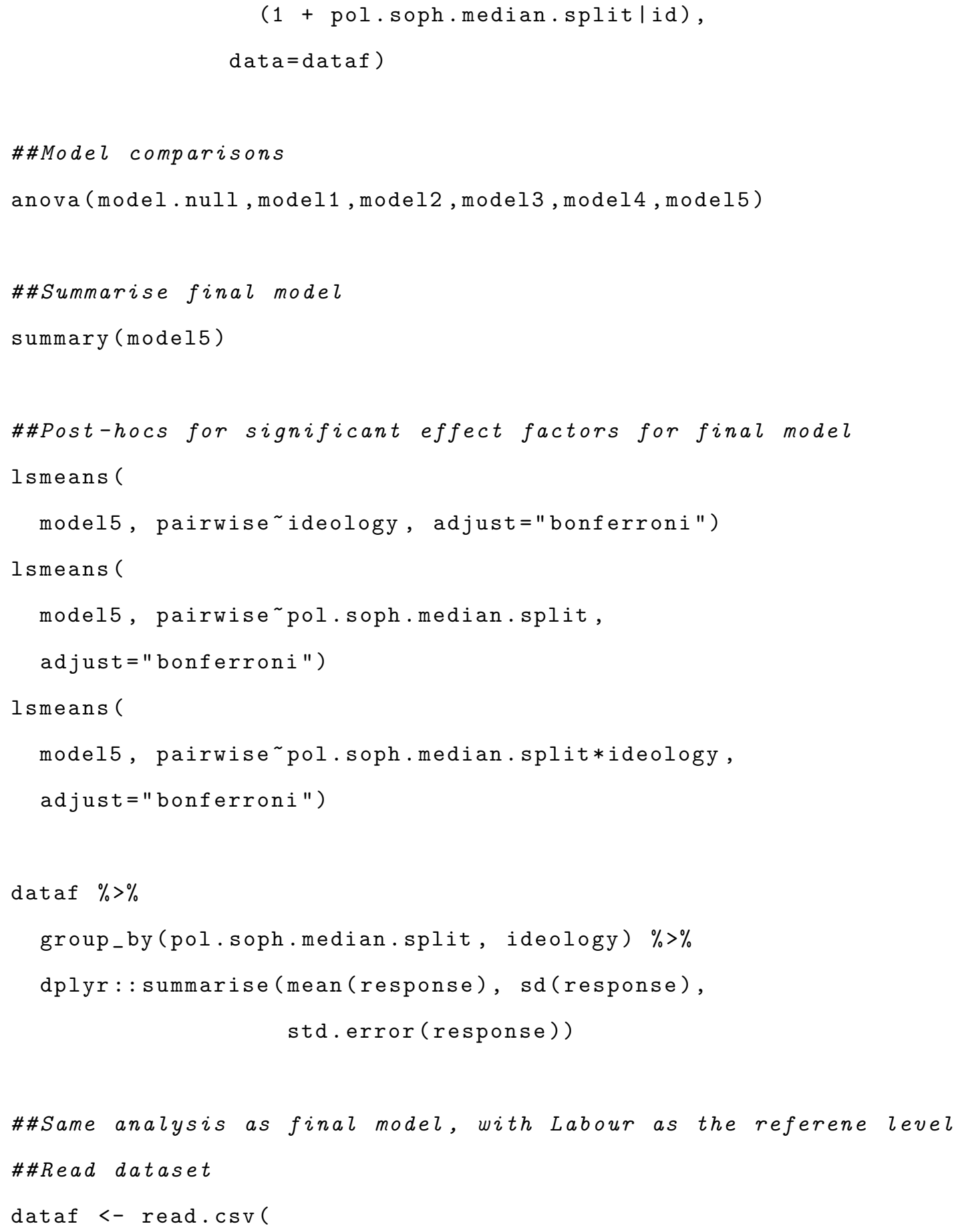




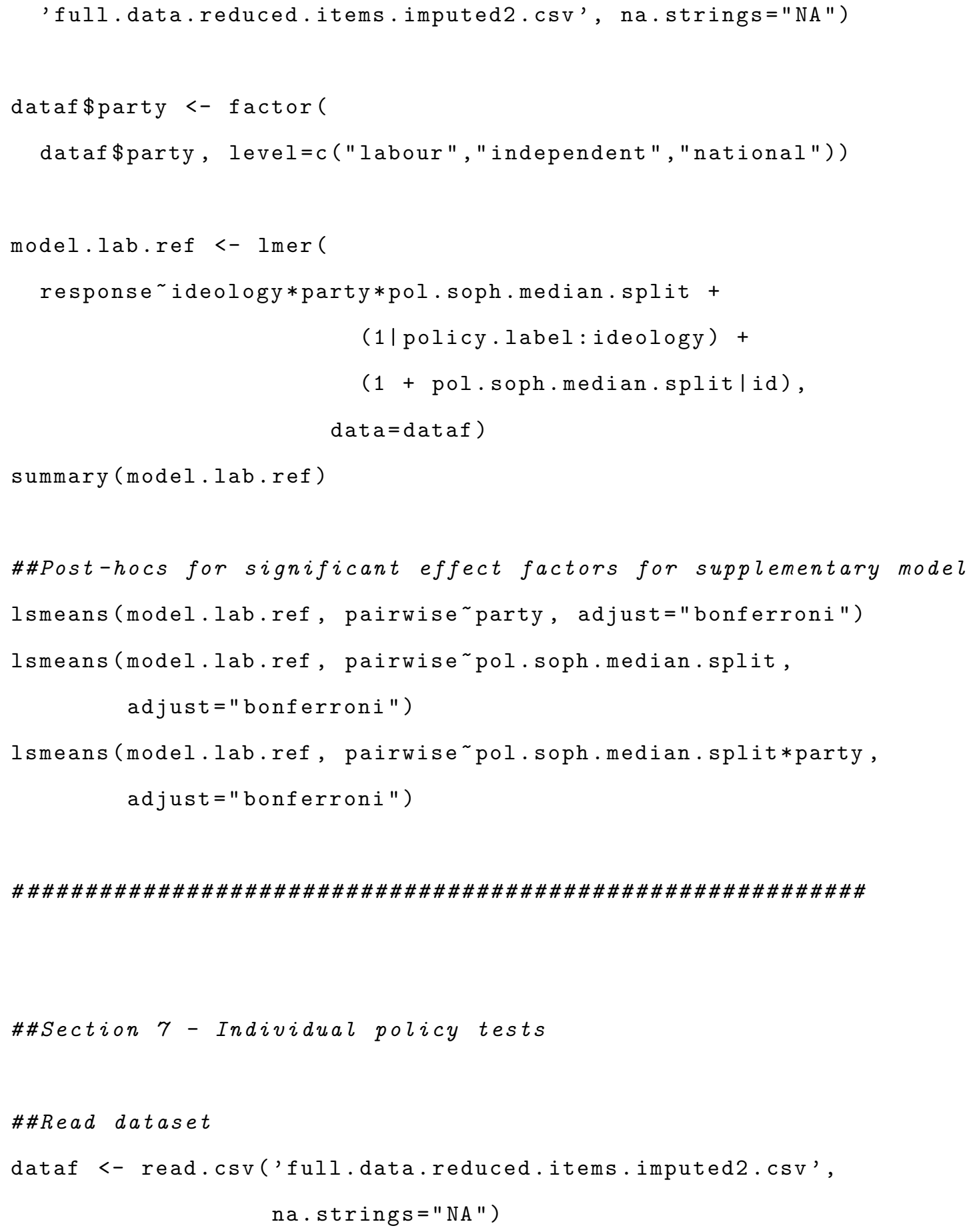




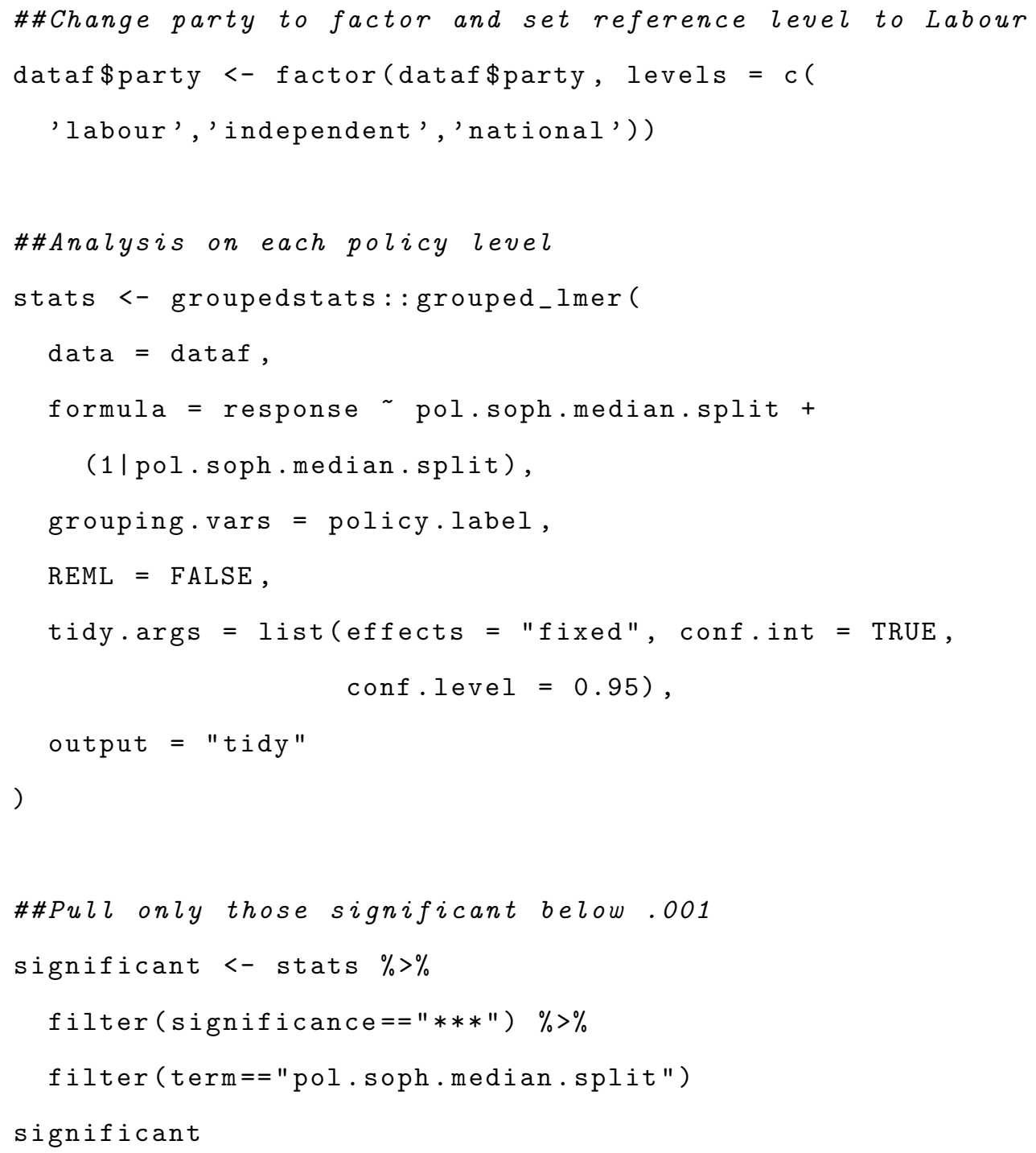




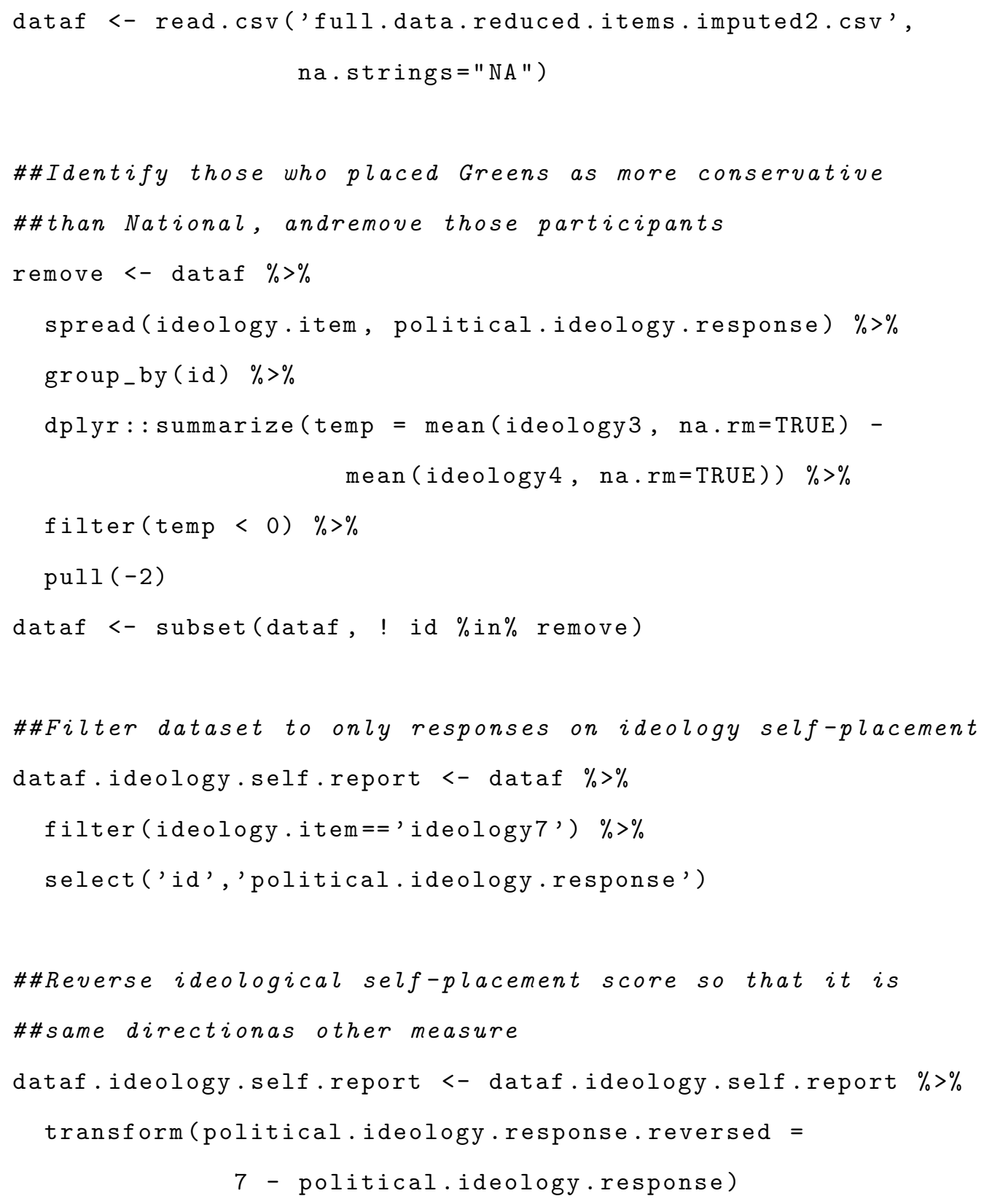




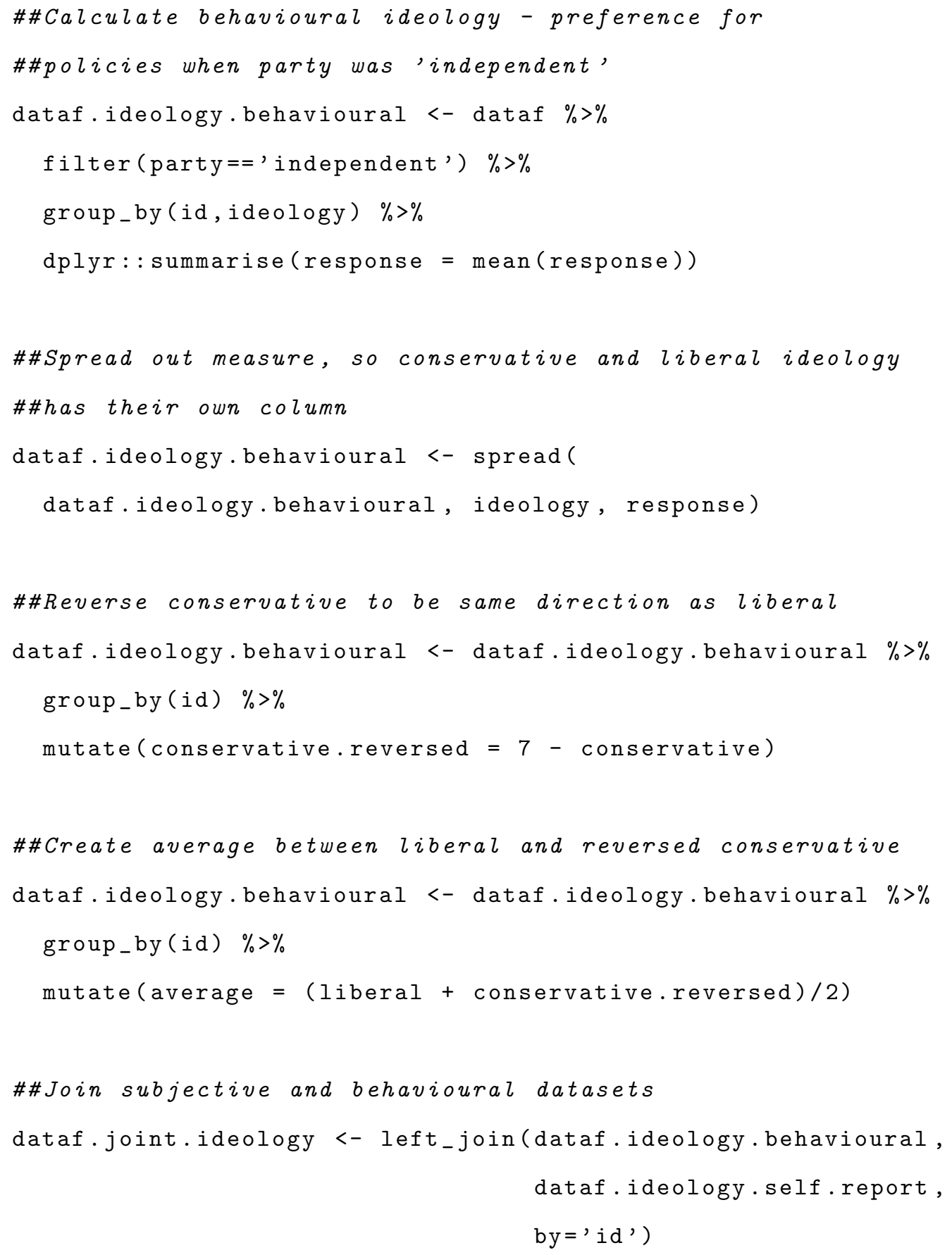




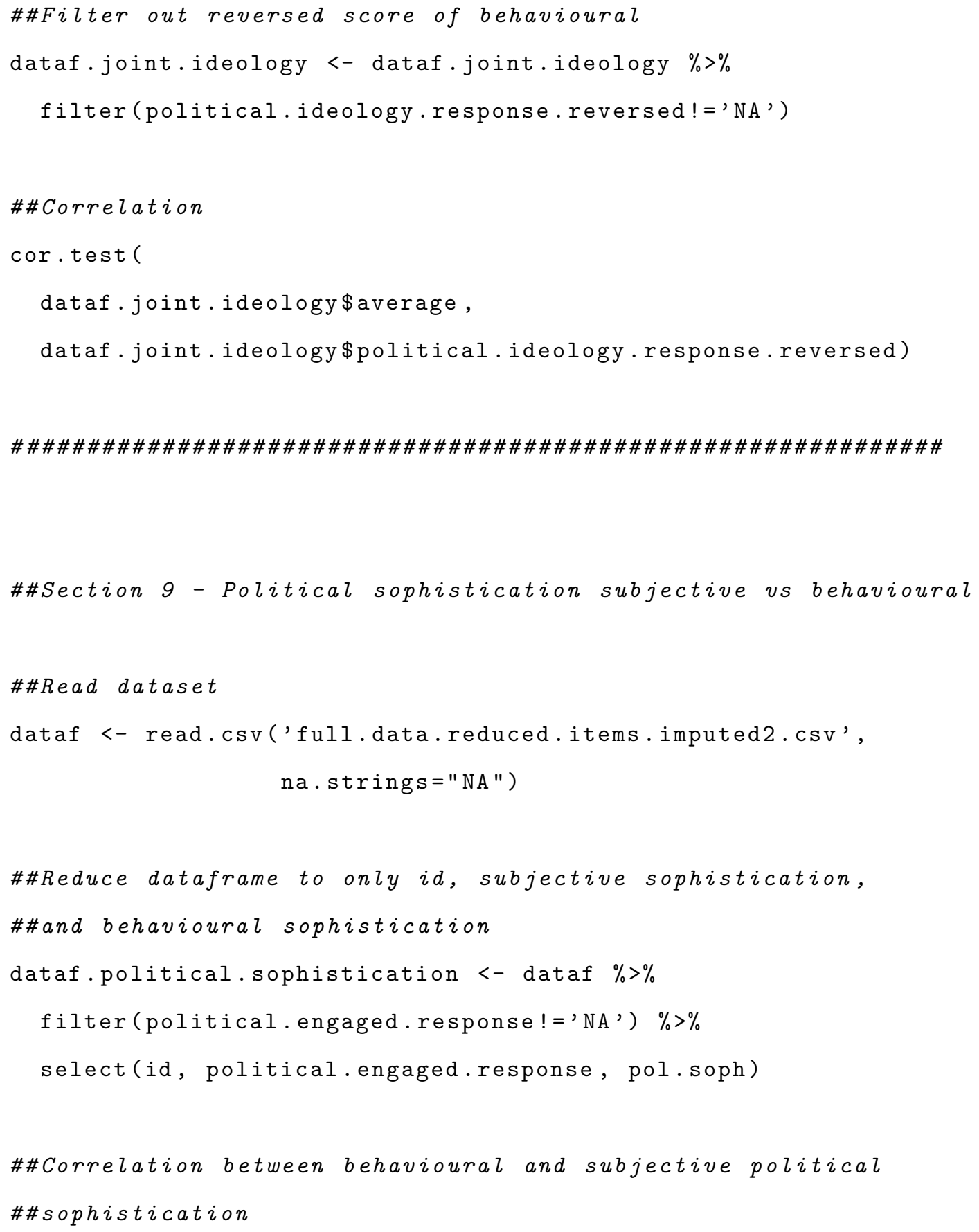




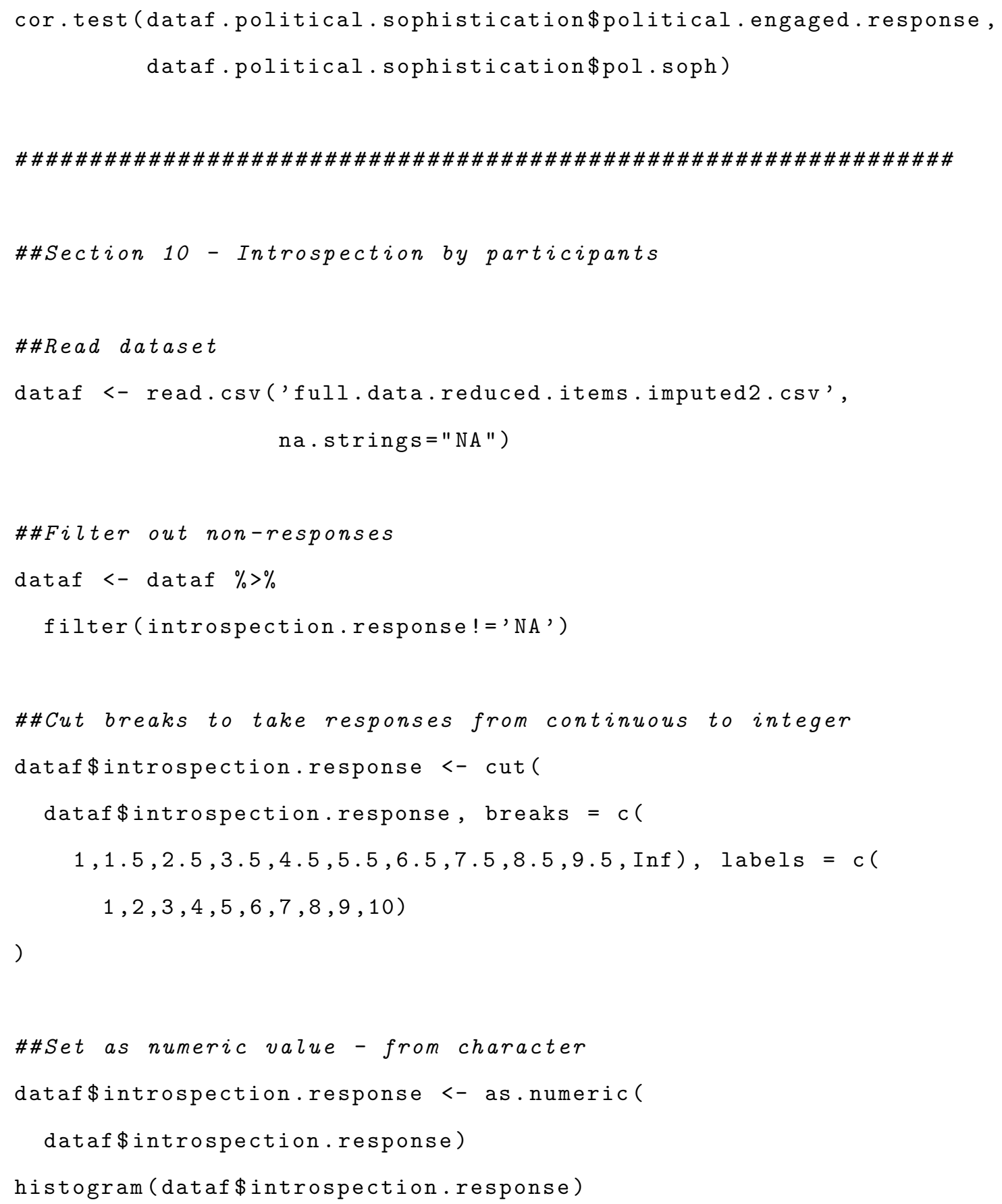




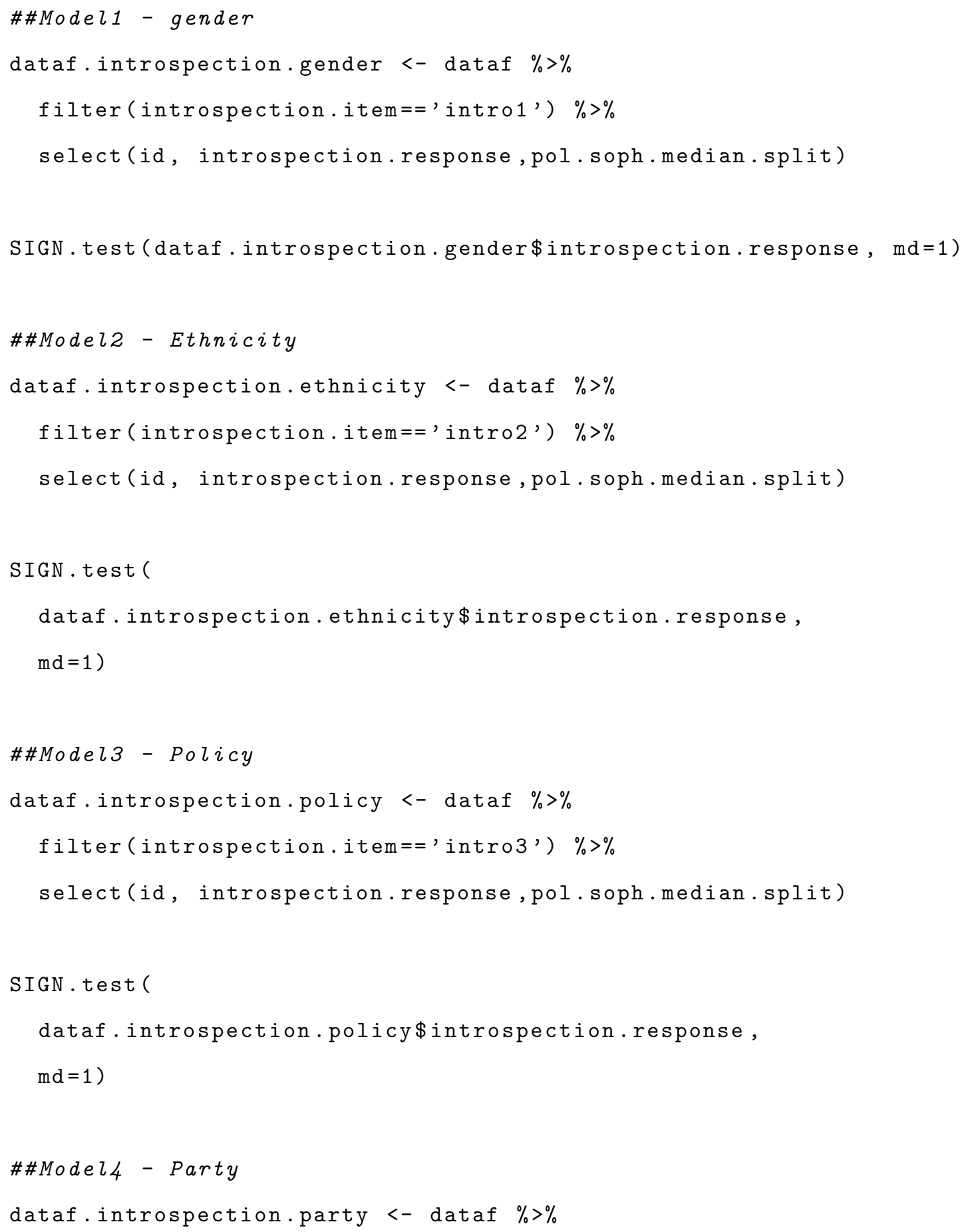




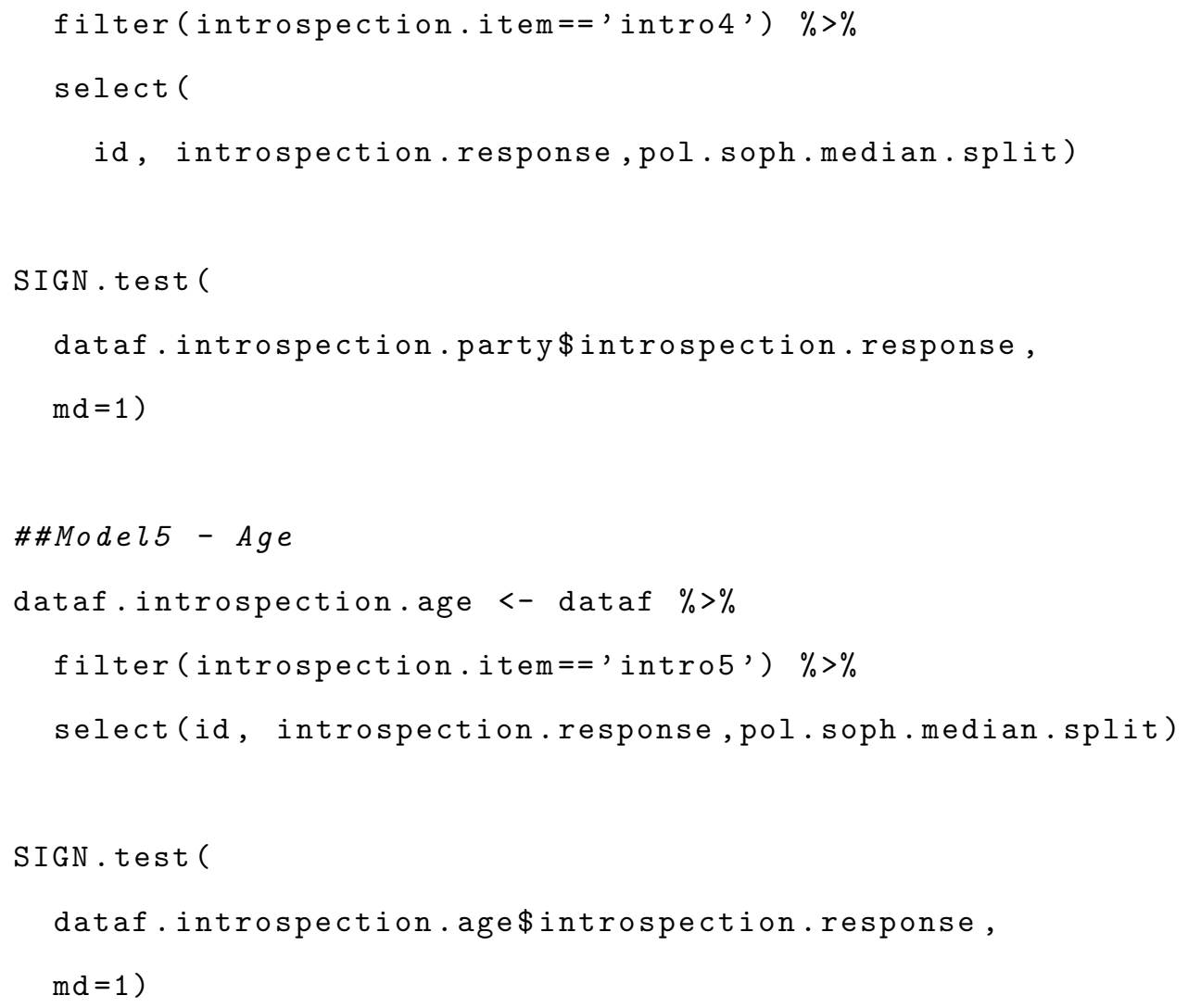




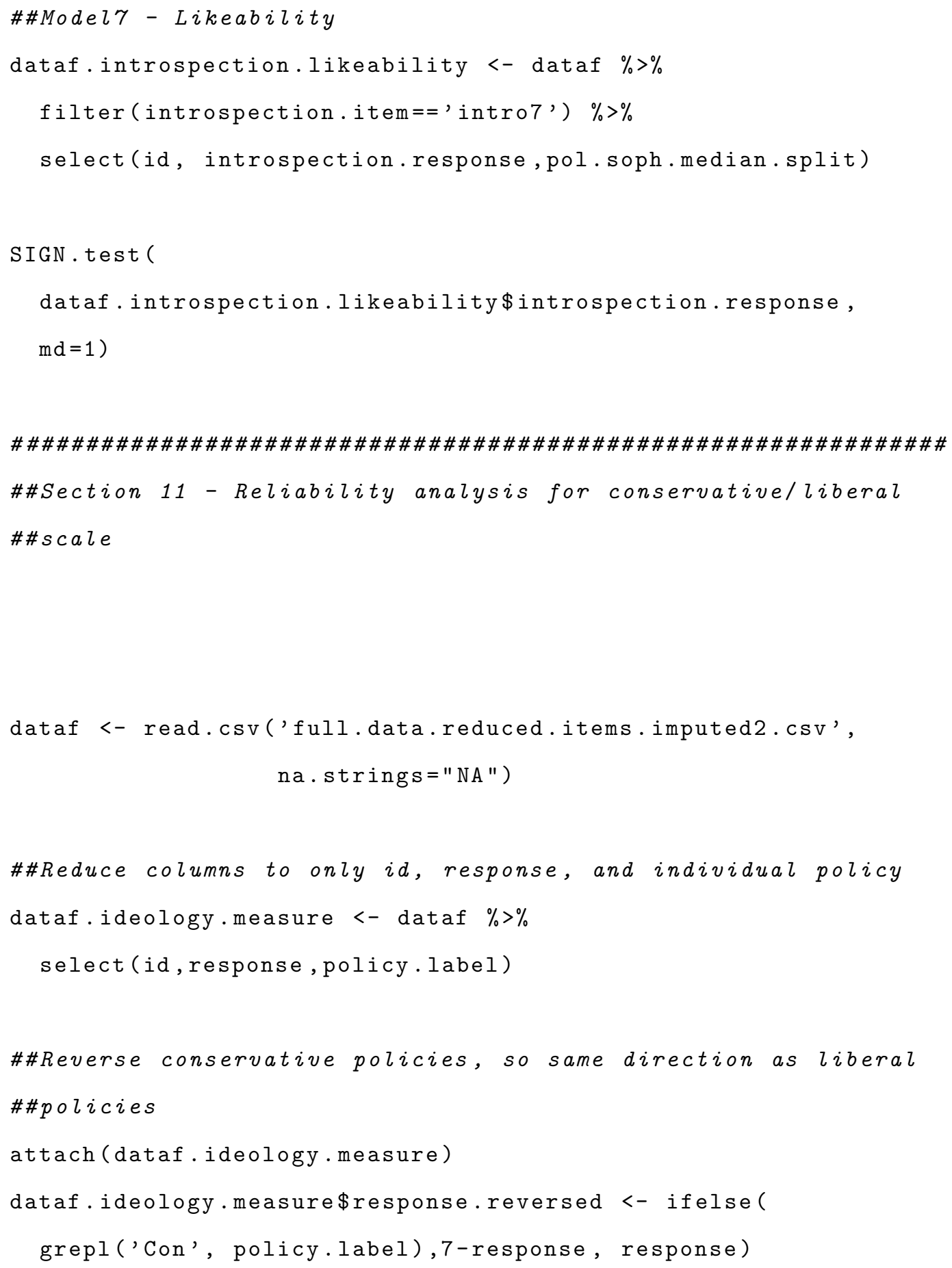




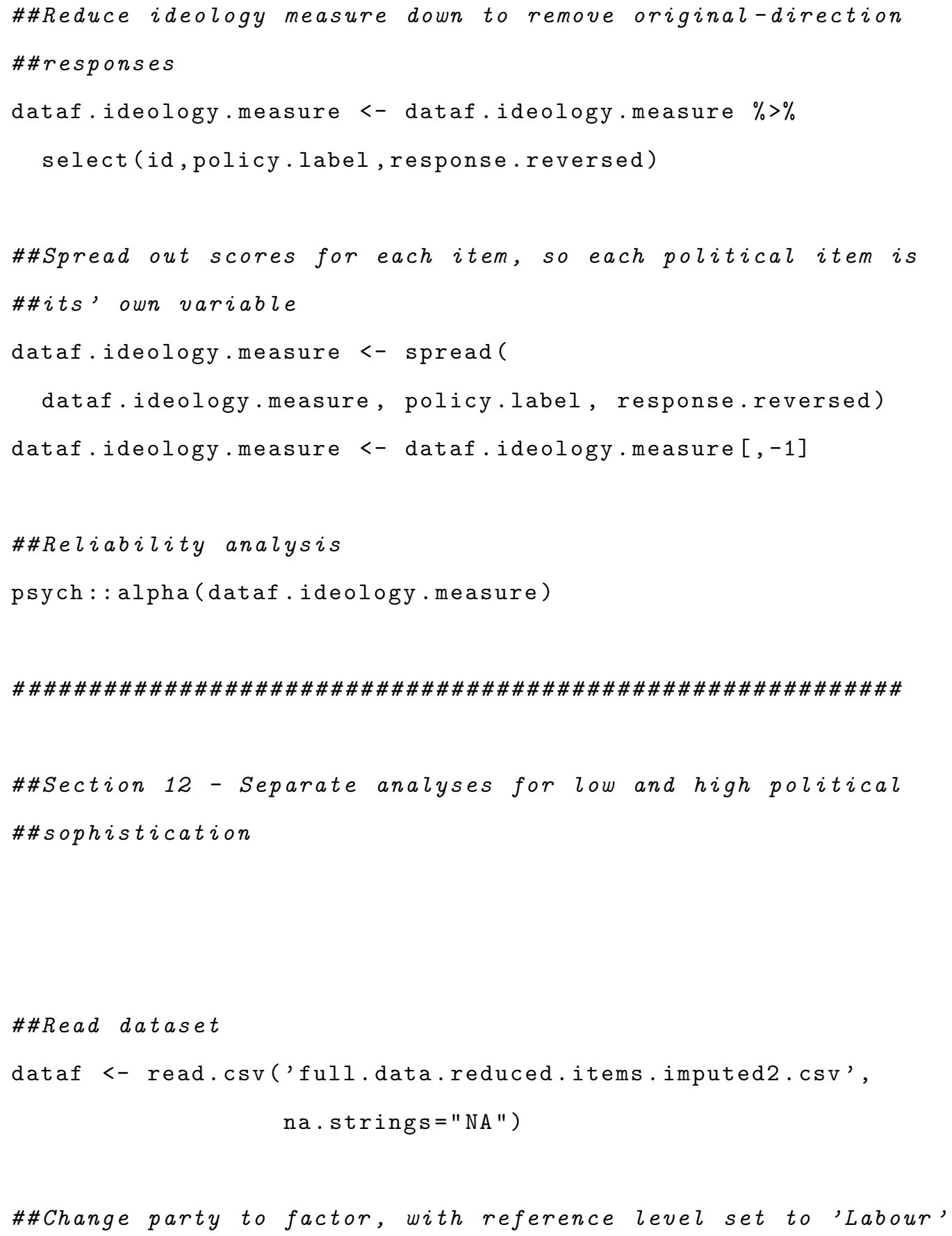




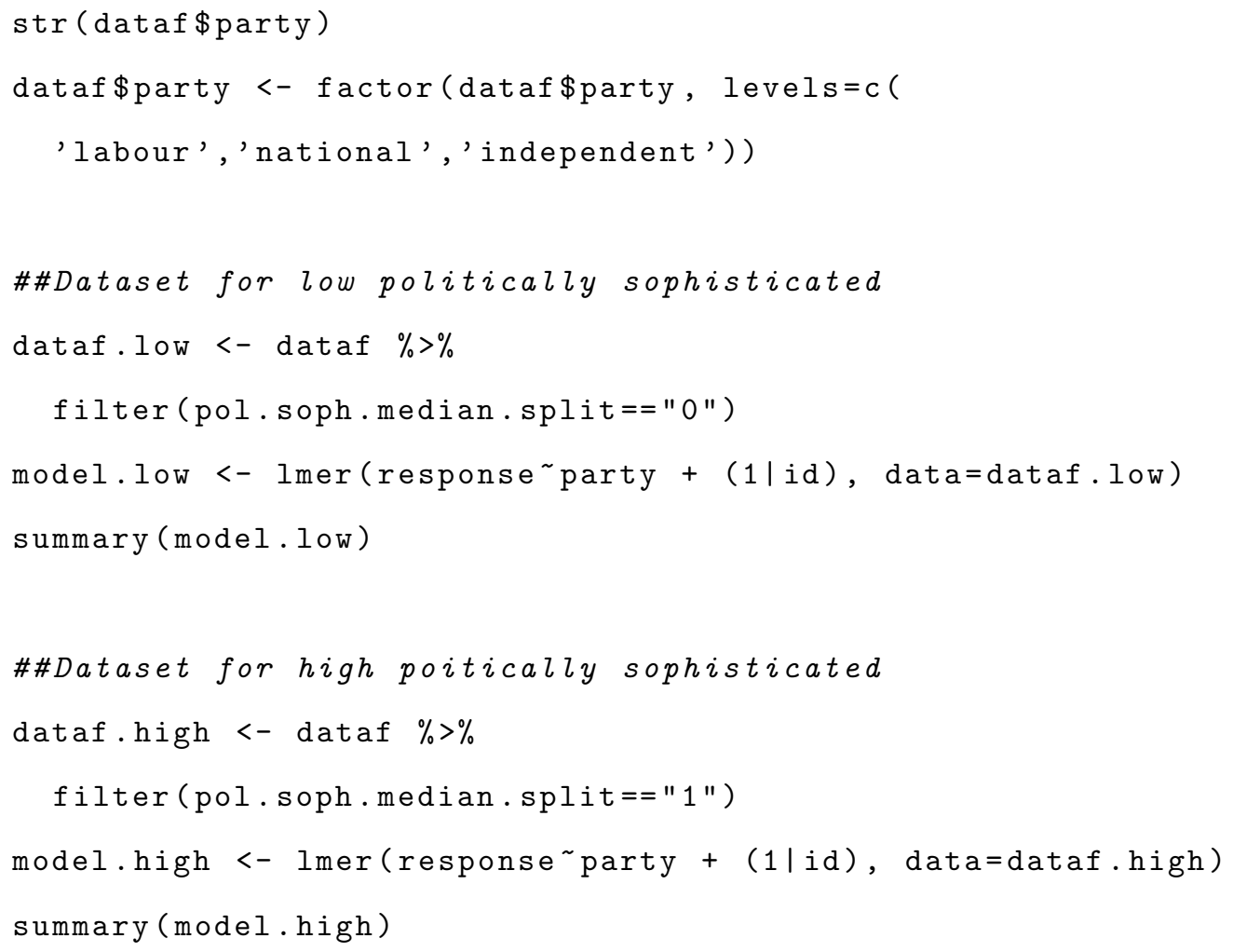

